OPEN ACCESS

Edited by:

Emanuela Ricciotti,

University of Pennsylvania,

United States

Reviewed by:

Marc Diederich,

Seoul National University, South Korea

Syed Nasir Abbas Bukhari,

Al Jouf University, Saudi Arabia

Gianluigi Lauro,

University of Salerno, Italy

*Correspondence:

Stefan Lorkowsk

stefan.lorkowski@uni-jena.de

${ }^{\dagger}$ These authors have

contributed equally to this work

and share first authorship

FThese authors have contributed equally to this work and share senior authorship

Specialty section:

This article was submitted to Translational Pharmacology,

a section of the journal

Frontiers in Pharmacology

Received: 12 December 2019

Accepted: 10 March 2020

Published: 21 April 2020

Citation:

Wallert M, Kluge S, Schubert M, Koeberle A, Werz O, Birringer $M$ and

Lorkowski S (2020) Diversity of Chromanol and Chromenol Structures and Functions: An Emerging

Class of Anti-Inflammatory and Anti-Carcinogenic Agents.

Front. Pharmacol. 11:362.

doi: 10.3389/fphar.2020.00362

\section{Diversity of Chromanol and Chromenol Structures and Functions: An Emerging Class of Anti-Inflammatory and Anti-Carcinogenic Agents}

\author{
Maria Wallert ${ }^{1 \dagger}$, Stefan Kluge ${ }^{1 \dagger}$, Martin Schubert ${ }^{1}$, Andreas Koeberle $^{2,3}$, Oliver Werz ${ }^{2}$, \\ Marc Birringer ${ }^{4,5 \neq}$ and Stefan Lorkowski ${ }^{1,6^{* \pm}}$ \\ ${ }^{1}$ Department of Biochemistry and Physiology of Nutrition, Institute of Nutritional Sciences, Friedrich Schiller University Jena, \\ Jena, Germany, ${ }^{2}$ Department of Pharmaceutical/Medicinal Chemistry, Institute of Pharmacy, Friedrich Schiller University \\ Jena, Jena, Germany, ${ }^{3}$ Michael Popp Research Institute, University of Innsbruck, Innsbruck, Austria, ${ }^{4}$ Department of \\ Nutrition, Food and Consumer Sciences, University of Applied Sciences Fulda, Fulda, Germany, ${ }^{5}$ Regionales \\ Innovationszentrum Gesundheit und Lebensqualität (RIGL), Fulda, Germany, ${ }^{6}$ Competence Center for Nutrition and \\ Cardiovascular Health (nutriCARD) Halle-Jena-Leipzig, Jena, Germany
}

Natural chromanols and chromenols comprise a family of molecules with enormous structural diversity and biological activities of pharmacological interest. A recently published systematic review described more than 230 structures that are derived from a chromanol ortpd chromenol core. For many of these compounds structure-activity relationships have been described with mostly anti-inflammatory as well as anticarcinogenic activities. To extend the knowledge on the biological activity and the therapeutic potential of these promising class of natural compounds, we here present a report on selected chromanols and chromenols based on the availability of data on signaling pathways involved in inflammation, apoptosis, cell proliferation, and carcinogenesis. The chromanol and chromenol derivatives seem to bind or to interfere with several molecular targets and pathways, including 5-lipoxygenase, nuclear receptors, and the nuclear-factor "kappa-light-chain-enhancer" of activated B-cells (NFkB) pathway. Interestingly, available data suggest that the chromanols and chromenols are promiscuitively acting molecules that inhibit enzyme activities, bind to cellular receptors, and modulate mitochondrial function as well as gene expression. It is also noteworthy that the molecular modes of actions by which the chromanols and chromenols exert their effects strongly depend on the concentrations of the compounds. Thereby, low- and highaffinity molecular targets can be classified. This review summarizes the available knowledge on the biological activity of selected chromanols and chromenols which may represent interesting lead structures for the development of therapeutic anti-inflammatory and chemopreventive approaches.

Keywords: chromanols, chromenols, inflammation, cancer, molecular targets 


\section{INTRODUCTION}

Chromanols and chromenols are collective terms for about 230 structures derived from photosynthetic organisms like plants, algae, cyanobacteria, fungi, corals, sponges, and tunicates (Birringer et al., 2018). Both compound classes are formed by a cyclization of substituted 1,4-benzoquinones. While 6hydroxy-chromanols are derived from a 2-methyl-3,4-dihydro$2 \mathrm{H}$-chromen-6-ol structure, 6-hydroxy-chromenols are derived from 2-methyl-2H-chromen-6-ol (Figure 1). The respective bicyclic core structure is associated to a side-chain with varying chain length and modifications, resulting in a great diversity of chromanol and chromenol derivates (Birringer et al., 2018). In a systematic review, Birringer and coworkers were the first implying the great potential of these structures by providing a comprehensive overview of the structural diversity and chemical transformation of all 230 chromanols and chromenols known at that time together with their natural source. The aim of the comprehensive review was rather the detailed description of the complexity of this group of compounds than an outline of their biological activity. Based on this systematic review, the intention of our review was to more selectively describe the effects of this class of natural products on signaling pathways involved in inflammation, apoptosis, cell proliferation, and carcinogenesis, and the underlying molecular modes of action for selected chromanols and chromenols. Our review therefore represents a useful and relevant addition to the work of Birringer et al., focusing on the evaluation of selected compounds with known biological activity as possible lead structures for putative therapeutic approaches. Based on the mentioned inclusion criteria, we here focus on tocopherol (TOH) and tocotrienol (T3) structures, sargachromanols, amplexichromanols, and sargachromenols, which show structure-activity relationships with mostly antiinflammatory as well as anti-carcinogenic activities.

Tocopherols and T3s differ in the saturation of the side-chain and form in its entirety the group of vitamin E. Based on the methylation pattern of the chromanol ring system $\alpha-, \beta-, \gamma-, \delta-$ forms of TOHs and T3s can be distinguished. Oxidative modifications of the terminal side-chain increase antiinflammatory activities. Therefore, hepatic metabolites of vitamin $\mathrm{E}$ are supposed to have important physiological activities and will also be included in this review.

\footnotetext{
Abbreviations: $\alpha$-T-13'-COOH, $\alpha-13^{\prime}$-carboxychromanol; $\alpha-\mathrm{T}-13^{\prime}-\mathrm{OH}, \alpha-13^{\prime}-$ hydrochromanol; $\delta$-T3-13'-COOH, garcinoic acid; AC, amplexichromanol; BMDM, bone marrow-derived macrophages; CEHC, carboxyethylhydroxychromanol; JNK, c-Jun N-terminal kinase; CoA, coenzyme A; COX, cyclooxygenases; CYP, cytochrome P450; ERK, extracellular signal-regulated kinase; ICM, intermediate-chain metabolite; IL, interleukin; iNOS, inducible nitric oxide synthase; ІКВ, nuclear factor of kappa light polypeptide gene enhancer in B-cells inhibitor; LCM, long-chain metabolite; LPS, lipopolysaccharide; LO, lipoxygenases; MAPKs, mitogen-activated kinases; NF-кB, nuclear factor kappa-light-chain-enhancer of activated B cells; NLRP3, NLR family pyrin domain containing 3 ; NO, nitric oxide; PARP-1, poly-[ADPribose]-polymerase 1; PG, prostaglandin; PMA, phorbol-12-myristat-13-acetate; PMNL, polymorphonuclear neutrophils; ROS, reactive oxygen species; SCA, sargachromanols; SCE, sargachromenols; SCM, short-chain metabolites; TX, thromboxane; TOH, tocopherol; TNF- $\alpha$, tumor necrosis factor $\alpha$; T3, tocotrienol.
}

Sargachromanols (SCA), sargachromenols (SCE), and amplexichromanols (AC) have a tocotrienol-derived backbone implying similar biological activities. Our review focuses in more detail on the current knowledge about the biological activity as well as on potential regulatory pathways and molecular targets of chromanols and chromenols.

\section{CHROMANOL AND CHROMENOL STRUCTURES}

\section{Chromanols}

\section{Tocopherols and Tocotrienols}

Vitamin E, more precisely $R R R$ - $\alpha$-tocopherol, has been identified in 1922 as a vital factor for fertility in rats (Evans and Bishop, 1922). Vitamin E does naturally occur in various plant-derived foods, such as oils, nuts, germs, seeds as well as vegetables and, in lower amounts, fruits. Thus, vitamin $\mathrm{E}$ represents the most widely distributed and abundant chromanol in nature. The term vitamin $\mathrm{E}$ comprises different lipophilic molecules that consist of the chromanol ring structure with a covalently bound phytyl-like side-chain. Depending on the saturation of the $\mathrm{C}-16^{\prime}$ side-chain, these molecules are classified as TOH, T3s (Figure 2), and vitamin E related structures named tocomonoenols and marine-derived TOHs. Tocopherols are characterized by a saturated phytyl side-chain whereas tocomonoenols, marine-derived TOHs and T3 are unsaturated at either the terminal isoprene unit or have three double bonds within the side-chain (Fujisawa et al., 2010; Kruk et al., 2011). Further, the methylation pattern of the chromanol ring determines the classification as $\alpha-, \beta-, \gamma$-, and $\delta$-forms of TOHs and T3s. Although several similar molecules form the group of vitamin $\mathrm{E}$, only $\alpha-\mathrm{TOH}$ seems to have vitamin property in animals and humans. For instance, in rats $\alpha-\mathrm{TOH}$ preserves fertility, whereas in humans the deficiency disease ataxia with vitamin $E$ deficiency (AVED) is prevented by $\alpha-\mathrm{TOH}$ supplementation (Azzi, 2019).

For a long time, the health-promoting effects of vitamin $\mathrm{E}$ were only attributed to its antioxidant properties, but more recent studies revealed additional non-antioxidant functions of vitamin $\mathrm{E}$. It is evident that vitamin $\mathrm{E}$ modulates gene expression and enzyme activities and also interferes with signaling cascades (Brigelius-Flohé, 2009; Zingg, 2019). Examples for these regulatory effects are the suppression of inflammatory mediators, reactive oxygen species (ROS) and adhesion molecules, the induction of scavenger receptors as well as the activation of nuclear factor kappa-light-chain-enhancer of activated B cells (NF-кB) (reviewed in Glauert, 2007; Rimbach et al., 2010; Wallert et al., 2014b; Zingg, 2019).

All forms of vitamin E undergo metabolic degradation in the liver. Although the detailed mechanisms remain poorly understood, the principles of the degradation of vitamin $\mathrm{E}$ to vitamer-specific physiological metabolites with intact chromanol ring (the nomenclature as $\alpha-, \beta-, \gamma$ - and $\delta$-metabolites is used as described for the metabolic precursors in order to distinguish the 
<smiles>CC1CCc2cc(O)ccc2O1</smiles>

B<smiles>CC1C=Cc2cc(O)ccc2O1</smiles>

FIGURE 1 | (A) Chromanol (2-methyl-3,4-dihydro-2H-chromen-6-ol) and (B) chromenol (2-methyl-2H-chromen-6-ol) core structure.

\section{A}<smiles>[R]c1c([R])c2c(c([R])c1O)CC[C@@](C)(CCC[C@@H](C)CCC[C@H](C)CCCC(C)C)O2</smiles>

\begin{tabular}{|c|c|c|c|}
\hline -tocopherol & $\mathbf{R}_{\mathbf{1}}$ & $\mathbf{R}_{\mathbf{2}}$ & $\mathbf{R}_{\mathbf{3}}$ \\
\hline $\boldsymbol{\alpha}$ & $-\mathrm{CH}_{3}$ & $-\mathrm{CH}_{3}$ & $-\mathrm{CH}_{3}$ \\
\hline $\boldsymbol{\beta}$ & $-\mathrm{CH}_{3}$ & $-\mathrm{H}$ & $-\mathrm{CH}_{3}$ \\
\hline $\boldsymbol{\gamma}$ & $-\mathrm{H}$ & $-\mathrm{CH}_{3}$ & $-\mathrm{CH}_{3}$ \\
$\mathbf{\delta}$ & $-\mathrm{H}$ & $-\mathrm{H}$ & $-\mathrm{CH}_{3}$ \\
\hline
\end{tabular}<smiles>[R]c1c([R])c2c(c([R])c1O)CC[C@@]([PH+])(CC/C=C(\C)CC/C=C(\C)CCC=C(C)C)O2</smiles>

\begin{tabular}{c|cc|c|}
\hline -tocotrienol & $\mathbf{R}_{\mathbf{1}}$ & $\mathbf{R}_{\mathbf{2}}$ & $\mathbf{R}_{\mathbf{3}}$ \\
\hline $\boldsymbol{\alpha}$ & $-\mathrm{CH}_{3}$ & $-\mathrm{CH}_{3}$ & $-\mathrm{CH}_{3}$ \\
$\boldsymbol{\beta}$ & $-\mathrm{CH}_{3}$ & $-\mathrm{H}$ & $-\mathrm{CH}_{3}$ \\
$\boldsymbol{\gamma}$ & $-\mathrm{H}$ & $-\mathrm{CH}_{3}$ & $-\mathrm{CH}_{3}$ \\
$\boldsymbol{\delta}$ & $-\mathrm{H}$ & $-\mathrm{H}$ & $-\mathrm{CH}_{3}$
\end{tabular}

FIGURE 2 | Core structure of (A) tocopherol and (B) tocotrienol forms.

different forms of vitamin E metabolites) is widely accepted (Figure 3). Thus, enzymatic modifications are restricted to the side-chain (extensively reviewed in (Kluge et al., 2016; Schmölz et al., 2016)). $\alpha$-Tocopherol is the main form of vitamin $E$ in the human body due to its higher binding affinity to the $\alpha$ tocopherol transfer protein (Hosomi et al., 1997). Thus, we will focus on the metabolic conversion of $\alpha-\mathrm{TOH}$ in the following. Nevertheless, it should be noted that all forms of vitamin E (TOHs as well as T3s) follow the same metabolic route. However, due to the unsaturated side-chain, the degradation of T3s requires further enzymes such as 2,4 dienoyl-coenzyme A $(\mathrm{CoA})$ reductase and 3,2-enoyl-CoA isomerase, which are also 


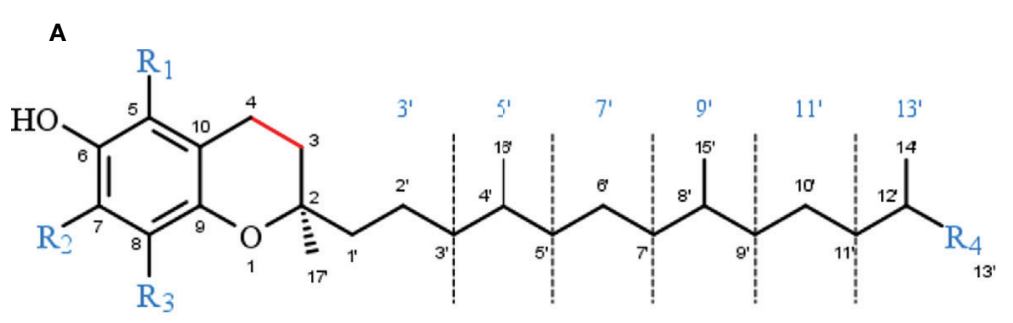

\begin{tabular}{|c|c|c|}
\hline $\boldsymbol{\alpha} / \boldsymbol{\beta} / \boldsymbol{\gamma} / \boldsymbol{\delta}-\mathrm{metabolite}$ & $\mathbf{R}_{\mathbf{4}}$ & sidechain length \\
\hline$-13^{4}-\mathrm{T}-\mathrm{OH}$ & $-\mathrm{OH}$ & 13 \\
\hline$-13^{6}-\mathrm{T}-\mathrm{COOH}$ & $-\mathrm{COOH}$ & 13 \\
\hline$-11^{6}-\mathrm{T}-\mathrm{COOH}$ & $-\mathrm{COOH}$ & 11 \\
\hline$-9^{6}-\mathrm{T}-\mathrm{COOH}$ & $-\mathrm{COOH}$ & 9 \\
\hline$-7^{6}-\mathrm{T}-\mathrm{COOH}$ & $-\mathrm{COOH}$ & 7 \\
\hline$-5^{6}-\mathrm{T}-\mathrm{COOH}$ & $-\mathrm{COOH}$ & 5 \\
\hline$-3^{6}-\mathrm{T}-\mathrm{COOH}$ & $-\mathrm{COOH}$ & 3 \\
\hline
\end{tabular}

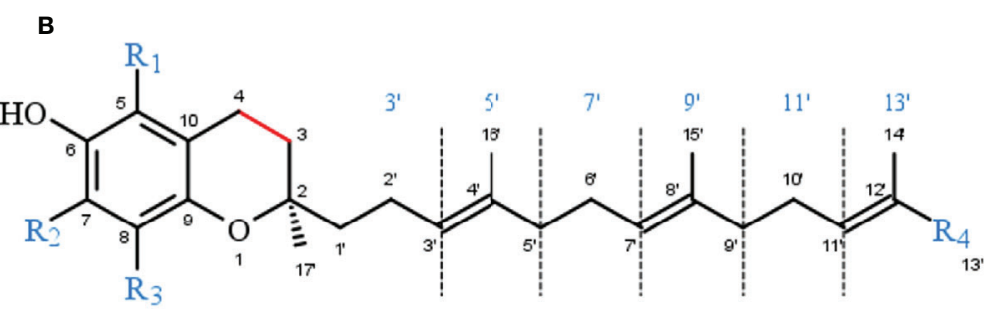

\begin{tabular}{|c|c|c|}
\hline $\boldsymbol{\alpha} / \mathbf{\beta} / \boldsymbol{\gamma} / \boldsymbol{\delta}-$ metabolite & $\mathbf{R}_{4}$ & sidechain length \\
\hline$-13^{6}-\mathrm{T} 3-\mathrm{OH}$ & $-\mathrm{OH}$ & 13 \\
\hline$-13^{6}-\mathrm{T} 3-\mathrm{COOH}$ & $-\mathrm{COOH}$ & 13 \\
\hline$-11^{6}-\mathrm{T} 3-\mathrm{COOH}$ & $-\mathrm{COOH}$ & 11 \\
\hline$-9^{6}-\mathrm{T} 3-\mathrm{COOH}$ & $-\mathrm{COOH}$ & 9 \\
\hline$-7^{6}-\mathrm{T} 3-\mathrm{COOH}$ & $-\mathrm{COOH}$ & 7 \\
\hline$-5^{6}-\mathrm{T} 3-\mathrm{COOH}$ & $-\mathrm{COOH}$ & 5 \\
\hline$-3^{6}-\mathrm{T} 3-\mathrm{COOH}$ & $-\mathrm{COOH}$ & 3 \\
\hline
\end{tabular}

FIGURE 3 | Core structure of (A) tocopherol and (B) tocotrienol metabolites. The substitutions R1 to R3 are given in Figure $\mathbf{2}$ (A) and (B).

involved in the metabolism of unsaturated fatty acids (Birringer et al., 2002). The initial step of $\alpha$-TOH modification via $\omega$-hydroxylation in the endoplasmic reticulum leads to the formation of the long-chain metabolite (LCM) $\alpha-13^{\prime}$ hydroxychromanol $\left(\alpha-\mathrm{T}-13^{\prime}-\mathrm{OH}\right)$. It is supposed that this hydroxylation is catalyzed by cytochrome P450 (CYP)4F2 and CYP3A4 (Parker et al., 2000; Sontag and Parker, 2002). After its transfer from the endoplasmic reticulum to the peroxisome, $\alpha$-T$13^{\prime}-\mathrm{OH}$ is converted to $\alpha-13^{\prime}$-carboxychromanol ( $\alpha-\mathrm{T}-13^{\prime}-$ $\mathrm{COOH}$ ) via $\omega$-oxidation, likely via a two-step mechanism involving alcohol and aldehyde dehydrogenases. $\alpha-\mathrm{T}-13^{\prime}-\mathrm{OH}$ and $\alpha-\mathrm{T}-13^{\prime}-\mathrm{COOH}$ have been found in human serum (Wallert et al., 2014a; Ciffolilli et al., 2015; Giusepponi et al., 2017), supporting the idea of a more complex physiologic role of vitamin $\mathrm{E}$ with physiological relevance of its metabolites for various processes. In healthy humans $\alpha-\mathrm{TOH}$ is the most abundant form of vitamin E, occurring in concentrations of about 20-30 $\mu \mathrm{M}$ in serum (Péter et al., 2015). However, supplementation of $\alpha-\mathrm{TOH}$ increases $\alpha$-TOH serum concentration in humans up to $90 \mu \mathrm{M}$ (Dieber-Rotheneder 
et al., 1991). Following supplementation, the hepatic metabolism is enhanced to protect the liver from excessive accumulation of $\alpha$ - TOH. Consequently, metabolites of vitamin $\mathrm{E}$ are formed and accumulate in turn in human serum. The LCMs $\alpha-\mathrm{T}-13^{\prime}-\mathrm{OH}$ and $\alpha-\mathrm{T}-13^{\prime}-\mathrm{COOH}$ were found in concentrations of $1-7 \mathrm{nM}$ and $1-10 \mathrm{nM}$ at baseline, respectively, whereas supplementation of $\alpha-\mathrm{TOH}$ increased serum concentrations of the LCMs up to 12-32 nM and 3-55 nM, respectively (Wallert et al., 2014a; Ciffolilli et al., 2015; Giusepponi et al., 2017). Recent studies showed that the active metabolites of vitamin E exert effects on lipid metabolism, apoptosis, proliferation, and inflammatory processes as well as xenobiotic metabolism (Wallert et al., 2014a; Jang et al., 2016; Podszun et al., 2017; Schmölz et al., 2017). Finally, $\alpha-\mathrm{T}-13^{\prime}-\mathrm{COOH}$ is excreted via bile and feces or is further degraded via several rounds of oxidation to the hydrophilic short-chain metabolite $\alpha$-carboxyethylhydroxychromanol (CEHC), which is largely excreted via urine (Zhao et al., 2010; Johnson et al., 2012; Jiang, 2014). Another characteristic of the hepatic degradation of vitamin $\mathrm{E}$ is that the metabolites are chemically modified. In particular, the LCMs and the short-chain metabolites (SCMs) have been found as sulfated or glucuronidated conjugates in different biological matrices (Galli et al., 2002; Wallert et al., 2014a). Freiser and Jiang (2009) reported that more than $75 \%$ of $\gamma$-CEHC in the plasma of $\gamma$-T3-supplemented rats occurred in conjugated form. Further, also the LCMs, especially $13^{\prime}-\mathrm{COOH}$ and $11^{\prime}-\mathrm{COOH}$ metabolites were found as conjugates. Conjugation (sulfation or glucoronidation) seems to occur in the liver in parallel to the $\beta$-oxidation of the side-chain of vitamin $\mathrm{E}$ (Freiser and Jiang, 2009).

Beside the mentioned LCMs, intermediate-chain metabolites (ICMs) and SCMs that are formed via hepatic degradation of the different vitamin $\mathrm{E}$ forms, and vitamin $\mathrm{E}$ is also the precursor of quinones, representing another class of vitamin E-derived metabolites that exhibit antioxidant activity. Vitamin E quinones, in particular $\alpha$-TOH-derived quinones, are formed as byproducts of $\alpha-\mathrm{TOH}$ oxidation during peroxidation reactions in in vitro systems (Liebler et al., 1990; Infante, 1999). In addition, these metabolites can also be synthesized by photosynthetic organisms (Liebler et al., 1990). Although the knowledge on this group of tocopherol-derived metabolites is sparse, $\alpha-\mathrm{TOH}$ quinone has been described as an essential enzymatic cofactor for fatty acid desaturase (Liebler et al., 1990).

The natural compound $\delta$-T3-13'-COOH, also known as $\delta$ garcinoic acid or $\delta$-tocotrienolic acid, shares structural similarity with the $\delta$-T-LCM $\delta$-T-13'-COOH, the second LCM originating from the hepatic metabolism of $\delta$ - $\mathrm{TOH}$. As described previously, hepatic metabolism of tocotrienols follows that of tocopherols. Consequently, $\delta$-T3-13'-COOH is formed during the degradation of $\delta$-T3. Since the concentration of $\delta$-T3 in human plasma is below $1 \%$ compared to $\alpha$-TOH, the physiological relevance of $\delta$-T3-13'-COOH in humans is likely low. So far, the detection of $\delta-\mathrm{T} 3-13^{\prime}-\mathrm{COOH}$ in human blood is still pending. However, local accumulation of $\delta-\mathrm{T} 3-13^{\prime}-\mathrm{COOH}$ in cells or tissues cannot be excluded. $\delta$-T3-13'-COOH can be obtained in relatively high amounts and purity from the seeds of
Garcinia kola E. Heckel (Bartolini et al., 2019; Wallert et al., 2019), a plant that is used in traditional African ethnomedicine (extensively reviewed in Kluge et al., 2016). This compound can be used as precursor for the semi-synthesis of $\alpha$ - and $\delta$-LCMs (including $\alpha$-T-13'-OH, $\alpha$-T-13'-COOH, $\delta$-T-13'-OH, and $\delta$-T$\left.13^{\prime}-\mathrm{COOH}\right)$ for experimental use in vitro and in mice and is therefore important for vitamin $\mathrm{E}$ metabolite research (Maloney and Hecht, 2005; Birringer et al., 2010). Further, $\delta$-T3-13'$\mathrm{COOH}$ also appeared to be a potent anti-inflammatory (Wallert et al., 2019) and anti-proliferative agent (Mazzini et al., 2009) and has been shown to act as an inhibitor of DNA polymerase $\beta$ (Maloney and Hecht, 2005), indicating that $\delta$-T3$13^{\prime}-\mathrm{COOH}$ may disturb base excision repair in tumor cells. A recent preprint of Bartolini et al. described $\delta-\mathrm{T} 3-13^{\prime}-\mathrm{COOH}$ as a potent agonist of PXR, which is known to be involved in inflammatory processes (Bartolini et al., 2019).

\section{Sargachromanols}

Sargachromanols (SCA) comprise a group of chromanols that occur in the brown algae family Sargassaceae (Figure 4). Their high structural diversity results from various side-chain modifications, leading to their classification from SCA-A to SCA-S. The entirety of sargachromanols has been isolated from Sargassum siliquastrum and has been classified via twodimensional nuclear magnetic resonance experiments (Jang et al., 2005; Im Lee and Seo, 2011). The extensive analysis revealed detailed structural differences between the sargachromanols. For example SCA-C contains a 9'-hydroxyl group with $R$-configuration in the side-chain, while SCA-F has a methoxy group at C-9' and a hydroxyl group with $R$ configuration at C-10' (extensively reviewed in Birringer et al., 2018). SCAs have been reported to exhibit various biological activities, including anti-oxidative (Lim et al., 2019) (SCA-G), anti-osteoclastogenic (Yoon et al., 2012b; Yoon et al., 2013) (SCA-G), anti-inflammatory (Yoon et al., 2012a; Lee et al., 2013; Heo et al., 2014) (SCA-G and SCA-D), as well as antidiabetic (Pak et al., 2015) (SCA-I) ones. To the best of our knowledge, metabolism of sargachromanols in humans or animals has not been investigated.

\section{Amplexichromanols}

Amplexichromanols represent a small group of hydroxylated T3 derivatives found in different parts of Garcinia plants. For instance, lipophilic extracts from the bark of Garcinia amplexicaulis were used to isolate $\gamma$-AC and $\delta$-AC (Figure 5). The chemical structure of $\gamma$-AC and $\delta$-AC are similar to $\gamma$-T3 and $\delta$-T3, respectively, but carry two additional hydroxyl groups at $\mathrm{C}-13^{\prime}$ and $\mathrm{C}-14^{\prime}$. In an initial in vitro experiment, $\delta$-AC reduced vascular endothelial growth factor induced cell proliferation in low nanomolar concentrations, while $\gamma$-AC had no effect. This observation probably indicates distinct efficiencies for the different amplexichromanols (Lavaud et al., 2013). However, further experiments revealed strong anti-oxidative potential for both compounds (Lavaud et al., 2015), but nothing is known about the metabolization, systemic distribution, tissue accumulation, or excretion of amplexichromanols so far. 

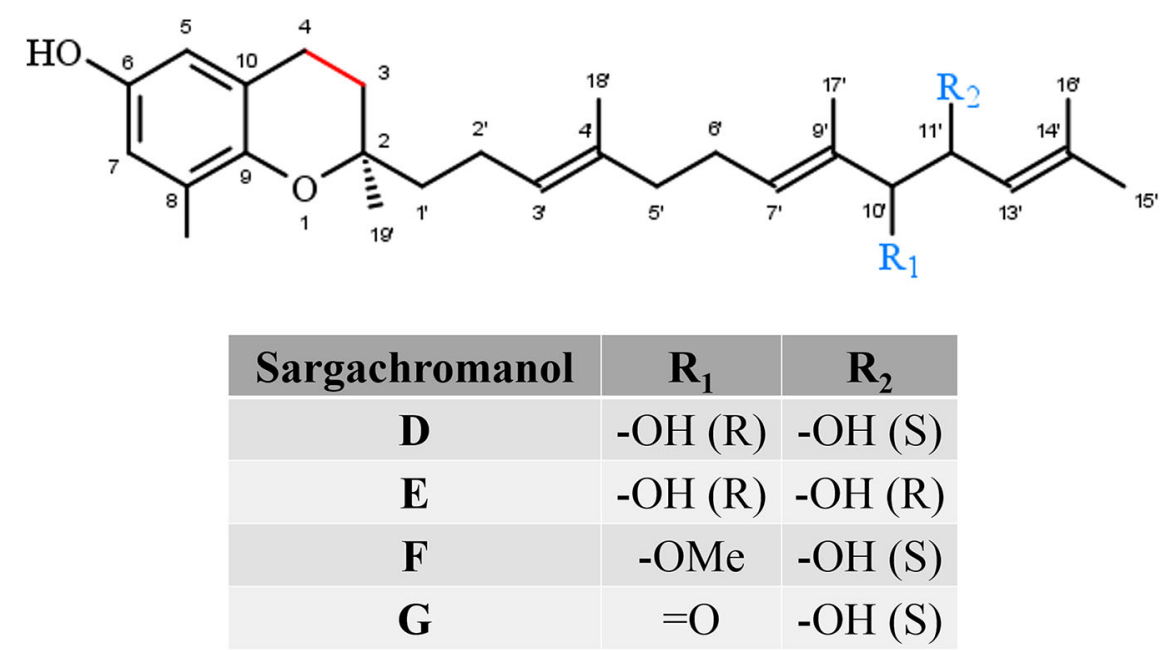

FIGURE 4 | Core structure of sargachromanol forms.

\section{Chromenols}

Chromenols consist of a 2-methyl-2H-chromen-6-ol core that is associated with a side-chain with varying chain length and varying chemical modifications, leading to high structural diversity. The multitude of these compounds can be obtained from photosynthetic organisms like plants, algae, cyanobacteria, fungi, corals, sponges, and tunicates (Birringer et al., 2018). As the current knowledge on the biological functions of chromenol structures is sparse, this review will exemplarily focus on the most studied sargachromenols (Figure 6). Similar to their chromanol counterparts, sargachromenols were named after the brown algae species Sargassum serratifolium, from which they have been isolated first (Kusumi et al., 1979). Just like sargachromanols, sargachromenols comprise a molecule class of high structural diversity due to different side-chain modifications. In the first systematic review on the field of chromanols and chromenols, Birringer and coworkers described 15 sargachromenols, 13 compounds with marine origin (brown algae) and two with marine and plant origin (Birringer et al., 2018). As an example, $\delta$-SCE, a structure consisting of a $\delta$-chromenol ring system with an unsaturated side-chain containing a carboxy group at $\mathrm{C}^{-15^{\prime}}$, is widely distributed in algae of the Sargassaceae family but can also be obtained from plants like Iryanthera juruensis. Another interesting sargachromenol is dehydro- $\delta$-T3, or Sargol, which is supposed to serve as a biosynthetic precursor for most of the sargachromenols and is occurring in brown algae (Birringer et al., 2018). Brown algae from the Sargassaceae family have been used in traditional Asian medicine as well as in health promoting diets, revealing a variety of biological functions (Kim et al., 2014). For example, ethanolic extracts from the Sargassaceae species Myagropsis myagroides, an alga that grows at the coast of East Asia, revealed potent anti-inflammatory activity. After HPLC-based separation, sargachromenols
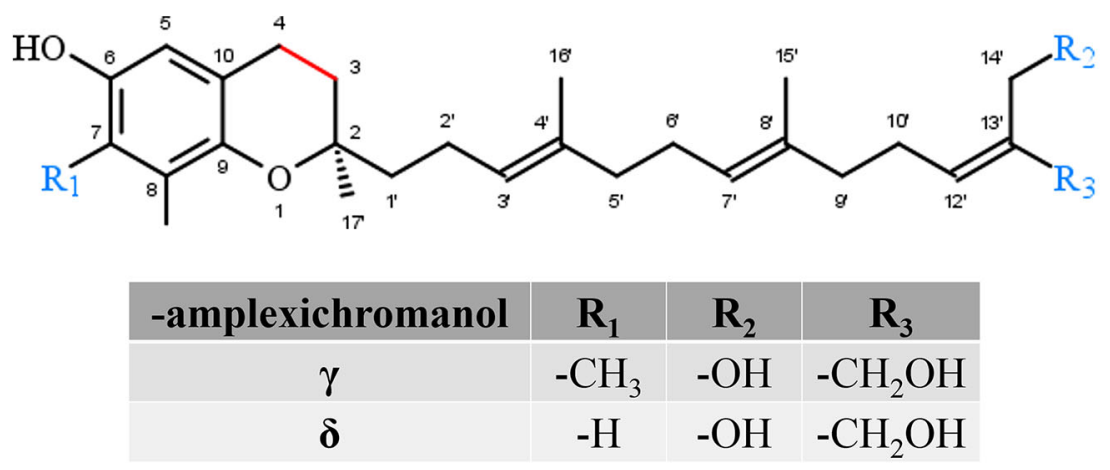

FIGURE 5 | Core structure of amplexichromanol forms. 


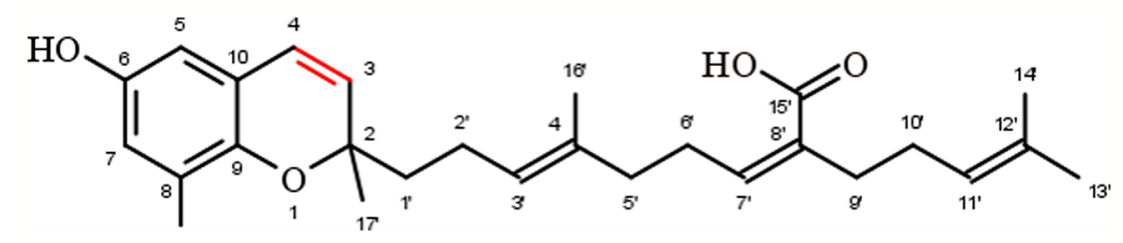

FIGURE 6 | Molecular structure of $\delta$-sargachromenol.

(mostly $\delta$-SCE) have been identified as the most potent antiinflammatory compounds within these extracts, based on their inhibitory effect on nitric oxide (NO) production in lipopolysaccharide (LPS)-treated immortalized murine microglial BV-2 cells (Kim et al., 2014). Beside their antiinflammatory activity, anti-carcinogenic (Hur et al., 2008), anti-photoaging (Kim et al., 2012), and anti-cholinesterase activities (Choi et al., 2007) have been described for SCEs. Further, sargachromenols isolated from Sargassum macrocarpum mediate nerve-growth-factor-driven neuronal growth in pheochromocytoma of rat adrenal medulla derived PC12D cells (Tsang et al., 2005).

\section{BIOLOGICAL ACTIVITY OF NATURAL CHROMANOLS AND CHROMENOLS}

Based on published data, we have chosen signaling pathways that are central for inflammation, apoptosis, cell proliferation, and carcinogenesis (Figure 7). Respective effects of tocopherol-

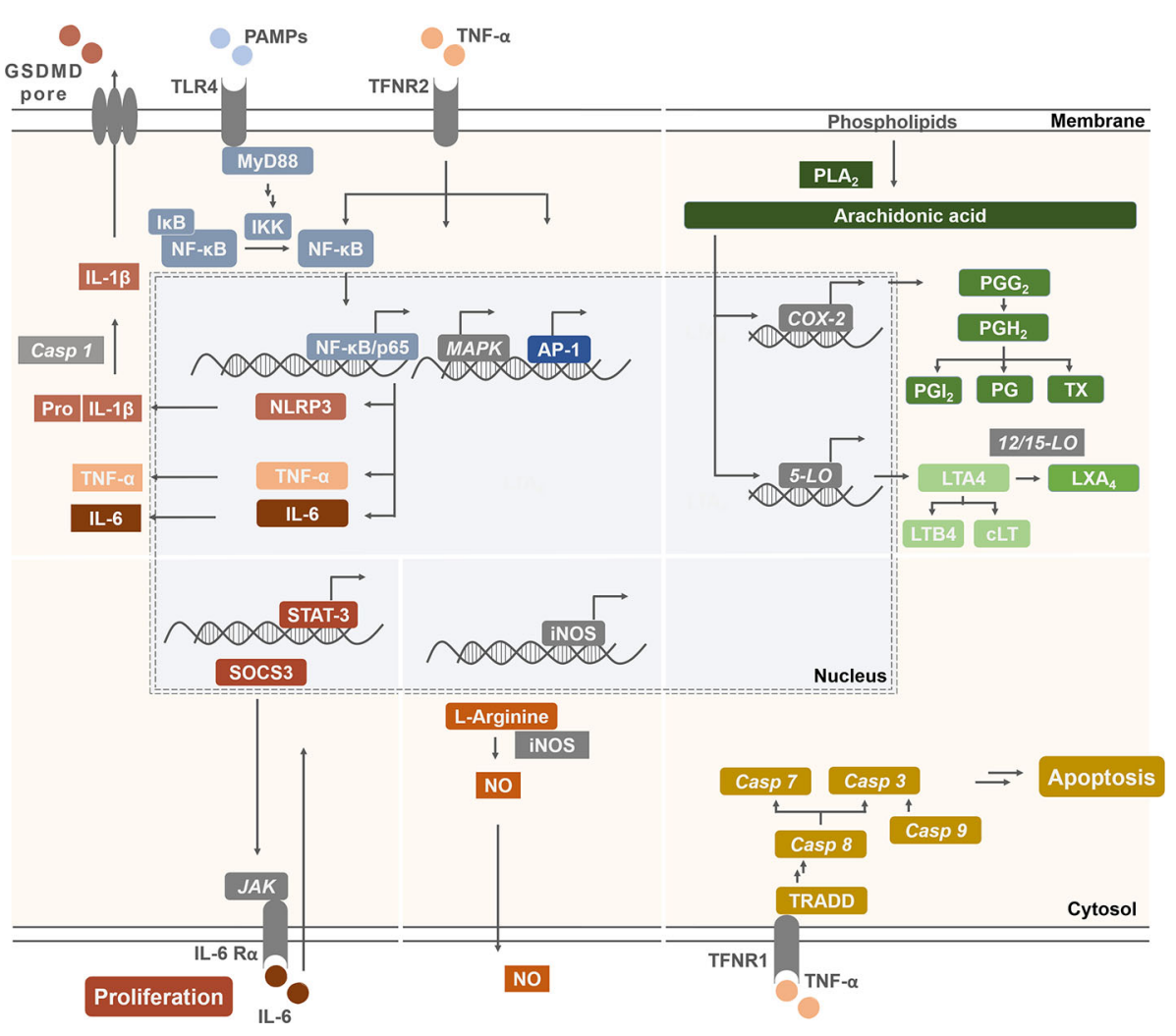

FIGURE 7 | Schematic illustration of signaling targets, pathways, and molecules involved in inflammatory response and cancer progression. Pathways were chosen due to known interactions with the compounds of interest. Inflammatory signaling molecules are interleukins (IL), tumor necrosis factor- $\alpha$ (TNF- $\alpha$ ), nitric oxide (NO), prostaglandins $(P G)$, prostacyclin $\left(\left.P G\right|_{2}\right)$, tromboxanes $(T X)$, leukotriens $(L T)$, and lipoxins $(L X)$. Their expression, synthesis, or release depends, among others, on the activation of NF-kB, NLR family pyrin domain containing 3 (NLRP3) inflammasome, inducible nitric oxide synthase (iNOS), cyclooxygenase (COX)-2, and lipoxygenases (LO). In addition, membrane receptors, such as cytokine or epidermal growth factor receptors regulate the activation of nuclear receptor signal transducer and activator of transcription (STAT) 3 as well as extrinsic or intrinsic pathways which trigger the activation of caspases (Casp). These mediators are therefore important factors for modulating the balance between cell proliferation and apoptosis, which is essential to prevent carcinogenesis. 
derived (T) and tocotrienol-derived (T3) chromanol and chromenol structures on nuclear receptors and target enzymes were screened and are discussed in the following.

\section{Inflammation}

Inflammation is essential for wound healing as well as defense and clearance of pathogens (Kunnumakkara et al., 2018). However, excessive and persistent inflammation is a driving force for many chronic diseases. In addition to obvious inflammatory diseases such as rheumatoid arthritis, it is well accepted that cancer, Alzheimer's disease, and metabolic syndrome-related diseases like atherosclerosis, non-alcoholic fat liver disease, and diabetes mellitus type 2 are triggered by chronic low-grade inflammation (Kunnumakkara et al., 2018). As systemic inflammation is a complex process, this review refers only to inflammatory pathways that have been studied for chromanol and/or chromenol structures. Key regulatory factors and mediators of inflammatory processes in this context are receptors that sense proinflammatory stimuli, e.g. the toll-like receptors (TLRs), intracellular signaling molecules, like mitogenactivated protein kinases (MAPKs), and transcription factors, such as NF- $\mathrm{BB}$ or nuclear factor erythroid 2-related factor 2 (Nrf2). Further, enzymes that produce pro-inflammatory mediators such as prostaglandins (PGs) and leukotrienes (LTs) play a central role during the coordinated orchestra of the inflammatory process. This includes cyclooxygenases (COX) and lipoxygenases (LO). Other key players of inflammation are cytokines which are secreted by various cells and affect the interaction and communication between the different types of cells involved in inflammation (Aggarwal, 2009; Kunnumakkara et al., 2018). Important pro-inflammatory cytokines are interleukin (IL)-1 $\beta$, IL-6, and IL- 8 as well as tumor necrosis factor- $\alpha$ (TNF- $\alpha)$. Another important signaling molecule in inflammatory processes is nitric oxide (Aggarwal, 2009). In the following, chromanol and chromenol structures regulating the expression of key pro-inflammatory enzymes and the respective formation of signaling molecules are outlined.

\section{Chromanols}

A detailed overview on the biological activities of chromanols linked to inflammation is provided in Table $\mathbf{1}$.

\section{Tocopherols and Tocotrienols}

Data available for TOHs and T3s correlate with their abundance in humans. Therefore, $\alpha$ - and $\gamma-\mathrm{TOH}$ as well as their respective T3 forms were mostly investigated so far. $\alpha$-Tocopherol is regarded as the only form within the group of vitamin $\mathrm{E}$ that has been shown to mediate actual vitamin $\mathrm{E}$ function (Azzi, 2019). Further, $\alpha-\mathrm{TOH}$ is considered as the most abundant vitamin $\mathrm{E}$ form in human nutrition, followed by $\gamma$-TOH. Relevance of T3s as anti-inflammatory compounds has just recently come to fore of research and will be presented in the following sections.

Tocopherols. For many years, TOHs were solely known for their anti-oxidative capacity. However, Azzi and colleagues discovered additional gene regulatory effects of $\alpha-\mathrm{TOH}$ that are independent from its capacity as an antioxidant. $\alpha-\mathrm{TOH}$ revealed distinct effects on nitric oxide- and eicosanoid-mediated inflammation. For instance, $\alpha$-TOH $(10 \mu \mathrm{M})$ decreased the expression level of inducible nitric oxide synthase (iNOS) in LPSstimulated murine RAW264.7 macrophages (Jiang et al., 2000). However, others could not confirm the observed alteration of iNOS expression using $5 \mu \mathrm{M}$ (Wallert et al., 2015), $20 \mu \mathrm{M}$ (Schmölz et al., 2017), or even $100 \mu \mathrm{M}$ (Ciffolilli et al., 2015) $\alpha$ $\mathrm{TOH}$. In line with this, iNOS-mediated formation of nitric oxide remained unchanged in RAW264.7 macrophages by coincubation with $\alpha$-TOH (Jiang et al., 2000; Ciffolilli et al., 2015; Wallert et al., 2015). In contrast, the formation of $\mathrm{PGE}_{2}$ was blocked by 23 to $100 \mu \mathrm{M} \alpha-\mathrm{TOH}$ in LPS-stimulated RAW264.7 macrophages (Jiang et al., 2000; Yam et al., 2009; Ciffolilli et al., 2015; Wallert et al., 2015), but not in IL-1 $\beta$-stimulated A549 epithelial cells (Jiang et al., 2008). Unexpectedly, upstream-regulated COX-2 expression and activity remained unchanged in RAW264.7 macrophages at concentrations of 23 to $100 \mu \mathrm{M} \alpha$ TOH. Furthermore, cytokine-mediated inflammation was not regulated by $\alpha-\mathrm{TOH}$ (Yam et al., 2009), except for an inhibition of IL-1 $\beta$ gene expression in RAW264.7 macrophages using 100 $\mu \mathrm{M}$ (Ciffolilli et al., 2015; Wallert et al., 2015). Beside external stimuli, induction of inflammation, mainly via the TLR4-NF- $\kappa B$ signaling pathway, senescence of cells, and aging are also known triggers of inflammation (Lasry and Ben-Neriah, 2015). Indeed, 24-months-old mice are characterized by an increased inflammatory state compared to younger mice (six months). Application of $500 \mathrm{ppm} \alpha$-TOH acetate lowered aging-induced increases of nitric oxide and $\mathrm{PGE}_{2}$ plasma levels as well as COX-2 activity compared to 24-months-old mice fed $30 \mathrm{ppm}$ (Beharka et al., 2002). In line with this, supplementation with $800 \mathrm{mg} \alpha-\mathrm{TOH} /$ $\mathrm{kg} / \mathrm{d}$ in elder humans for 30 days lead to significantly lower levels of $\mathrm{PGE}_{2}$ in plasma and peripheral blood mononuclear cells compared to vehicle-treated controls (Meydani et al., 1990).

The second most abundant form of vitamin $\mathrm{E}, \gamma-\mathrm{TOH}$, is more prominent for its anti-inflammatory capacity compared to $\alpha$-TOH. Release of nitric oxide by LPS-stimulated RAW264.7 cells was significantly inhibited using $10 \mu \mathrm{M} \gamma$-TOH (Jiang et al., 2000). Release of eicosanoids inflammation, more precisely $\mathrm{PGE}_{2}$, in LPS-stimulated RAW264.7 cells and in IL-1 $\beta$ stimulated A549 cells was inhibited by $10 \mu \mathrm{M}\left(\mathrm{IC}_{50} 7.5 \mu \mathrm{M}\right)$ (Jiang et al., 2000) and 25-40 $\mu \mathrm{M}\left(\mathrm{IC}_{50} 4-7 \mu \mathrm{M}\right.$ ) (Jiang et al., 2000; Jiang et al., 2008), respectively. However, COX-2 expression (Jiang et al., 2000; Jiang et al., 2008) and activity (Jiang et al., 2000; Jang et al., 2016) remained unchanged in LPSstimulated RAW264.7 macrophages, whereas COX-2 activity was inhibited by $50 \mu \mathrm{M} \gamma$-TOH in IL- $1 \beta$-stimulated A549 epithelial cells (Jiang et al., 2008). Azoxymethane-induced IL-6 production was dampened in BALB/c mice by a $\gamma$-TOH-enriched diet (Jiang et al., 2013).

$\delta$-tocopherol $(20 \mu \mathrm{M})$ significantly decreased LPS-induced expression of iNOS (by $60 \%$ at mRNA and by $48 \%$ at protein level) and formation of nitric oxide (by 36\%) in RAW264.7 macrophages (Schmölz et al., 2017). Jiang et al. reported an inhibition of COX-2 activity, but not COX-2 expression in IL$1 \beta$-stimulated A549 cells (Jiang et al., 2008), whereas Jang et al. 
TABLE 1 | Overview on the biological activities of chromanols linked to inflammation.

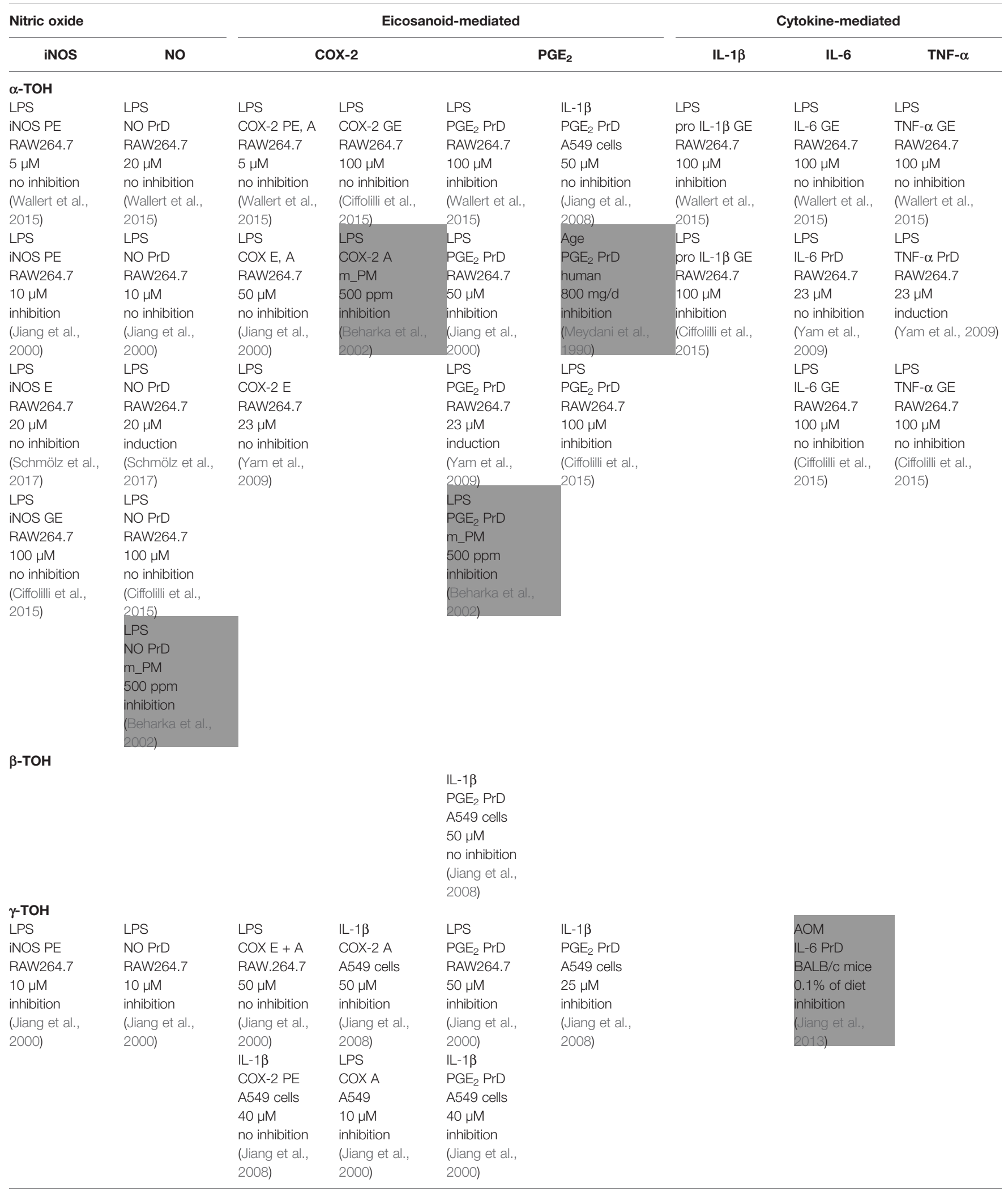


TABLE 1 | Continued

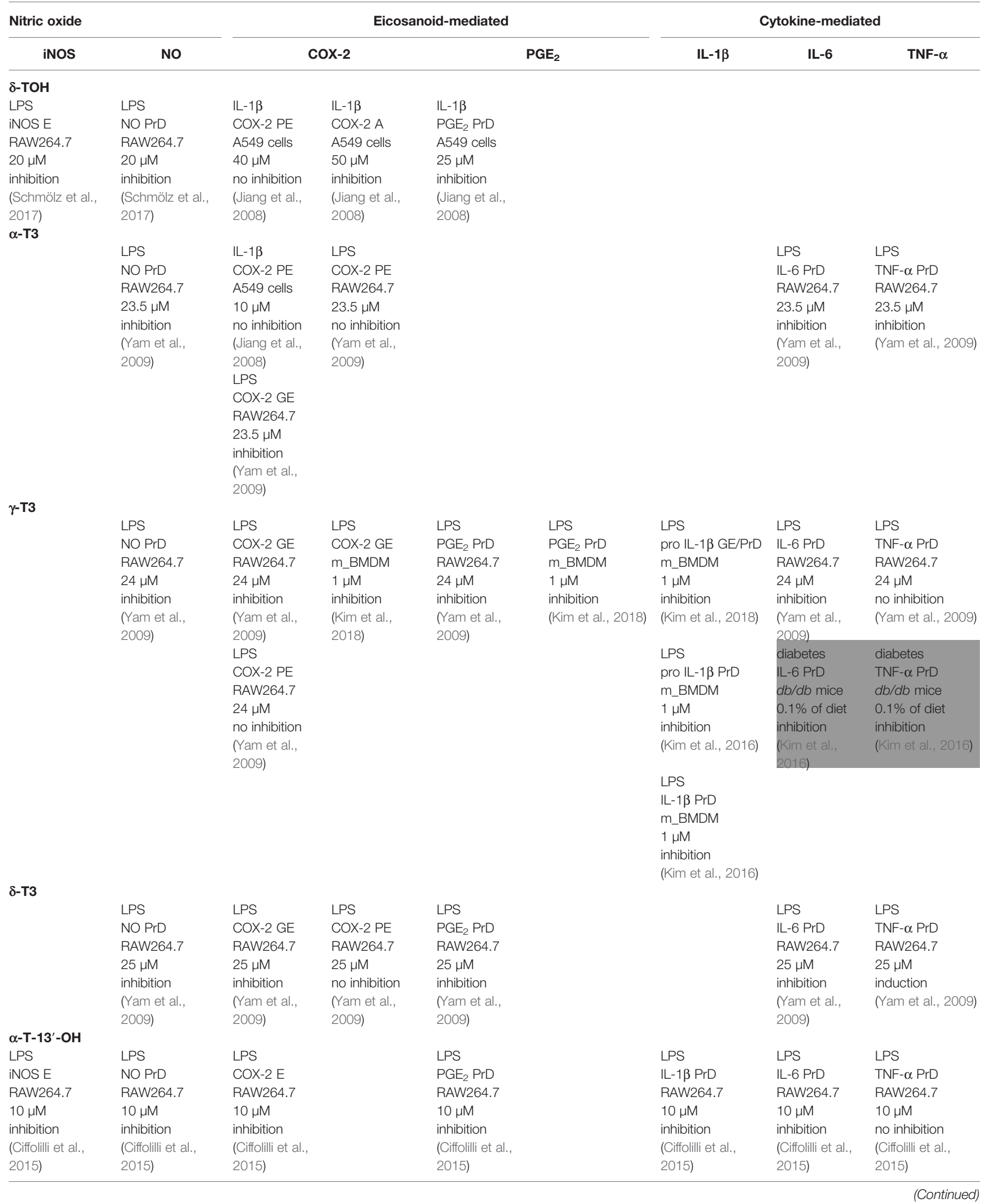


TABLE 1 | Continued

\begin{tabular}{|c|c|c|c|c|c|c|c|c|}
\hline \multicolumn{2}{|l|}{ Nitric oxide } & \multicolumn{4}{|c|}{ Eicosanoid-mediated } & \multicolumn{3}{|c|}{ Cytokine-mediated } \\
\hline iNOS & NO & \multicolumn{2}{|c|}{ cox-2 } & \multicolumn{2}{|c|}{$\mathrm{PGE}_{2}$} & \multirow[t]{2}{*}{ IL-1 $\beta$} & \multirow[t]{2}{*}{ IL-6 } & TNF- $\alpha$ \\
\hline LPS & LPS & & & & & & & \\
\hline iNOS E & NO PrD & & & & & & & \\
\hline RAW264.7 & RAW264.7 & & & & & & & \\
\hline $10 \mu \mathrm{M}$ & $10 \mu \mathrm{M}$ & & & & & & & \\
\hline inhibition & inhibition & & & & & & & \\
\hline $\begin{array}{l}\text { (Schmölz et al., } \\
\text { 2017) }\end{array}$ & $\begin{array}{l}\text { (Schmölz et al., } \\
\text { 2017) }\end{array}$ & & & & & & & \\
\hline \multicolumn{9}{|l|}{$\alpha-\mathrm{T}-13^{\prime}-\mathrm{COOH}$} \\
\hline LPS & LPS & LPS & IL-1 $1 \beta$ & LPS & LPS & LPS & LPS & LPS \\
\hline iNOS PE & NO PrD & COX-2 PE & COX-2 A & $\mathrm{PGE}_{2} \operatorname{PrD}$ & $\mathrm{PGE}_{2} \operatorname{PrD}$ & pro IL-1 $\beta$ GE & IL-6 GE & TNF- $\alpha$ GE \\
\hline RAW264.7 & RAW264.7 & RAW264.7 & platelet & RAW264.7 & h_monocytes & RAW264.7 & RAW264.7 & RAW264.7 \\
\hline $5 \mu \mathrm{M}$ & $5 \mu \mathrm{M}$ & $5 \mu \mathrm{M}$ & $10 \mu \mathrm{M}$ & $5 \mu \mathrm{M}$ & $10 \mu \mathrm{M}$ & $5 \mu \mathrm{M}$ & $5 \mu \mathrm{M}$ & $5 \mu \mathrm{M}$ \\
\hline inhibition & inhibition & inhibition & inhibition & inhibition & no inhibition & inhibition & no inhibition & no inhibition \\
\hline $\begin{array}{l}\text { (Wallert et al., } \\
\text { 2015) }\end{array}$ & $\begin{array}{l}\text { (Wallert et al., } \\
\text { 2015) }\end{array}$ & $\begin{array}{l}\text { (Wallert et al., } \\
\text { 2015) }\end{array}$ & $\begin{array}{l}\text { (Pein et al., } \\
\text { 2018) }\end{array}$ & $\begin{array}{l}\text { Wallert et al., } \\
\text { 2015) }\end{array}$ & $\begin{array}{l}\text { (Pein et al., } \\
\text { 2018) }\end{array}$ & $\begin{array}{l}\text { (Wallert et al., } \\
\text { 2015) }\end{array}$ & $\begin{array}{l}\text { (Wallert et al., } \\
\text { 2015) }\end{array}$ & $\begin{array}{l}\text { (Wallert et al., } \\
\text { 2015) }\end{array}$ \\
\hline LPS & LPS & LPS & - & & & & & \\
\hline iNOS E & NO PrD & COX-2 A & COX-2 A & & & & & \\
\hline RAW264.7 & RAW264.7 & RAW264.7 & enzyme & & & & & \\
\hline $5 \mu \mathrm{M}$ & $5 \mu \mathrm{M}$ & $5 \mu \mathrm{M}$ & $10 \mu \mathrm{M}$ & & & & & \\
\hline inhibition & inhibition & no inhibition & no inhibition & & & & & \\
\hline $\begin{array}{l}\text { (Schmölz et al., } \\
\text { 2017) }\end{array}$ & $\begin{array}{l}\text { (Schmölz et al., } \\
\text { 2017) }\end{array}$ & $\begin{array}{l}\text { (Wallert et al., } \\
\text { 2015) }\end{array}$ & $\begin{array}{l}\text { (Pein et al., } \\
\text { 2018) }\end{array}$ & & & & & \\
\hline \multicolumn{9}{|l|}{$\delta-\mathrm{T}-13^{\prime}-\mathrm{OH}$} \\
\hline LPS & LPS & & & & & & & \\
\hline iNOS E & NO PrD & & & & & & & \\
\hline RAW264.7 & RAW264.7 & & & & & & & \\
\hline $10 \mu \mathrm{M}$ & $10 \mu \mathrm{M}$ & & & & & & & \\
\hline inhibition & inhibition & & & & & & & \\
\hline $\begin{array}{l}\text { (Schmölz et al., } \\
\text { 2017) }\end{array}$ & $\begin{array}{l}\text { (Schmölz et al., } \\
\text { 2017) }\end{array}$ & & & & & & & \\
\hline \multicolumn{9}{|l|}{$\delta-\mathrm{T}-13^{\prime}-\mathrm{COOH}$} \\
\hline LPS & LPS & IL-1 $\beta$ & - & & & & & \\
\hline iNOS E & NO PrD & COX-2 A & COX-2 A & & & & & \\
\hline RAW264.7 & RAW264.7 & A549 & enzyme & & & & & \\
\hline $5 \mu \mathrm{M}$ & $5 \mu \mathrm{M}$ & $4 \mu \mathrm{M}$ & $5 \mu \mathrm{M}$ & & & & & \\
\hline inhibition & inhibition & inhibition & inhibition & & & & & \\
\hline (Schmölz et al., & (Schmölz et al., & (Jiang et al., & (Jang et al., & & & & & \\
\hline 2017$)$ & & $\begin{array}{l}2008) \\
-\end{array}$ & 2016) & & & & & \\
\hline & & coX-2 A & & & & & & \\
\hline & & enzyme & & & & & & \\
\hline & & $4 \mu \mathrm{M}$ & & & & & & \\
\hline & & inhibition & & & & & & \\
\hline & & (Jiang et al., & & & & & & \\
\hline \multicolumn{9}{|l|}{$\delta-\mathrm{T}-9^{\prime}-\mathrm{COOH}$} \\
\hline & & - & $\| \mathrm{L}-1 \beta$ & & & & & \\
\hline & & COX-2 A & COX-2 A & & & & & \\
\hline & & enzyme & A549 & & & & & \\
\hline & & $20 \mu \mathrm{M}$ & $6 \mu \mathrm{M}$ & & & & & \\
\hline & & no inhibition & inhibition & & & & & \\
\hline & & (Jiang et al., & (Jiang et al., & & & & & \\
\hline \multicolumn{9}{|l|}{$\alpha-{ }^{-T}-5^{\prime}-\mathrm{COOH}$} \\
\hline & & - & & & & & & \\
\hline & & COX-2 A & & & & & & \\
\hline & & enzyme & & & & & & \\
\hline & & $140 \mu \mathrm{M}$ & & & & & & \\
\hline & & inhibition & & & & & & \\
\hline & & (Jiang et al., & & & & & & \\
\hline
\end{tabular}


TABLE 1 | Continued

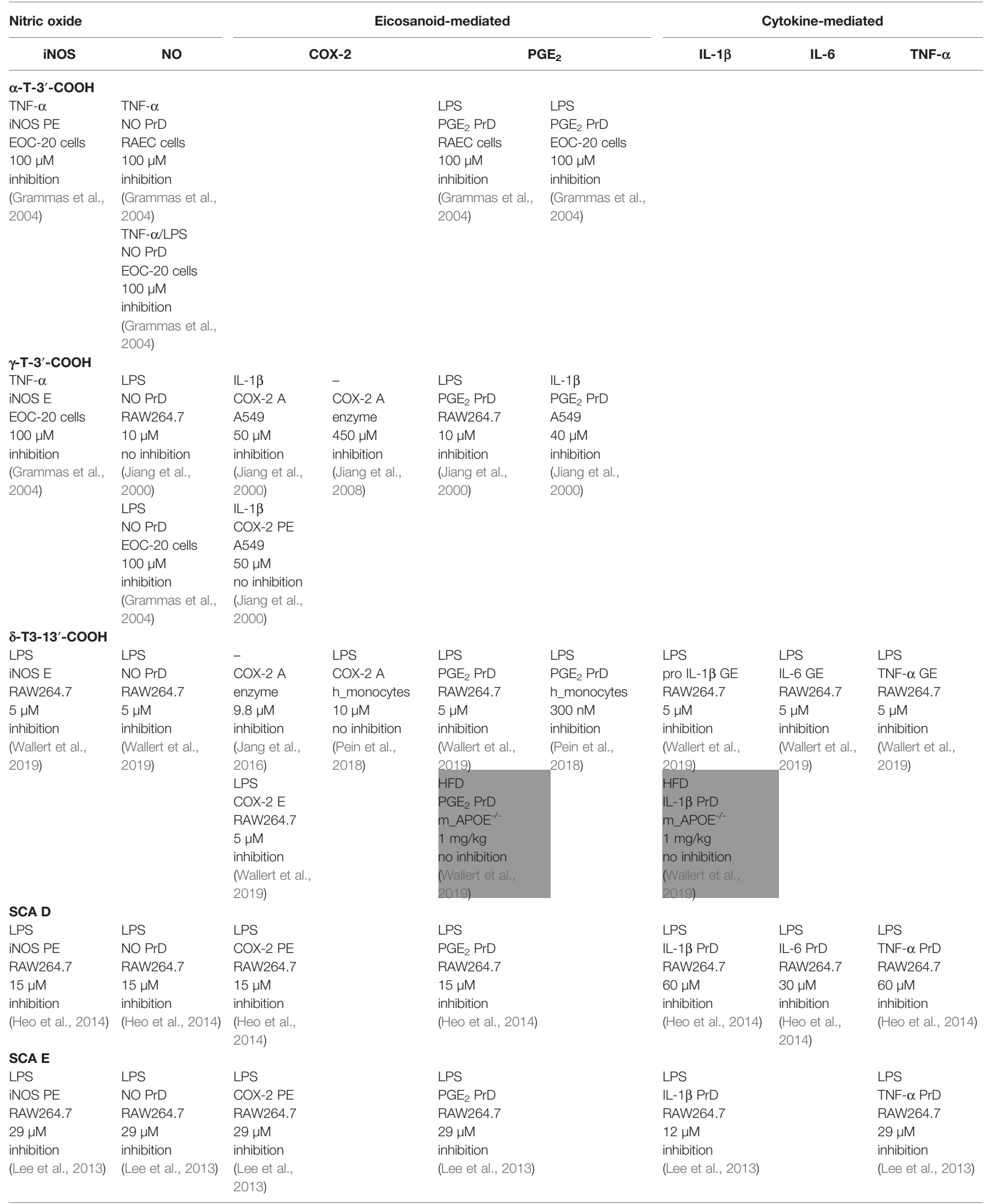


TABLE 1 | Continued

\begin{tabular}{|c|c|c|c|c|c|c|}
\hline \multicolumn{2}{|l|}{ Nitric oxide } & \multicolumn{2}{|c|}{ Eicosanoid-mediated } & \multicolumn{3}{|c|}{ Cytokine-mediated } \\
\hline iNOS & NO & cox-2 & $\mathrm{PGE}_{2}$ & IL-1 $\beta$ & IL-6 & TNF- $\alpha$ \\
\hline \multicolumn{7}{|l|}{ SCA G } \\
\hline LPS & LPS & LPS & LPS & LPS & LPS & LPS \\
\hline iNOS PE & NO PrD & COX-2 PE & $\mathrm{PGE}_{2} \mathrm{PrD}$ & IL-1 $\beta \operatorname{PrD}$ & IL-6 PrD & TNF- $\alpha \operatorname{PrD}$ \\
\hline RAW264.7 & RAW264.7 & RAW264.7 & RAW264.7 & RAW264.7 & RAW264.7 & RAW264.7 \\
\hline $10 \mu \mathrm{M}$ & $10 \mu \mathrm{M}$ & $10 \mu \mathrm{M}$ & $10 \mu \mathrm{M}$ & $10 \mu \mathrm{M}$ & $10 \mu \mathrm{M}$ & $10 \mu \mathrm{M}$ \\
\hline inhibition & inhibition & inhibition & inhibition & inhibition & inhibition & inhibition \\
\hline (Yoon et al., & (Yoon et al., & (Yoon et al., & Yoon et al., & (Yoon et al., & (Yoon et al., & (Yoon et al., \\
\hline \multicolumn{7}{|l|}{$\delta-A C$} \\
\hline & & & & LPS & & LPS \\
\hline & & & & IL-1 $\beta \operatorname{PrD}$ & & TNF- $\alpha \operatorname{PrD}$ \\
\hline & & & & monocytes & & monocytes \\
\hline & & & & $1 \mu \mathrm{M}$ & & $10 \mu \mathrm{M}$ \\
\hline & & & & inhibition & & inhibition \\
\hline & & & & $\begin{array}{l}\text { (Richomme et al., } \\
\text { 2017) }\end{array}$ & & $\begin{array}{l}\text { (Richomme et al., } \\
\text { 2017) }\end{array}$ \\
\hline
\end{tabular}

The effects of the respective compounds on inflammation have been divided into activities mediated by nitric oxide (iNOS, NO), eicosanoids (COX-2, PGE 2 ), and cytokines (IL-1 $\beta$, IL-6, TNF- $\alpha$ ). The content of each cell of the table is constructed as follows (read from top to bottom): (i) used stimulus; (ii) investigated parameter; (iii) cell type, tissue, mouse, or other models used for investigation; (iv) used concentration of the respective compound; (v) observed effect on the studied parameter; (vi) reference. When no stimulus was used or was required for the studies, the respective row is marked with a dash. The following abbreviations are used: A, activity; A549, human adenocarcinoma alveolar basal epithelial cells; BALB/C mice, albino laboratory-bred strain of the house mouse; Apoe-- mice, apolipoprotein E deficient mice; BMDM, bone marrow derived macrophages; COX-2, cyclooxygenase 2; EOC-20, epithelial ovarian cancer cells; E, expression; GE, gene expression; HFD, high-fat diet; $h$, human; iNOS, inducible nitric oxide synthase; IL, interleukin; db/db mice, leptin receptor activity deficient

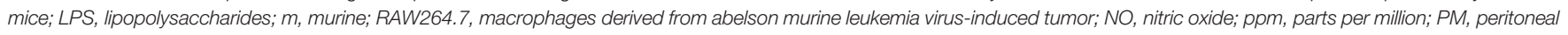
macrophages; PrD, production; $P G E_{2}$, prostaglandin $E_{2} ;$ PE, protein expression; RAEC, rat aortic endothelial cells; TNF- $\alpha$, tumor necrosis factor $\alpha$.

All results obtained from in vivo studies are marked in gray.

did not observe altered COX-2 activity after $\delta$-TOH treatment using a human recombinant enzyme-based assay (Jang et al., 2016). However, formation of $\mathrm{PGE}_{2}$ was significantly blocked ( IC $_{50} 1-3 \mu \mathrm{M}$ ) (Jiang et al., 2008). The least abundant form of tocopherols, $\beta$-TOH has been rarely studied regarding its antiinflammatory capacity. Studies available so far did not reveal any anti-inflammatory effects of $\beta$-TOH (Jiang et al., 2008).

Tocotrienols. Recent publications reported a more pronounced anti-inflammatory capacity of T3s compared to TOHs, with $\gamma$-T3 and $\alpha$-T3 showing the strongest effects. $\alpha-, \delta$-, and $\gamma$-T3 significantly decreased LPS-mediated formation of nitric oxide (by $11 \%, 31 \%$, 19\%, respectively) and $\mathrm{PGE}_{2}$ (by $30 \%, 55 \%, 20 \%$, respectively) in RAW264.7 macrophages treated with $23.5 \mu \mathrm{M}$ of the respective compound (Yam et al., 2009) as well as bone marrow-derived macrophages (BMDMs) using $1 \mu \mathrm{M}$ of $\gamma$-T3 (Kim et al., 2018). Expression of COX-2 mRNA was inhibited by $\alpha-, \quad \delta$, , and $\gamma$-T3, whereas protein expression remained unchanged (Jiang et al., 2008; Yam et al., 2009; Kim et al., 2018). In addition, cytokine-driven inflammation is also dampened by $\alpha-, \delta$-, and $\gamma$-T3, which reduced the release of IL- 6 and TNF- $\alpha$ in LPS-stimulated RAW264.7 cells. However, $\gamma$-T3 reduced expression of IL- 6 and TNF- $\alpha$ mRNA as well as the secretion of IL-6, but not of TNF- $\alpha$ in this cell model (Yam et al., 2009). Furthermore, first reports suggest inhibitory effects of $\gamma$-T3 on the NLR family pyrin domain containing 3 (NLRP3) inflammasome. In brief, $1 \mu \mathrm{M} \gamma$-T3 suppressed mRNA expression of pro-IL-1 $\beta$ and -18 as well as respective formation of active IL- $1 \beta$ and -18 . This has been observed in LPS/nigericin- as well as LPS/palmitate-stimulated BMDMs and $d b / d b$ mice fed with a diet containing $0.1 \% \gamma$-T3 for eight weeks (Kim et al., 2016; Kim et al., 2018).

\section{Metabolites of Tocopherols and Tocotrienols}

We here present a report on selected structures formed during hepatic catabolism of vitamin $\mathrm{E}$, for which data on the biological activity was available. Metabolites formed during physiological hepatic metabolism of vitamin $\mathrm{E}$ are highly potent antiinflammatory compounds with different efficiencies, depending on their methylation pattern (Azzi, 2019) and the number of isoprene units forming the side-chain (Schmölz et al., 2017). Metabolism of non- $\alpha-\mathrm{TOH}$ forms of vitamin $\mathrm{E}$ is more pronounced, resulting from the lower affinities of these molecules to the $\alpha$-tocopherol transfer protein. However, $\alpha$ metabolites revealed significant anti-inflammatory properties. The most widely studied metabolites are the LCMs $\alpha-\mathrm{T}-13^{\prime}$ $\mathrm{OH}$ and $-\mathrm{COOH}$ and the short-chain metabolites $\alpha-$ and $\gamma-3^{\prime}-\mathrm{T}$ $\mathrm{COOH}$, likely due to their presence in plasma, feces, and urine, respectively, which may account for their physiological relevance (Jiang et al., 2007).

Long- and Intermediate-Chain Tocopherol-Derived Metabolites. Birringer and coworkers showed the relevance of the terminal oxidative modification of the side-chain for biological activity (Birringer et al., 2018). During the hepatic metabolism of TOHs, $\mathrm{T}-13^{\prime}-\mathrm{OH}$ are the first metabolites that are formed; these LCMs show distinct effects that are different from those of their respective metabolic precursor (for details, see Chapter 2.1.1. Tocopherols and Tocotrienols). Both, $\alpha-$ and $\delta-\mathrm{T}-13^{\prime}-\mathrm{OH}$ significantly decreased mRNA (29-72\% and $87 \%$, respectively) and 
protein (40-53\% and 53\%, respectively) expression of iNOS and the production of nitric oxide (56-69\% and 49\%, respectively) in LPS-stimulated murine RAW264.7 macrophages at a concentration of $10 \mu \mathrm{M}$, thus showing comparable effect sizes independent from the methylation pattern of the chromanol ring system (Ciffolilli et al., 2015; Schmölz et al., 2017). Furthermore, $\alpha-\mathrm{T}-13^{\prime}-\mathrm{OH}$ significantly decreased expression of COX-2 mRNA and protein (64\% and $49 \%$, respectively), IL-1 $\beta$ (64\%) and IL-6 (68\%) mRNA, and the production of $\mathrm{PGE}_{2}(55 \%)$ (Ciffolilli et al., 2015).

Notably, the length of the side-chain is important for the mediation of anti-inflammatory effects. Accordingly, both $\alpha$-T$13^{\prime}-\mathrm{COOH}(5 \mu \mathrm{M})$ and $\delta$-T-13'-COOH $(5 \mu \mathrm{M})$ significantly decreased expressions of iNOS and COX-2 mRNAs as well as proteins in murine LPS-stimulated RAW264.7 macrophages (Wallert et al., 2015; Schmölz et al., 2017). Further, $\delta$-T-13'$\mathrm{COOH}$ inhibited the activity of purified recombinant COX-2 enzyme (5 $\mu \mathrm{M}$ [Jiang et al., 2008; Jang et al., 2016]) as well as in human lung adenocarcinoma A549 cells ( $4 \mu \mathrm{M}$, [Jiang et al., 2008)). Interestingly, the activity of recombinant COX-2 enzymes remained unchanged by $\alpha$-T-13'-COOH $(5-10 \mu \mathrm{M})$ (Wallert et al., 2015; Pein et al., 2018). LPS-induced production of the respective signaling molecules, nitric oxide and $\mathrm{PGE}_{2}$, was completely blocked in murine macrophages $(5 \mu \mathrm{M})$, but not in LPS-activated human primary monocytes $(10 \mu \mathrm{M})$ (Pein et al., 2018). In addition, 5-LO-induced formation of proinflammatory leukotrienes was dampened by $\alpha-\mathrm{T}-13^{\prime}-\mathrm{COOH}$ in LPS-stimulated monocytes $\left(\mathrm{LTB}_{4}\right)$, activated human neutrophils, activated human blood, zymosan-induced mouse peritonitis (LTC4), as measured in plasma and exudate, and ovalbumin-induced bronchial hyperreactivity in mice (Pein et al., 2018). Effective concentrations of $\alpha-\mathrm{T}-13^{\prime}-\mathrm{COOH}$, that inhibit 5-LO product formation in vitro, were in a range that was detected for the metabolite in human and mice serum without supplementation $(<0.3 \mu \mathrm{M})$. Furthermore, expression of pro-IL$1 \beta$ was down-regulated by $5 \mu \mathrm{M} \alpha-\mathrm{T}-13^{\prime}-\mathrm{COOH}$, whereas IL-6 and TNF- $\alpha$ remained unchanged (Wallert et al., 2015).

Degradation of the LCMs of different vitamin E forms results in formation of respective ICMs that are further processed to SCMs. These metabolic end-products do not accumulate in plasma or tissues and their physiological relevance is therefore considered as less important. Hence, data on these metabolites are scarce. To date, anti-inflammatory effects, i.e. the inhibition of COX-2 activity $\left(\mathrm{IC}_{50} 6 \mu \mathrm{M}\right)$, by $\delta$-9'-T-COOH have been reported in human lung adenocarcinoma A549 cells (Jiang et al., 2008).

Long- and Intermediate-Chain Tocotrienol-Derived Metabolites. Within the group of T3-derived metabolites, the LCM $\delta$-T3-13'$\mathrm{COOH}$ (i.e. garcinoic acid) is the most potent anti-inflammatory compound of the ones studied so far. Expression of iNOS (by 97\%), COX-2 (by 70\%), pro-IL-1 $\beta$ (by $61 \%$ ), IL-6 (by 70\%), and TNF- $\alpha$ (by $25 \%$ ) mRNA was decreased by $5 \mu \mathrm{M} \delta$-T3-13'$\mathrm{COOH}$ in LPS-stimulated murine RAW264.7 macrophages. Consequently, protein expression of iNOS (by 83\%), COX-2 (by $33 \%$ ), and the respective formation of $\mathrm{NO}$ (by $81 \%$ ), $\mathrm{PGE}_{2}$ (by $90 \%$ ) and thromboxane (TX)B $\mathrm{B}_{2}$ (by $91 \%$ ) were dampened in
LPS-stimulated murine RAW264.7 macrophages (Wallert et al., 2019). Formation of $\mathrm{PGE}_{2}$ in LPS-stimulated monocytes was inhibited already by $300 \mathrm{nM} \delta$-T3-13' $-\mathrm{COOH}$ (Pein et al., 2018). In line with this, $\delta$-T3-13'-COOH also inhibited activity of microsomal $\mathrm{PGE}_{2}$ synthase (by nearly $70 \%$ ) at a concentration of $10 \mu \mathrm{M}$ in a cell-free assay using microsomes of IL-1 $\beta$-stimulated human lung adenocarcinoma A549 cells as an enzyme source

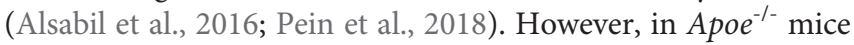
fed a high fat diet with $1 \mathrm{mg} / \mathrm{kg} \delta$-T3-13'-COOH for 8 weeks neither nitric oxide, $\mathrm{PGE}_{2}, \mathrm{TXB}_{2}$ nor IL- $1 \beta$ concentrations in plasma were altered compared to the control group (Wallert et al., 2019). However, contrary data exist also for the alteration of prostaglandins following inhibition of COX-2 activity: $\mathrm{IC}_{50} 9.8$ $\mu \mathrm{M}$ (Jang et al., 2016) and $\mathrm{IC}_{50}>10 \mu \mathrm{M}$ (Pein et al., 2018).

Short-Chain Tocopherol-Derived Metabolites. 5'-T-COOH (CMBHC) and $3^{\prime}-\mathrm{T}-\mathrm{COOH}(\mathrm{CEHC})$ are the SCMs. Physiologically formed $\gamma-3^{\prime}$-T-COOH was mainly detected in urine. Supplementation of $\alpha$-TOH enhances the hepatic metabolism of $\alpha$ $\mathrm{TOH}$, which in turn increases degradation of $\alpha-\mathrm{TOH}$ and excretion of $\alpha-5^{\prime}-\mathrm{T}-\mathrm{COOH}$ and $\alpha-3^{\prime}-\mathrm{T}-\mathrm{COOH}$ via urine. Both, $\alpha-5^{\prime}-\mathrm{T}-\mathrm{COOH}\left(\mathrm{IC}_{50} 140 \mu \mathrm{M}\right)$ and $\gamma-3^{\prime}-\mathrm{T}-\mathrm{COOH}\left(\mathrm{IC}_{50} 450 \mu \mathrm{M}\right)$ showed marginal inhibitory effects on human recombinant COX-2 activity (Jiang et al., 2008). However, in IL-1 $\beta$-stimulated A549 cells, $\gamma$ - $3^{\prime}$-T-COOH $(50 \mu \mathrm{M})$ exhibited stronger inhibition of COX-2 activity. Formation of $\mathrm{PGE}_{2}$ was also inhibited in IL$1 \beta$-stimulated A549 (50 $\mu \mathrm{M})$, LPS-stimulated RAW264.7 (10 $\mu \mathrm{M})$, as well as TNF- $\alpha$-stimulated RAEC $\left(\mathrm{IC}_{50} 59 \mu \mathrm{M}\right)$ and EOC-20 cells ( $\left.\mathrm{IC}_{50} 66 \mu \mathrm{M}\right)$ (Jiang et al., 2000; Grammas et al., 2004). The TNF- $\alpha$-induced release of nitric oxide was blocked in EOC-20 ( IC $\left._{50} 58 \mu \mathrm{M}\right)$ and RAEC cells $\left(\mathrm{IC}_{50} 56 \mu \mathrm{M}\right)$ by $\alpha-3^{\prime}-\mathrm{T}$ $\mathrm{COOH}$, whereas $100 \mu \mathrm{M} \gamma-3^{\prime}$-T-COOH inhibited production of nitric oxide in EOC-20 cells by $10 \%$ only (Grammas et al., 2004). In contrast, both $\alpha-3^{\prime}-\mathrm{T}-\mathrm{COOH}$ and $\gamma-3^{\prime}-\mathrm{T}-\mathrm{COOH}$ decreased production of nitric oxide in LPS-stimulated EOC-20 cells (Grammas et al., 2004). Notably, lower concentrations did not alter production of nitric oxide (Jiang et al., 2000; Grammas et al., 2004).

\section{Sargachromanols}

The sargachromanol forms D, E, and G isolated from Sargassum siliquastrum also exert anti-inflammatory effects in LPSstimulated RAW264.7 macrophages in a concentrationdependent manner. Sargachromanol forms D, E, and G inhibited expression of iNOS protein to $30-50 \%$ with concentrations of $15,12.5$, and $20 \mu \mathrm{M}$, respectively. In contrast, inhibitory effects on the formation of the respective signaling molecule nitric varies compound-dependent between 10 and 90\% (Lee et al., 2013), with SCA E being the most effective (Yoon et al., 2012a; Lee et al., 2013; Heo et al., 2014). Within the inflammatory eicosanoid pathway, expression of COX-2 was inhibited by $15 \%$ by SCA D and G and up to $90 \%$ by SCA E. The $\mathrm{IC}_{50}$ for the formation of COX-2-derived $\mathrm{PGE}_{2}$ was $15 \mu \mathrm{M}$ (SCA D [Heo et al., 2014]), $12.5 \mu \mathrm{M}$ (SCA E [Lee et al., 2013]), and $20 \mu \mathrm{M}$ (SCA G [Yoon et al., 2012a]), respectively. The LPSinduced production of TNF- $\alpha$, IL- 6 and IL- $1 \beta$ was effectively blocked by SCA D $\left(\mathrm{IC}_{50}>60,>20-25\right.$, and $40 \mu \mathrm{M}$, respectively 
[Heo et al., 2014]), E ( $\mathrm{IC}_{50}>25 \mu \mathrm{M}$, not investigated and $>15 \mu \mathrm{M}$, respectively [Lee et al., 2013]), and $\mathrm{G}\left(\mathrm{IC}_{50} 40,20\right.$, and $20 \mu \mathrm{M}$, respectively [Yoon et al., 2012a]). The total inflammatory capacity, as determined by the expression of iNOS and COX-2, the production of their respective signaling molecules, nitric oxide and $\mathrm{PGE}_{2}$, as well as the production of cytokines leads to the following estimation of compound effectiveness: SCA E > D $>$ G.

\section{Amplexichromanols}

Amplexichromanols can be distinguished as $\alpha-, \beta-, \gamma-, \delta$-forms. $\delta$-Amplexichromanols have been shown to inhibit the secretion of TNF- $\alpha\left(\mathrm{IC}_{50}<10 \mu \mathrm{M}\right)$ and IL-1 $\beta\left(\mathrm{IC}_{50} 10 \mu \mathrm{M}\right)$ in LPSstimulated monocytes (Richomme et al., 2017). To the best of our knowledge, there are no reports on anti-inflammatory effects of the other forms of AC.

\section{Chromenols}

Compared to the complex group of structures comprising the chromanol family, chromenol structures are less ubiquitous. Sargachromenol is described here as a representative of the chromenols with anti-inflammatory effects. An ethanolic extract of Myagropsis myagroides inhibited nitric oxide-, eicosanoid-, and cytokine-mediated pathways and the inflammatory response (Table 2), with sargachromenol being the lead compound in the extract (Kim et al., 2014). Further studies using isolated sargachromenol from different sources confirmed the results obtained by Kim et al. For instance, sargachromanol isolated from the marine brown alga Sargassum serratifolium inhibited peroxinitrite anion-mediated albumin nitration with an $\mathrm{IC}_{50}$ of $5 \mu \mathrm{M}$ (Ali et al., 2017). Furthermore, the COX-2 pathway was inhibited using $50 \mu \mathrm{M}$ and $100 \mathrm{ppm}$ sargachromenol isolated from Sargassum micracanthum (Yang et al., 2013) and Iryanthera juruensis seeds (Silva et al., 2007), respectively. Here, the effect sizes of 70 and $84 \%$ found by Yang et al. and Silva et al., respectively, are comparable with respect to the inhibition of the expression of COX-2 protein. For the respective signaling molecule $\mathrm{PGE}_{2}$ an $\mathrm{IC}_{50}$ value of $30 \mu \mathrm{M}$ was defined (Yang et al., 2013). In addition, inhibitory effects were observed for the expression of iNOS protein $(95 \%)$ and the formation of nitric oxide ( $\left.\mathrm{IC}_{50} 82 \mu \mathrm{M}\right)$ (Yang et al., 2013).

\section{Carcinogenesis}

For the evaluation of anti-carcinogenic effects of chromanol and chromenol structures, key apoptotic pathways, such as cleavage of poly-[ADP-ribose]-polymerase 1 (PARP-1), caspases 3, 7, 8, and 9 as well as anti-proliferative and cytotoxic properties on cancer cell lines and further markers of carcinogenesis marker in mice were evaluated (Figure 7). In addition, large-scaled human trials investigating preventive and therapeutic effects of some tested compounds will be discussed in the following chapter.

\section{Chromanols}

A detailed overview on the biological activities of chromanols linked to carcinogenesis is provided in Table 3.

\section{Tocopherols and Tocotrienols}

Like the mediation of anti-inflammatory effects, anticarcinogenic actions were profoundly investigated for $\alpha$-TOH

TABLE 2 | Overview on the biological activities of chromenols linked to inflammation.

\begin{tabular}{|c|c|c|c|c|c|c|}
\hline \multicolumn{2}{|l|}{ Nitric oxide } & \multicolumn{2}{|c|}{ Eicosanoid-mediated } & \multicolumn{3}{|c|}{ Cytokine-mediated } \\
\hline iNOS & NO & cox-2 & PGE2 & IL-1 $\beta$ & IL-6 & TNF- $\alpha$ \\
\hline \multicolumn{7}{|l|}{ Sargachromenol } \\
\hline LPS & LPS & LPS & LPS & LPS & LPS & LPS \\
\hline iNOS PE & NO PrD & COX-2 E & $\mathrm{PGE}_{2} \operatorname{PrD}$ & $\mathrm{IL}-1 \beta \operatorname{PrD}$ & IL-6 PrD & TNF- $\alpha \operatorname{PrD}$ \\
\hline BV-2 cells & BV-2 cells & BV-2 cells & BV-2 cells & BV-2 cells & BV-2 cells & BV-2 cells \\
\hline $2.7 \mu \mathrm{M}$ & $2.7 \mu \mathrm{M}$ & $2.7 \mu \mathrm{M}$ & $2.7 \mu \mathrm{M}$ & $2.7 \mu \mathrm{M}$ & $2.7 \mu \mathrm{M}$ & $2.7 \mu \mathrm{M}$ \\
\hline inhibition & inhibition & inhibition & inhibition & inhibition & inhibition & inhibition \\
\hline (Kim et al., 2014) & (Kim et al., 2014) & (Kim et al., 2014) & (Kim et al., 2014) & (Kim et al., 2014) & (Kim et al., 2014) & (Kim et al., 2014) \\
\hline LPS & LPS & LPS & LPS & & & \\
\hline iNOS PE & NO PrD & COX-2 PE & $\mathrm{PGE}_{2} \operatorname{PrD}$ & & & \\
\hline RAW264.7 & RAW264.7 & RAW264.7 & RAW264.7 & & & \\
\hline $50 \mu \mathrm{M}$ & $50 \mu \mathrm{M}$ & $50 \mu \mathrm{M}$ & $50 \mu \mathrm{M}$ & & & \\
\hline inhibition & inhibition & inhibition & inhibition & & & \\
\hline \multirow[t]{7}{*}{ (Yang et al., 2013) } & (Yang et al., 2013) & (Yang et al., 2013) & (Yang et al., 2013) & & & \\
\hline & peroxynitrite & - & & & & \\
\hline & NO PrD & COX-2 A & & & & \\
\hline & BSA nitrition & enzyme & & & & \\
\hline & $2.5 \mu \mathrm{M}$ & 100 ppm & & & & \\
\hline & inhibition & inhibition & & & & \\
\hline & (Ali et al., 2017) & (Silva et al., 2007) & & & & \\
\hline
\end{tabular}

The effects of the respective compounds on inflammation have been divided into activities mediated by nitric oxide (iNOs, NO), eicosanoids (COX-2, PGE $)$, and cytokines (IL-1 $\beta$, IL-6, TNF- $\alpha$ ). The content of each cell of the table is constructed as follows (read from top to bottom): (i) used stimulus; (ii) investigated parameter; (iii) cell type or other models used for investigation; (iv) used concentration of the respective compound; (V) observed effect on the studied parameter; (vi) reference. In the publications where no stimulus was used or was required for the studies, the respective row is marked with a dash. The following abbreviations are used: A, activity; BSA, bovine serum albumin; BV-2, brain microglial cells transformed by recombinant retrovirus ( $v$-raff $/ v$-mic); COX-2, Cyclooxygenase 2; $E$, expression; iNOS, induce able nitric oxide synthase; IL-1 $\beta$, interleukin 1 $\beta$; IL-6, interleukin 6; LPS, lipopolysaccharides; $m$, murine; RAW264.7, macrophages derived from abelson murine leukemia virus-induced tumor; NO, nitric oxide; PrD, production; $P G E_{2}$, prostaglandin $E_{2}$; $P E$, protein expression; TNF- $\alpha$, tumor necrosis factor $\alpha$. 
TABLE 3 | Overview on the biological activities of chromanols linked to carcinogenesis.

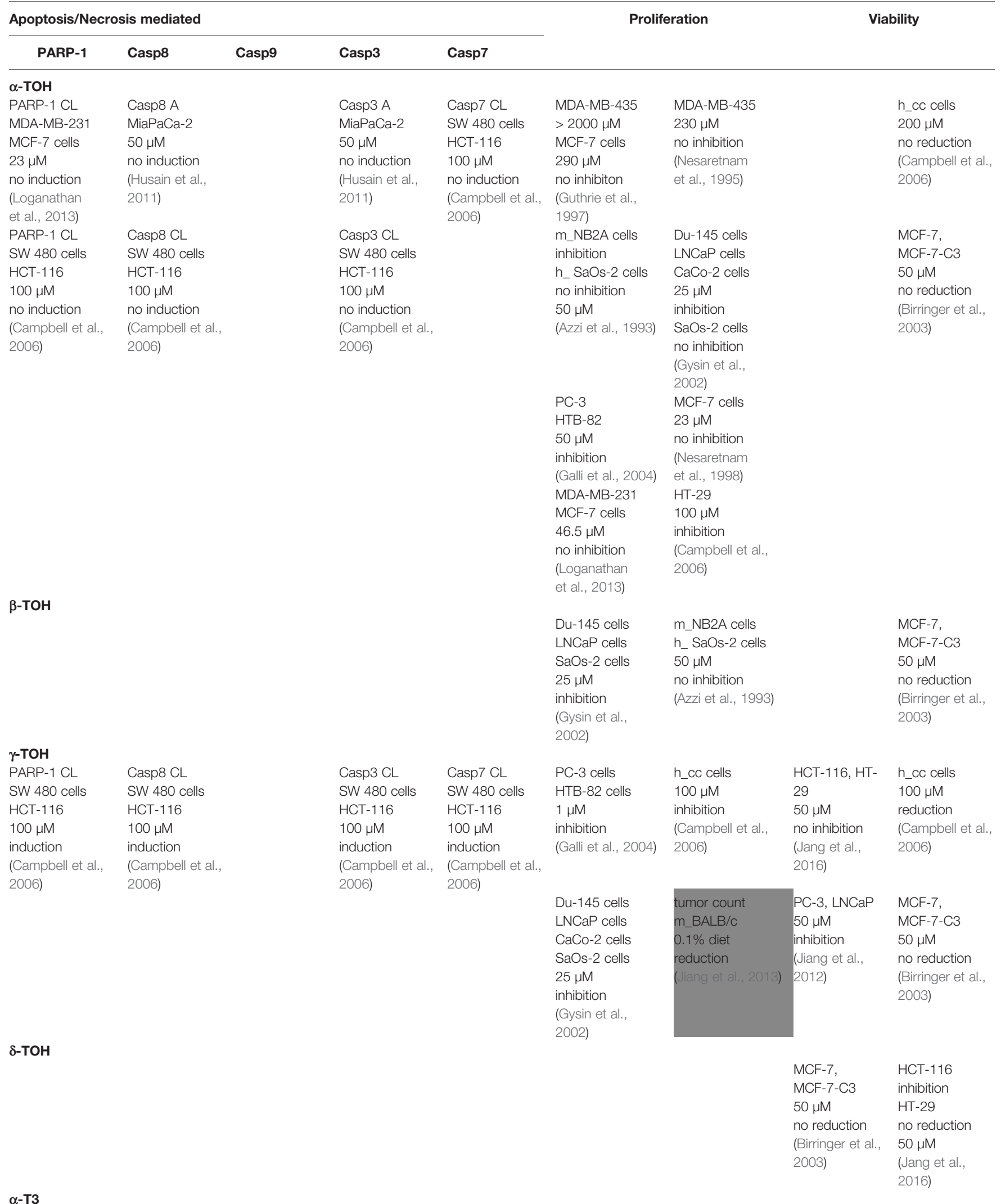


TABLE 3 | Continued

Apoptosis/Necrosis mediated

Proliferation

Viability

\begin{tabular}{l} 
PARP-1 \\
\hline PARP-1 CL, \\
MDA-MB-231, \\
MCF-7 cells \\
$23.5 \mu \mathrm{M}$ \\
induction \\
(Loganathan \\
et al., 2013) \\
PARP-1 CL \\
MiaPaCa-2 \\
50 $\mu$ M \\
no induction \\
(Husain et al., \\
2011 )
\end{tabular}

$\beta-$ T3

\section{$\gamma$-T3} MDA-MB-231, MCF-7 cells

$24.2 \mu \mathrm{M}$

induction

(Loganathan

et al., 2013)

PARP-1 CL

MiaPaCa-2

$50 \mu \mathrm{M}$

induction

(Husain et al.,

2011)

PARP-1 CL

PC-3, LNCaP

$20 \mu \mathrm{M}$

induction

(Jiang et al.,

2012)

PARP-1 CL

PC-3, LNCap

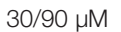

induction

(Yap et al., 2008)

\section{8-T3}

PARP-1 CL,

MDA-MB-231,

MCF-7 cells

$25.2 \mu \mathrm{M}$

induction

(Loganathan

et al., 2013)

PARP-1 CL

MiaPaCa-2

$50 \mu \mathrm{M}$

induction

Casp8 A
MiaPaCa-2
$50 \mu \mathrm{M}$
induction
(Husain et al.,
2011 )
Casp8 CL
PC-3, LNCap
30/90 $\mu \mathrm{M}$
induction
(Yap et al.,
2008 )
Casp8 CL
rh_RLh-84
$25 \mu M$
induction
(Sakai et al.,
2004 )

Casp9 CL
PC-3, LNCaP
$20 \mu \mathrm{M}$
induction
(Jiang et al.,
2012)
Casp9 CL
PC-3, LNCap
30/90 $\mu \mathrm{M}$
induction
(Yap et al.,
2008)

Casp3 A

MCF-7,

MCF-7-C3

$50 \mu \mathrm{M}$

induction

(Birringer et al.

2003)

Casp3 A

MiaPaCa-2

$50 \mu \mathrm{M}$

induction

(Husain et al.,

2011)

Casp3 CL

PC-3, LNCap

30/90 $\mu \mathrm{M}$

induction

(Yap et al.,

2008)

Casp3 CL

rh_RLh-84

$25 \mu \mathrm{M}$

induction

(Sakai et al.,

2004)

Casp3 A

MiaPaCa-2

$50 \mu \mathrm{M}$

induction

(Husain et al.,

2011)

\section{Casp7}

$\begin{array}{ll}\text { MDA-MB-435 } & \text { m_B16(F10) } \\ 211.9 \mu \mathrm{M} & 110 \mu \mathrm{M} \\ \text { MCF-7 cells } & \text { inhibition } \\ \text { 14.1 } \mu \mathrm{M} & \text { (He et al., 1997) } \\ \text { inhibition } & \\ \text { (Guthrie et al., } & \\ \text { 1997) } & \\ \text { MDA-MB-231 } & \text { MCF-7 } \\ \text { 22.5 } \mu \mathrm{M} & 23.5 \mu \mathrm{M} \\ \text { MCF-7 cells } & \text { no inhibition } \\ \text { 26.1 } \mu \mathrm{M} & \text { (Nesaretnam } \\ \text { inhibition } & \text { et al., 1998) } \\ \text { (Loganathan } & \\ \text { et al., 2013) } & \end{array}$

SCID mice
$200 \mathrm{mg} / \mathrm{kg}$
no reduction
(Husain et al.,
2011 )

MiaPaCa-2,

$50 \mu \mathrm{M}$

no reduction

(Husain et al.,

2011)

MCF-7,

MCF-7-C3

$50 \mu \mathrm{M}$

no reduction

(Birringer et al., 2003)

MiaPaCa-2,

$50 \mu \mathrm{M}$

reduction

(Husain et al., 2011)

$\begin{array}{lllll}\text { Casp7 CL } & \text { SKBR3, } & \text { rh_RLh-84 } & \text { MiaPaCa-2, } & \text { PC-3, } \\ \text { PC-3, LNCap } & \text { BT474 } & 50 \mu \mathrm{M} & 50 \mu \mathrm{M} & \text { LNCaP } \\ \text { 30/90 } \mu \mathrm{M} & 5 \mu \mathrm{M} & \text { inhibition } & \text { reduction } & 20 \mu \mathrm{M} \\ \text { induction } & \text { inhibition } & \text { (Sakai et al., } & \text { (Husain et al., } & \text { reduction } \\ \text { (Yap et al., } & \text { (Alawin et al., } & \text { 2004) } & \text { 2011) } & \text { (Jiang et al., } \\ \text { 2008) } & \text { 2016) } & & & \text { 2012) }\end{array}$

m_B16(F10) PC-3

$20 \mu \mathrm{M} \quad 32 \mu \mathrm{M}$

inhibition inhibition

(He et al., 1997) (Yap et al., 2008)

MDA-MB-231 MCF-7

$11.4 \mu \mathrm{M} \quad 14.6 \mu \mathrm{M}$

MCF-7 cells inhibition

$15.4 \mu \mathrm{M}$ (Nesaretnam

inhibition et al., 1998)

(Loganathan

et al., 2013)

MDA-MB-435

$73.2 \mu \mathrm{M}$

MCF-7 cells

$4.9 \mu \mathrm{M}$

inhibition

(Guthrie et al.,

1997)

$\begin{array}{ll}\text { MDA-MB-435 } & \text { PC-3 } \\ 226.8 \mu \mathrm{M} & 41 \mu \mathrm{M} \\ \text { MCF-7 cells } & \text { LNCap } \\ 5 \mu \mathrm{M} & 75 \mu \mathrm{M} \\ \text { inhibition } & \text { inhibition } \\ \text { (Guthrie et al., } & \text { (Yap et al., 2008) } \\ \text { 1997) } & \\ \text { m_B16(F10) } & \text { MCF-7 } \\ \text { 10 } \mu \mathrm{M} & 25.2 \mu \mathrm{M} \\ \text { inhibition } & \text { inhibition } \\ \text { (He et al., 1997) } & \text { (Nesaretnam } \\ & \text { et al., 1998) }\end{array}$

MiaPaCa-2,

$50 \mu \mathrm{M}$

reduction

(Husain et al., 2011) 
TABLE 3 | Continued

Apoptosis/Necrosis mediated

Proliferation

Viability

$\begin{array}{lllll}\text { PARP-1 } & \text { Casp8 } & \text { Casp9 } & \text { Casp3 } & \text { Casp7 }\end{array}$

(Husain et al.,

2011)

\begin{tabular}{|c|c|c|c|}
\hline \multicolumn{4}{|c|}{$\alpha-\mathbf{T}-13$ '-OH (tocopherol derived) } \\
\hline PARP-1 CL & Casp9 CL & Casp3 CL & Casp7 CL \\
\hline HepG2 cells & HepG2 cells & HepG2 cells & HepG2 cells \\
\hline $20 \mu \mathrm{M}$ & $20 \mu \mathrm{M}$ & $20 \mu \mathrm{M}$ & $20 \mu \mathrm{M}$ \\
\hline no induction & no induction & no induction & no induction \\
\hline $\begin{array}{l}\text { (Birringer et al., } \\
\text { 2010) }\end{array}$ & $\begin{array}{l}\text { (Birringer et al., } \\
\text { 2010) }\end{array}$ & $\begin{array}{l}\text { (Birringer et al., } \\
2010 \text { ) }\end{array}$ & $\begin{array}{l}\text { (Birringer et al., } \\
\text { 2010) }\end{array}$ \\
\hline \multicolumn{4}{|c|}{$\mathbf{\alpha - T}-\mathbf{1 3}$ '-COOH (tocopherol derived) } \\
\hline PARP-1 CL & Casp9 CL & Casp3 CL & Casp7 CL \\
\hline HepG2 cells & HepG2 cells & HepG2 cells & HepG2 cells \\
\hline $20 \mu \mathrm{M}$ & $20 \mu \mathrm{M}$ & $20 \mu \mathrm{M}$ & $20 \mu \mathrm{M}$ \\
\hline induction & induction & induction & induction \\
\hline (Birringer et al., & (Birringer et al., & (Birringer et al., & (Birringer et al., \\
\hline \multicolumn{4}{|c|}{ ס-T-13'-OH (tocopherol derived) } \\
\hline PARP-1 CL & Casp9 CL & Casp3 CL & Casp7 CL \\
\hline HepG2 cells & HepG2 cells & HepG2 cells & HepG2 cells \\
\hline $20 \mu \mathrm{M}$ & $20 \mu \mathrm{M}$ & $20 \mu \mathrm{M}$ & $20 \mu \mathrm{M}$ \\
\hline induction & induction & no induction & induction \\
\hline (Birringer et al., & (Birringer et al., & (Birringer et al., & (Birringer et al., \\
\hline \multirow{2}{*}{\multicolumn{4}{|c|}{$\delta$-T-13'-CoOH (tocopherol derived) }} \\
\hline & & & \\
\hline PARP-1 CL & Casp9 CL & Casp3 CL & Casp7 CL \\
\hline HepG2 cells & HepG2 cells & HepG2 cells & HepG2 cells \\
\hline $20 \mu \mathrm{M}$ & $20 \mu \mathrm{M}$ & $20 \mu \mathrm{M}$ & $20 \mu \mathrm{M}$ \\
\hline induction & induction & induction & induction \\
\hline (Birringer et al., & (Birringer et al., & (Birringer et al., & (Birringer et al., \\
\hline 2010) & 2010) & 2010) & 2010) \\
\hline PARP-1 CL & Casp9 CL & & \\
\hline НCT-116 & НCT-116 & & \\
\hline $20 \mu \mathrm{M}$ & $20 \mu \mathrm{M}$ & & \\
\hline induction & induction & & \\
\hline (Jang et al., 2016) & $\begin{array}{l}\text { (Jang et al., } \\
\text { 2016) }\end{array}$ & & \\
\hline
\end{tabular}

MDA-MB-231
MCF-7 cells
$17 \mu \mathrm{M}$
inhibition
(Loganathan
et al., 2013)

$\boldsymbol{\alpha}-\mathbf{T}-1 \mathbf{1 3}^{\prime}-\mathbf{O H}$ (tocopherol derived)

$\alpha-\mathbf{T}-\mathbf{3}^{\prime}-\mathbf{C O O H}$ (tocopherol derived)

$\boldsymbol{\gamma}$-T-3'-COOH (tocopherol derived)

8-T3-13'-COOH

PC-3 cells

HTB-82 cells

$1 \mu \mathrm{M}$

inhibition

(Galli et al., 2004)

PC-3 cells

HTB-82 cells

$1 \mu \mathrm{M}$

inhibition

(Galli et al., 2004)

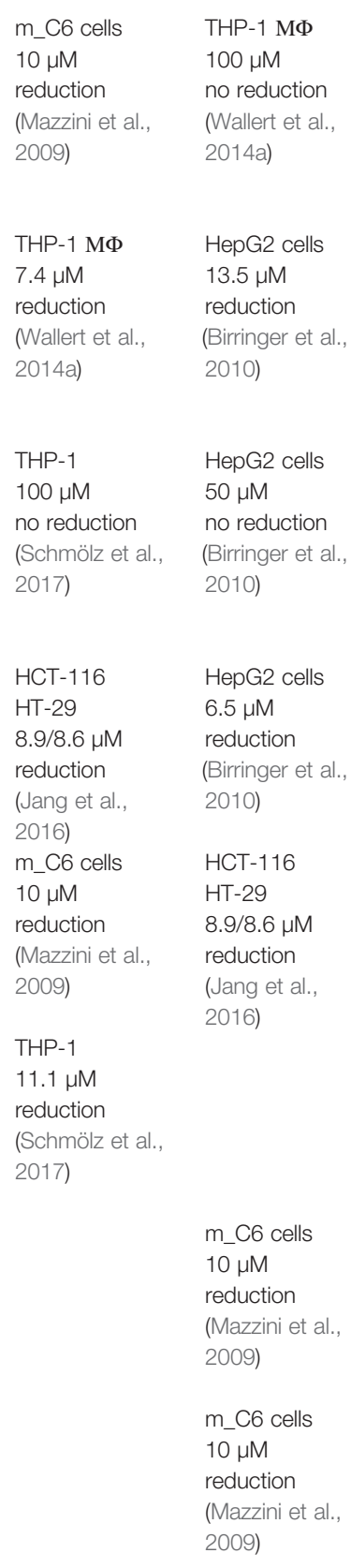

(Continued) 
TABLE 3 | Continued

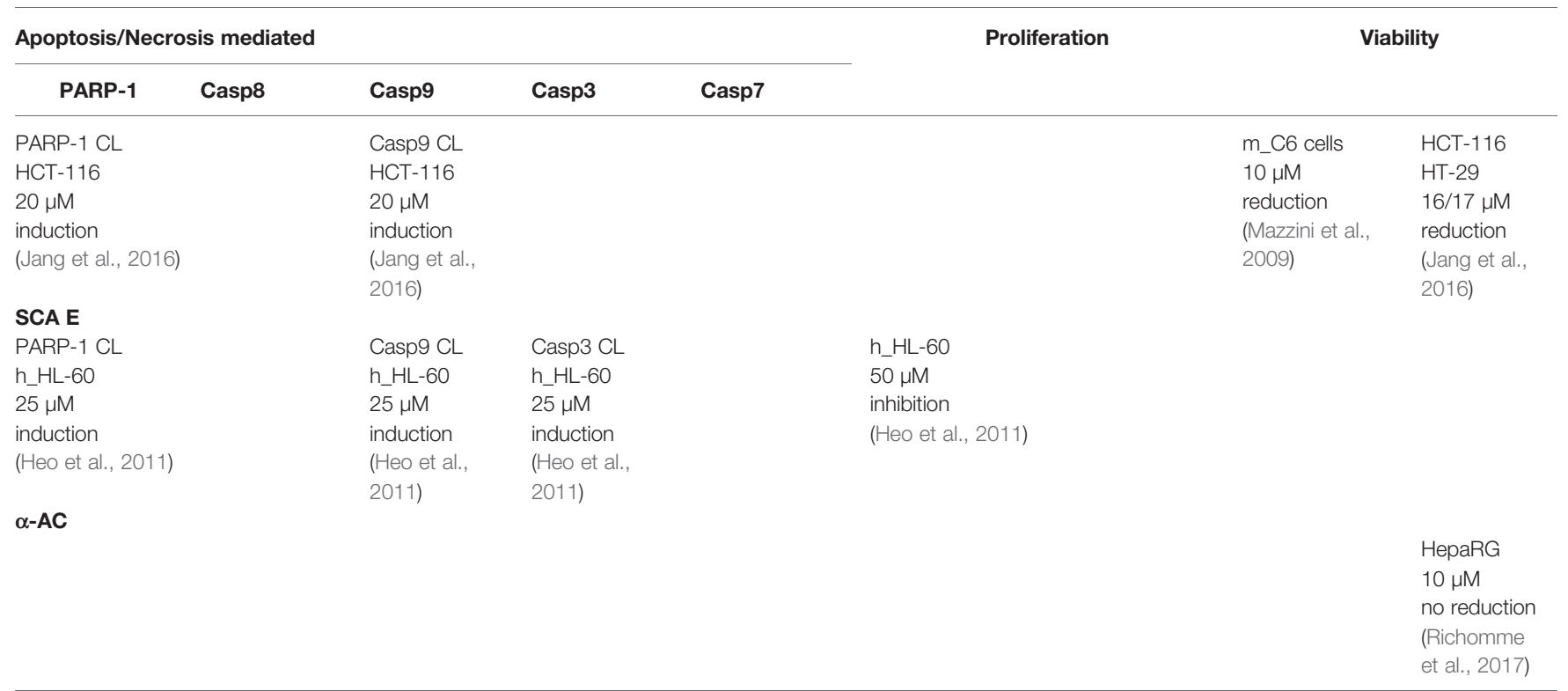

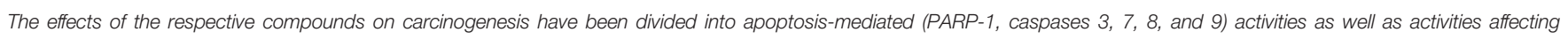

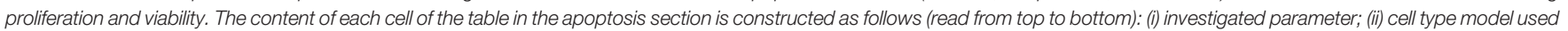

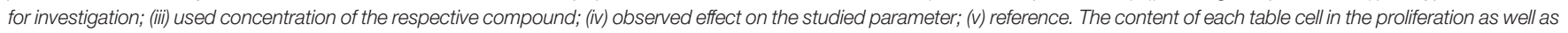

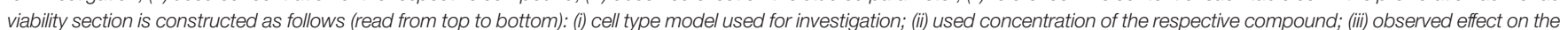

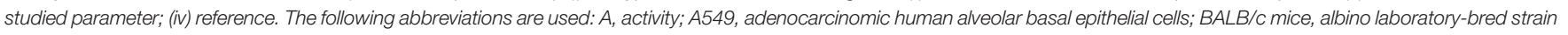

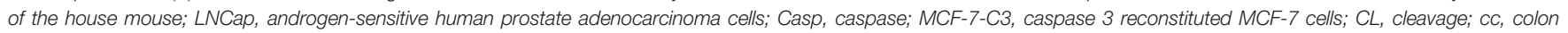

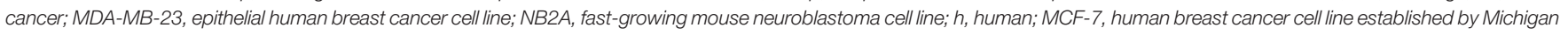

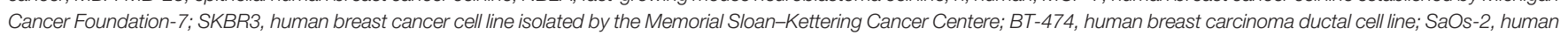

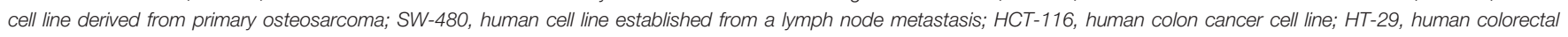

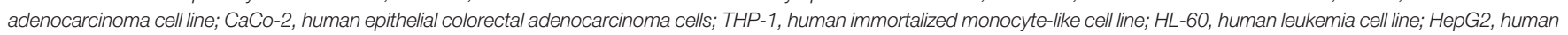

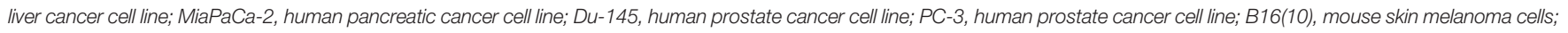

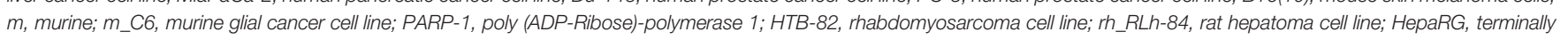
differentiated hepatic cells derived from a human hepatic progenitor cell line.

All results obtained from in vivo studies are marked in gray.

and $\gamma$-TOH, due to their biological relevance. Screening of multiple human breast cancer cell lines (Nesaretnam et al., 1995; Guthrie et al., 1997; Nesaretnam et al., 1998; Birringer et al., 2003; Loganathan et al., 2013) and the human osteosarcoma cell line Saos-2 (Azzi et al., 1993; Gysin et al., 2002) revealed no anti-proliferative effects or alteration of cell viability using $\alpha-\mathrm{TOH}(4.6-230 \mu \mathrm{M})$, whereas Campbell et al. found controversial results for different human colon cancer cell lines using different assays (Campbell et al., 2006). However, the colon cancer cell lines HT-29 (Campbell et al., 2006) and CaCo-2 (Gysin et al., 2002) treated with $100 \mu \mathrm{M}(48 \mathrm{~h}), 200 \mu \mathrm{M}(5 \mathrm{~h})$, and $25 \mu \mathrm{M}(24 \mathrm{~h}) \alpha-\mathrm{TOH}$ showed significantly induced cell death and dampened proliferation. In addition, proliferation of different human prostate cancer cells was significantly inhibited by $\alpha$-TOH. In brief, $25-50 \mu \mathrm{M} \alpha-\mathrm{TOH}$ inhibited proliferation of PC-3 cells $(41 \%, 24 \mathrm{~h}$ ) (Galli et al., 2004), Du145 cells $(50 \%, 24 \mathrm{~h})$, and LNCaP cells $(48 \%, 48 \mathrm{~h})$ (Gysin et al., 2002). Furthermore, $\alpha$-TOH $(50 \mu \mathrm{M})$ significantly inhibited the growth of murine neuroblastoma NB2A cells by $50 \%$ (Azzi et al., 1993), and rhabdomyosarcoma HTB- 82 cells by $32 \%$ (Galli et al., 2004). However, effects on proliferation and viability seemed to be independent from the cleavage and activity of the apoptosis marker PARP-1 and caspases 3, 7, and 8 in breast cancer $(23 \mu \mathrm{M}$ [Loganathan et al., 2013]), pancreas cancer (50 $\mu \mathrm{M}$ [Husain et al.,
2011]), and colon cancer cells (100 $\mu \mathrm{M}$ [Campbell et al., 2006]). $\beta$-TOH-treatment of cancer cells revealed similar effects compared to $\alpha-\mathrm{TOH}$. While growth of human prostate cancer cells was significantly inhibited by $>40 \%$ (Gysin et al., 2002), growth of human osteosarcoma cells was marginally inhibited. In neuroblastoma (Azzi et al., 1993) and breast cancer cells (Birringer et al., 2003) $\beta$-TOH did not alter cell viability.

$\gamma$-Tocopherol is by far the most potent anti-carcinogenic $\mathrm{TOH}$ regarding prostate-cancer. Indeed, viability or rather proliferation of prostate-cancer cell lines PC-3 $(1 \mu \mathrm{M}$ [Galli et al., 2004], $50 \mu \mathrm{M}$ [Jiang et al., 2012]), CaCo-2, Du-145, LNCaP (25 $\mu \mathrm{M}$ [Gysin et al., 2002]), SW480, HCT-116, HCT15 , and HCT-29 (100 $\mu \mathrm{M}$ [Campbell et al., 2006]) was blocked by $\gamma$-TOH. More precisely, $100 \mu \mathrm{M} \gamma$-TOH induced apoptosis in SW480 and HCT-116 cells following the cleavage of PARP-1 as well as caspases 3, 7, and 8 (Campbell et al., 2006). Described effects are most likely tumor-specific, finding no or weak alteration of tumor growth on breast cancer cell lines (Birringer et al., 2003) and colon carcinoma cells (Jang et al., 2016). However, in male BALB/c mice $\gamma$-TOH ( $0.1 \%$ of diet) suppressed DSS- and AOM-induced tumor multiplicity of macroscopic adenomas and large adenomatous polyps $\left(>2 \mathrm{~mm}^{2}\right)$ by 60,85 , and $36 \%$ (Jiang et al., 2013). Of the tested tumor cell lines, only viability of HCT-116 was inhibited by 50 
$\mu \mathrm{M} \delta$-TOH, whereas HT-29 cells, and the breast cancer cell lines MCF-7 and MCF-7-C3 were not affected (Birringer et al., 2003; Jang et al., 2016). Based on the presented data, anti-carcinogenic capacity for different forms of TOHs can be assessed as $\gamma-\mathrm{TOH}$ $>\beta$ - $\mathrm{TOH}>\alpha / \delta$-TOH.

Despite of the promising results outlined above, it should be noticed that several human trials failed to confirm preventive effects of vitamin $\mathrm{E}$, in particular $\alpha$-TOH, against cancer. The Alpha-Tocopherol Beta-Carotene (ATBC) Cancer Prevention Study examined whether a daily supplementation of $50 \mathrm{mg} \alpha$ $\mathrm{TOH}$ and/or $20 \mathrm{mg} \beta$-carotene could prevent lung cancer in male smokers (Virtamo et al., 2014). However, after five to eight years of supplementation of either $\alpha$-TOH or $\beta$-carotene or the combination of both failed to prevent lung cancer (Virtamo et al., 2014). In addition, other human intervention trails revealed disappointing results, with the Selenium and Vitamin E Cancer Prevention Trial (SELECT) representing a very interesting one. The aim of the SELECT study was to investigate the preventive potential of $\alpha-\mathrm{TOH}$ and/or selenium on prostate cancer. In the SELECT trial, healthy men received a daily dose of either 400 IU all-rac- $\alpha$-tocopheryl acetate or $200 \mu \mathrm{g}$ selenium or a combination of both for an average of 5.5 years (Lippman et al., 2009). Supplementation with both compounds failed to prevent prostate cancer development. Surprisingly, daily supplementation with all-rac- $\alpha$-tocopheryl acetate was slightly, but not significantly, associated with an increased overall risk for prostate cancer (Lippman et al., 2009). Next, in the 7 to 12 years follow-up the subjects who had received a daily dose of $400 \mathrm{IU}$ all-rac- $\alpha$-tocopheryl acetate showed a significantly enhanced risk for prostate cancer (Klein et al., 2011). This result indicates that a dietary supplementation with high doses of this vitamin $\mathrm{E}$ derivate could result in an increased risk for cancer.

The T3-rich fraction of palm oil is comprised of all T3 forms $(\alpha-[25 \%], \gamma-[29 \%], \delta$-T3 [14\%] relative to the total vitamin $\mathrm{E}$ amount) and inhibits the proliferation of the estrogen receptornegative human breast cancer cell line MDA-MB-435 with an IC $_{50}$ of $180 \mu \mathrm{g} / \mathrm{ml}$ (Nesaretnam et al., 1995). Based on that finding, single forms of T3s were tested regarding their effects on proliferation and viability of carcinoma cell lines. The $\alpha-, \gamma$-, and $\delta$-forms of $\mathrm{T} 3 \mathrm{~s}$ were found to mediate cancer type specific effectiveness, with breast cancer cell lines being most affected by the treatment with TOHs. Viability and proliferation of MDA-MB-231 ( IC $\left._{50} 22.5 \mu \mathrm{M}\right)$, MCF-7 ( $\left.\mathrm{IC}_{50} 14.1-26.1 \mu \mathrm{M}\right)$, and MDA-MB-435 cells ( $\left.\mathrm{IC}_{50}: 211.9 \mu \mathrm{M}\right)$ were concentrationdependently affected by $\alpha$-T3 treatment independent on whether they were responsive to estrogen and estradiol (Guthrie et al., 1997; Nesaretnam et al., 1998; Loganathan et al., 2013). However, whereas cleavage of PARP-1 (Loganathan et al., 2013) has been observed, general involvement of apoptosis has not been described yet (Birringer et al., 2003). Although cleavage of PARP-1 as well as caspases 3 and 8 has been observed in pancreatic MiaPaCa-2 carcinoma cells, $50 \mu \mathrm{M} \alpha$-T3 had no effect on cell viability (Husain et al., 2011). In contrast, $\beta$-T3 (50 $\mu \mathrm{M}$ ) reduced the viability of $\mathrm{MiaPaCa}-2$ cells (Husain et al., 2011). In mice, $200 \mathrm{mg} / \mathrm{kg} \alpha$-T3 did not affect tumor growth of AsPC-1 human pancreatic cancer xenografts (Husain et al.,
2011), whereas $110 \mu \mathrm{M} \alpha$-T3 suppressed proliferation of murine B16(F10) melanoma cells (He et al., 1997).

Within the group of TOHs and T3s, $\gamma$-T3 is the most potent anti-carcinogenic form that affects cell growth of breast, prostate, pancreas, and hepatic cancer cells, likely due to a preferred incorporation of $\gamma$-T3 in these cells (Sakai et al., 2004). There is strong evidence for the anti-proliferative effects of $\gamma$-T3 on breast cancer cell lines MDA-MB-231 ( $\left.\mathrm{IC}_{50} 11.4 \mu \mathrm{M}\right), \mathrm{MCF}-7$

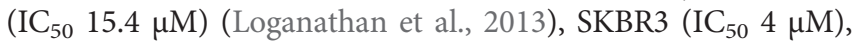
BT474 ( $\left.\mathrm{IC}_{50} 4 \mu \mathrm{M}\right)$ (Alawin et al., 2016), estrogen receptornegative $\mathrm{MDA}-\mathrm{MB}\left(\mathrm{IC}_{50} 73.2 \mu \mathrm{M}\right)$, and estrogen receptorpositive MCF-7 cells ( $\mathrm{IC}_{50} 4.9 \mu \mathrm{M}$ ) (Guthrie et al., 1997). Others even found complete inhibition of MCF-7 cell growth by $\gamma$-T3 at a concentration of $14.6 \mu \mathrm{M}$ (Nesaretnam et al., 1998). Inhibitory effects on proliferation were at least in part mediated via the activation of apoptosis, such as activation of caspase 3 in MCF-7 (25\%), and MCF-7-C3 cells (35\%) with $50 \mu \mathrm{M} \gamma$-T3 (Birringer et al., 2003). Furthermore, the proliferation of MiaPaCa-2 pancreas cancer cells (Husain et al., 2011), PC-3 prostate cancer cells $\left(\mathrm{IC}_{50}: 32 \mu \mathrm{M}, 24 \mathrm{~h}\right)$, and dRLh-84 hepatic cancer cells $\left(\mathrm{IC}_{50}: 80-100 \mu \mathrm{M}, 24 \mathrm{~h}\right.$ ) was suppressed by $\gamma$-T3, most likely via cleavage of PARP-1, and caspases 3, 7, 8, and 9 (Sakai et al., 2004; Yap et al., 2008) and induction of autophagy (Jiang et al., 2012). In murine B16(F10) melanoma cells (He et al., 1997) and the myelogenous leukemia cell line KBM-5 (Ahn et al., 2007) $\gamma$-T3 significantly suppressed proliferation $\left(\mathrm{IC}_{50} 20 \mu \mathrm{M}, 24\right.$ h). Comparable to $\gamma$-T3, $\delta$-T3 inhibits the proliferation of the breast cancer cell lines MDA-MB-435 ( $\left.\mathrm{IC}_{50} 226.8 \mu \mathrm{M}\right)$, MDAMB-231 ( $\left.\mathrm{IC}_{50} 17.4 \mu \mathrm{M}\right)$, and MCF-7 cells ( $\left.\mathrm{IC}_{50} 5-25.2 \mu \mathrm{M}\right)$ (Guthrie et al., 1997; Nesaretnam et al., 1998; Loganathan et al., 2013), as well as prostate cancer cell lines PC-3 ( $\left.\mathrm{IC}_{50} 41 \mu \mathrm{M}\right)$, and LNCaP ( $\mathrm{IC}_{50} 75 \mu \mathrm{M}$ ) (Yap et al., 2008), melanoma B16(F10) cells $\left(\mathrm{IC}_{50} 10 \mu \mathrm{M}\right)$ (He et al., 1997), and MiaPaCa-2 pancreas cancer cells $\left(\mathrm{IC}_{50} 50 \mu \mathrm{M}\right.$ ) (Husain et al., 2011) by the induction of apoptosis, as indicated by the cleavage of apoptosis-mediating PARP-1 as well as caspases 3 and 8 (Husain et al., 2011).

\section{Metabolites of Tocopherols and Tocotrienols}

In contrast to the $\mathrm{TOH}$ and $\mathrm{T} 3$ forms, the respective metabolites have been rarely investigated regarding their anti-carcinogenic properties. The LCMs of TOHs, namely $\alpha$-T-13'-COOH $(20$ $\mu \mathrm{M})$ and $\delta$-T-13'-COOH $(20 \mu \mathrm{M})$ induced apoptosis via the mitochondrial pathway, which was shown by cleavage of PARP1 and caspases 3, 7, and 9, resulting in decreased viability of HepG2 cells ( $\mathrm{IC}_{50} 13.5 \mu \mathrm{M}$ and $6.5 \mu \mathrm{M}$, respectively, Birringer et al., 2010). In human leukemia-derived THP-1 macrophages, viability was decreased by $\alpha-\mathrm{T}-13^{\prime}-\mathrm{COOH}\left(\mathrm{IC}_{50} 7.4 \mu \mathrm{M}\right.$, Wallert et al., 2014a) and $\delta$-T-13'-COOH (IC ${ }_{50} 11.1 \mu \mathrm{M}$, Schmölz et al., 2017). In addition, $\delta$-T-13'-COOH increased apoptosis-induced cytotoxicity in HCT-116 ( IC $\left._{50} 8.9 \mu \mathrm{M}\right), \mathrm{HT}-29\left(\mathrm{IC}_{50} 8.6 \mu \mathrm{M}\right)$ (Jang et al., 2016), and C6 cells ( $\mathrm{IC}_{50}<10 \mu \mathrm{M}$, Mazzini et al., 2009). The T3-derived $\delta$-garcinoic acid decreased the viability of HCT-116, HT-29 (Jang et al., 2016), glioma C6 (Mazzini et al., 2009), and human THP-1 macrophage-like cells $\left(\mathrm{IC}_{50}<20 \mu \mathrm{M}\right.$, unpublished data) to a similar extent. In BALB/c mice fed with $0.022 \%, \delta$-garcinoic acid in the diet, AOM- and DSS-induced 
colon tumor growth was decreased (Jang et al., 2016). In contrast to the carboxychromanol structures, the hydroxychromanols were less efficient in the cleavage of apoptosis markers and consequently did not affect the viability of HepG2 cells (Birringer et al., 2010) and THP-1 macrophages (Wallert et al., 2014a; Schmölz et al., 2017) at concentrations up to $50 \mu \mathrm{M}$ and $100 \mu \mathrm{M}$, respectively, whereas an anti-proliferative effect on glioma C6 cancer cells was determined using $10 \mu \mathrm{M} \alpha$-T-13'$\mathrm{OH}$ (Mazzini et al., 2009). Short-chain metabolites were found to affect growth of prostate cancer cells PC-3 and rhabdomyosarcoma HTB-82 cells at a concentration of $1 \mu \mathrm{M}$ (Galli et al., 2004).

\section{Sargachromanols}

The group of sargachromanols may serve as anti-carcinogenic agents that suppress cell proliferation as reported for SCA E in HL-60 leukemia cells accompanied by cleavage of PARP-1 as well as caspases 3 and 9 (Heo et al., 2011). However, confirmatory data are pending.

\section{Amplexichromanols}

To date, $\alpha$-AC has been studied only in HepaRG cells, without effects on viability up to concentrations of $10 \mu \mathrm{M}$ (Richomme et al., 2017). Therefore, studies on anti-carcinogenic effects of amplexichromanols are still on demand.

\section{Chromenols}

Within the group of chromenols, $\delta$-sargachromenol is the beststudied one. Previous studies revealed an induction of the cleavage of PARP-1 and caspases along with the induction of apoptosis and reduced cell viability in human skin keratinocyte (HaCaT) cells (Hur et al., 2008). Data obtained from cancer cell lines is still lacking.

\section{INTERFERENCE WITH MOLECULAR TARGETS AND KEY PROTEINS CONNECTING INFLAMMATION AND CARCINOGENESIS}

Many signaling molecules involved in inflammatory processes play in parallel also key roles in carcinogenesis. We here exemplarily focus on the interaction of selected chromanols and chromenols with the molecular crosstalk of NF- $\mathrm{KB}$ (Jurjus et al., 2016), lipoxygenases (Rådmark et al., 2015; Roos et al., 2016; Merchant et al., 2018), MAPK (Gkouveris and Nikitakis, 2017; Jiménez-Martínez et al., 2019), and the inflammasome (Moossavi et al., 2018; Swanson et al., 2019) due to their accepted involvement in both, inflammation and cancer (Figure 7). However, due to the sparse knowledge about their connection to chromanols and chromenols, further topics, like the interaction of tumor and immune cells, adhesion proteins, structure and regulation of tumor microenvironments, mechanisms for programed cell death as well as other prominent signaling pathways (PI3K/Akt/mTOR; PKC; STAT; $\mathrm{Wnt} / \beta$-catenin), were not considered in this review.

\section{Chromanols}

A detailed overview on the interference of chromanols with molecular targets and key enzymes connecting inflammation and carcinogenesis is provided in Table 4.

\section{Tocopherols and Tocotrienols}

As outlined above, inflammation and carcinogenesis are only marginally affected by $\alpha-\mathrm{TOH}$. This is probably the consequence of a lack of interference of $\alpha-\mathrm{TOH}$ with NF- $\mathrm{NB}$. Neither in phorbol-12-myristat-13-acetate (PMA)-stimulated BALBc/3T3 fibroblasts (Azzi et al., 1993), and human pancreatic cancer MiaPaCa-2 cells (Husain et al., 2011), nor TNF- $\alpha$-stimulated murine myelogenous leukemia KBM-5 cells (Ahn et al., 2007), $\alpha$ TOH $(50 \mu \mathrm{M}), \beta$-TOH $(50 \mu \mathrm{M})$, or $\gamma$-TOH $(25 \mu \mathrm{M})$ affected NF$\kappa \mathrm{B}$ binding affinity or its activation. In murine RAW264.7 macrophages, $100 \mu \mathrm{M} \alpha-\mathrm{TOH}$ even induced translocation of p65 into the nucleus (Wallert et al., 2015). However, pharmacological doses of $\alpha-\mathrm{TOH}(500 \mu \mathrm{M})$ inhibited NF- $\kappa \mathrm{B}$ transcriptional activity as well as the phosphorylation and subsequent degradation of nuclear factor of kappa light polypeptide gene enhancer in B-cells inhibitor (IאB)- $\alpha$, the inhibitor of NF- $\kappa \mathrm{B}$, resulting in decreased NF- $\kappa \mathrm{B}$ activation in multifactorially stimulated dendritic cells (Tan et al., 2005). $\gamma$ Tocotrienol and $\delta$-T3 significantly decreased NF- $\kappa \mathrm{B} / \mathrm{p} 65$ binding affinity in MiaPaCa-2 cells and diminished p65 subunit translocation in AsPc- 1 cells and tumor tissue. In addition, $\beta$ T3 and $\delta$-T3 inhibited the translocation in MiaPaCa-2 cells

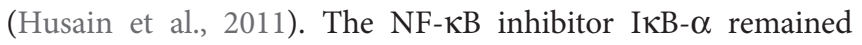
unchanged in the aforementioned study. Within the group of T3s, $\gamma$-T3 has been described to affect NF- $\kappa B$ activation and p65 subunit translocation in various cell lines and isolated tissue. For example, $\gamma$-T3 $(20-40 \mu \mathrm{M})$ inhibited the phosphorylation of IкB$\alpha$ and the nuclear translocation of the p65 subunit following various stimuli, including pro-inflammatory cytokines, tumor promoters, carcinogens, and growth factors in different cell lines (Ahn et al., 2007; Yap et al., 2008; Wang et al., 2015). Further, $\gamma$ T3 treatment also increased IКB- $\alpha$ protein expression in epididymal adipose tissues isolated from $\gamma$-T3-fed $d b / d b$ mice (Kim et al., 2016) as well as in LPS/palmitate-activated BMDM using $1 \mu \mathrm{M} \gamma$-T3 (Kim et al., 2018). In mice, $400 \mathrm{mg} \gamma$-T3/kg, applied orally, sensitized pancreatic tumors to gemcitabine treatment, a drug applied in clinical treatment of pancreatic cancer, by suppressing NF- $\kappa \mathrm{B}$-mediated inflammatory pathways linked to tumorigenesis (Kunnumakkara et al., 2010). The expression of A20 (acronym: TNFAIP3), another inhibitor of NF- $\kappa B$, was induced by $20 \mu \mathrm{M} \gamma$-T3 in RAW264.7, A549, PC3, and MCF-7 cells (Wang et al., 2015) as well as in peritoneal macrophages obtained from diabetic $d b / d b$ mice fed with a $\gamma$-T3containing diet (0.1\%) (Kim et al., 2016).

5-, 12-, and 15-LO pathways mediate the formation of lipid mediators (including leukotrienes, lipoxins, resolvins, protectins, and maresins), which orchestrate inflammation by triggering immune cell recruitment and allergic responses, and/or actively terminating inflammation, i.e. triggering resolution of inflammation. Leukotrienes and the so-called specialized proresolving lipid mediators (produced by the tumor- 
TABLE 4 | Overview on the interference of chromanols with molecular targets and key enzymes connecting inflammation and carcinogenesis.

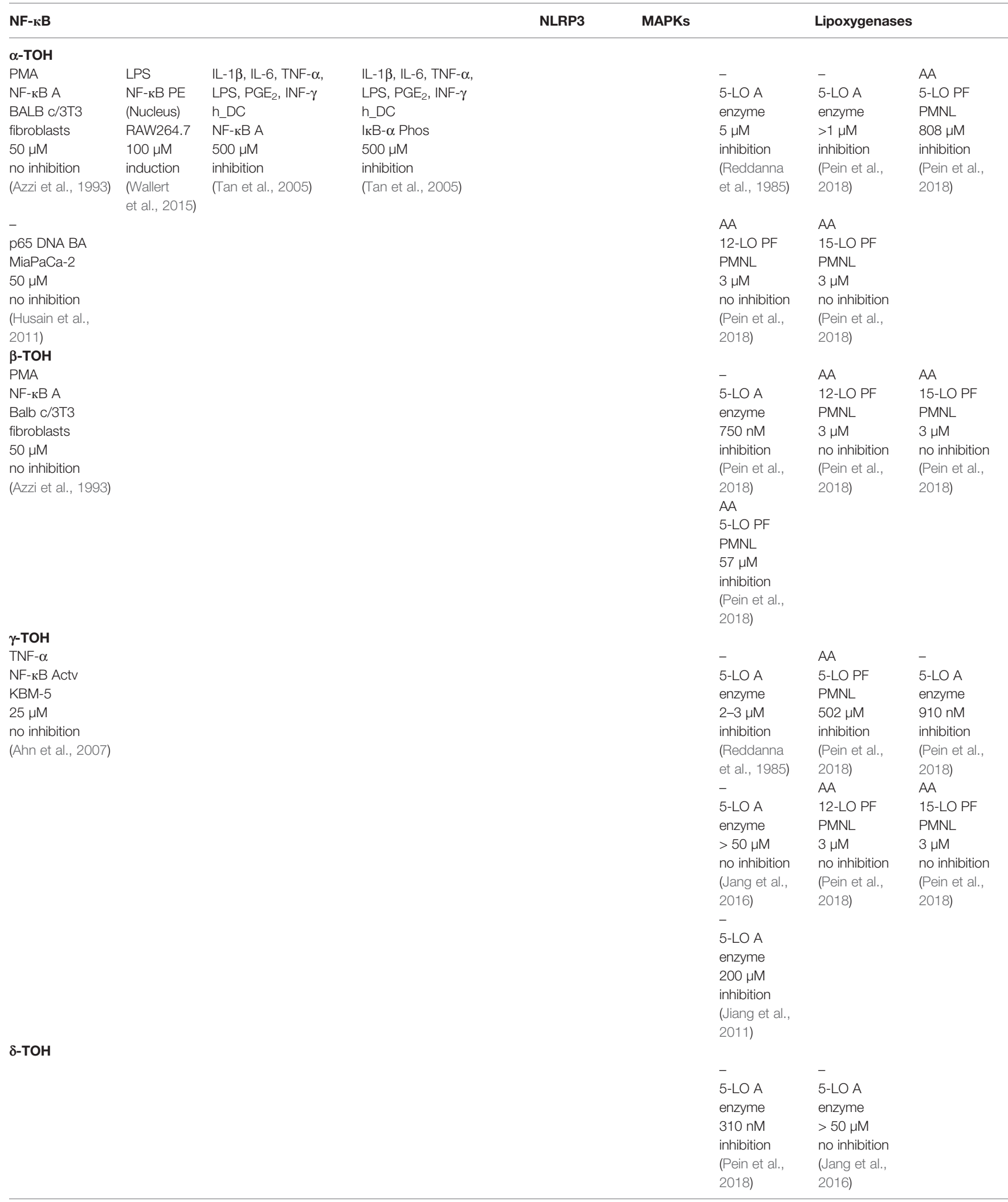


TABLE 4 | Continued

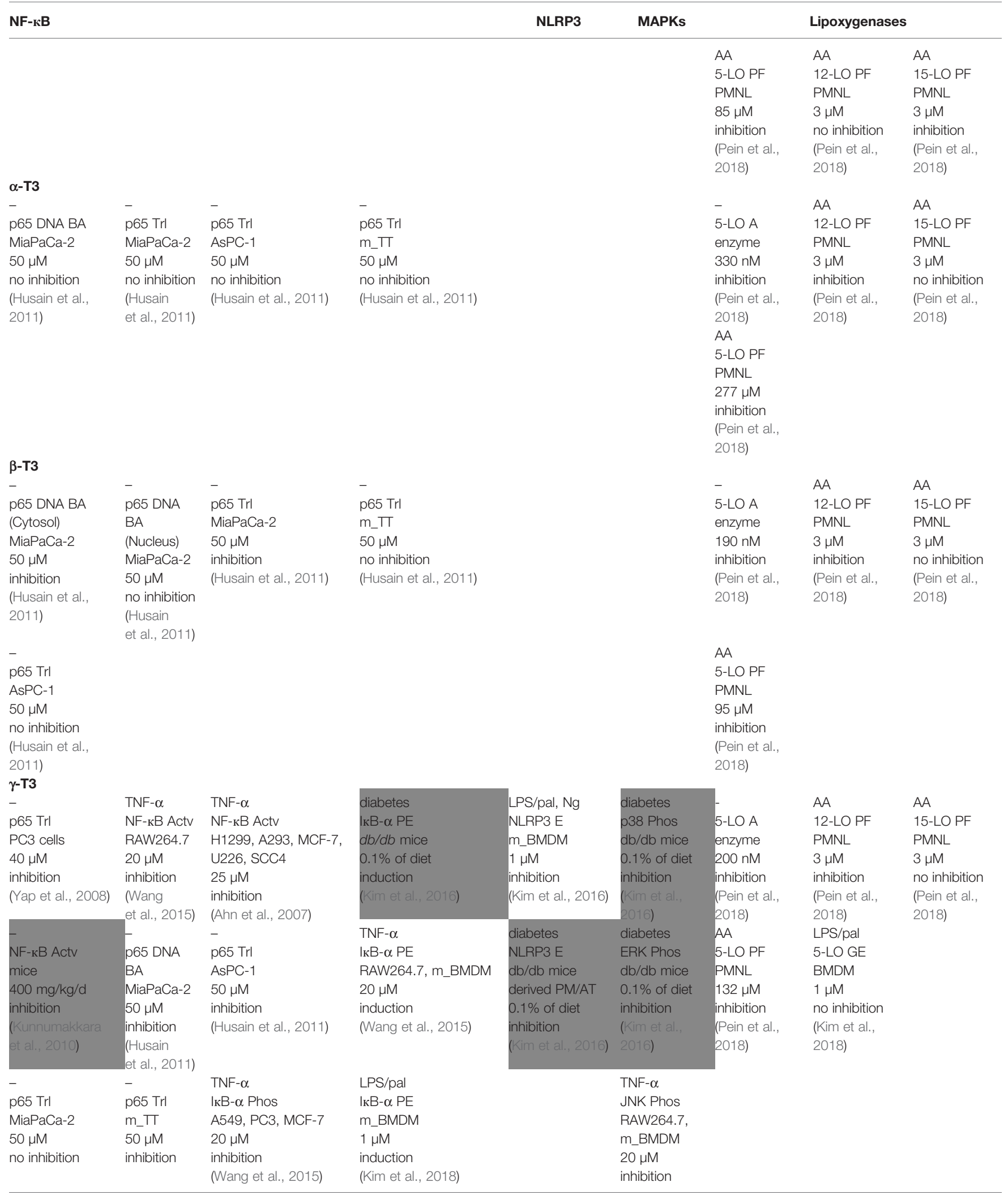


TABLE 4 | Continued

\begin{tabular}{|c|c|c|c|}
\hline \multicolumn{4}{|l|}{ NF-кB } \\
\hline $\begin{array}{l}\text { (Husain et al., } \\
\text { 2011) }\end{array}$ & $\begin{array}{l}\text { (Husain } \\
\text { et al., 2011) }\end{array}$ & & \\
\hline- & - & - & \\
\hline ІкB- $\alpha$ Phos & ІкB- $\alpha$ Phos & ІкB- $\alpha$ Phos & \\
\hline AsPC-1 & MiaPaCa-2 & $\mathrm{m}_{-} \pi$ & \\
\hline $50 \mu \mathrm{M}$ & $50 \mu \mathrm{M}$ & $50 \mu \mathrm{M}$ & \\
\hline inhibition & inhibition & inhibition & \\
\hline $\begin{array}{l}\text { (Husain et al., } \\
\text { 2011) }\end{array}$ & $\begin{array}{l}\text { (Husain } \\
\text { et al., 2011) }\end{array}$ & (Husain et al., 2011) & \\
\hline \multicolumn{4}{|l|}{$\delta$-T3 } \\
\hline- & - & - & - \\
\hline p65 DNA BA & p65 Trl & p65 Trl & |кB- $\alpha$ Phos \\
\hline MiaPaCa-2 & AsPC-1 & MiaPaCa-1 & MiaPaCa-2, \\
\hline $50 \mu \mathrm{M}$ & $50 \mu \mathrm{M}$ & $50 \mu \mathrm{M}$ & $50 \mu \mathrm{M}$ \\
\hline inhibition & inhibition & inhibition & inhibition \\
\hline $\begin{array}{l}\text { (Husain et al., } \\
\text { 2011) }\end{array}$ & $\begin{array}{l}\text { (Husain } \\
\text { et al., 2011) }\end{array}$ & (Husain et al., 2011) & (Husain et al., 2011) \\
\hline- & - & - & \\
\hline p65 Trl & ІкB- $\alpha$ Phos & ІкB- $\alpha$ Phos & \\
\hline m_Tा & MiaPaCa-2, & $\mathrm{m}_{-} \pi \mathrm{T}$ & \\
\hline $50 \mu \mathrm{M}$ & $50 \mu \mathrm{M}$ & $50 \mu \mathrm{M}$ & \\
\hline inhibition & inhibition & inhibition & \\
\hline $\begin{array}{l}\text { (Husain et al., } \\
\text { 2011) }\end{array}$ & $\begin{array}{l}\text { (Husain } \\
\text { et al., 2011) }\end{array}$ & (Husain et al., 2011) & \\
\hline$\alpha-\mathrm{T}-13^{\prime}-\mathrm{OH}$ & & & \\
\hline
\end{tabular}

\section{$\alpha-\mathrm{T}-13^{\prime}-\mathrm{COOH}$}

LPS

p65 Trl

RAW264.7

$2.5 \mu \mathrm{M}$

no inhibition

(Wallert et al.

2015)

\section{$\delta-\mathrm{T}-13^{\prime}-\mathrm{OH}$}

\begin{tabular}{ll} 
NLRP3 & \multicolumn{1}{c}{ MAPKs } \\
& (Wang et al., \\
$2015)$ & LPS \\
& ERK Phos \\
m_BMDM & \\
& $0.5 \mu M$ \\
inhibition & \\
(Kim et al., \\
2016)
\end{tabular}

$\begin{array}{lll}- & \text { AA } & \text { AA } \\ \text { 5-LO A } & \text { 12-LO PF } & \text { 15-LO PF } \\ \text { enzyme } & \text { PMNL } & \text { PMNL } \\ 170 \text { nM } & 3 \mu \mathrm{M} & 3 \mu \mathrm{M} \\ \text { inhibition } & \text { inhibition } & \text { no inhibition } \\ \text { (Pein et al., } & \text { (Pein et al., } & \text { (Pein et al., } \\ \text { 2018) } & \text { 2018) } & \text { 2018) }\end{array}$

AA

5-LO PF

PMNL

$60 \mu \mathrm{M}$

inhibition

(Pein et al.,

2018)

$\begin{array}{lll}- & \text { AA } & \text { AA } \\ \text { 5-LO A } & \text { 12-LO PF } & \text { 15-LO PF } \\ \text { enzyme } & \text { PMNL } & \text { PMNL } \\ 350 \mathrm{nM} & 3 \mu \mathrm{M} & 3 \mu \mathrm{M} \\ \text { inhibition } & \text { inhibition } & \text { induction } \\ \text { (Pein et al., } & \text { (Pein et al., } & \text { (Pein et al., } \\ \text { 2018) } & \text { 2018) } & \text { 2018) }\end{array}$

AA

5-LO PF

PMNL

$190 \mathrm{nM}$

inhibition

(Pein et al.,

2018)

$-$

5-LO A

enzyme

$270 \mathrm{nM}$

inhibition

(Pein et al.,

2018)

AA

5-LO PF

PMNL

$80 \mathrm{nM}$

inhibition

(Pein et al.,

2018)

-
5-LO A
enzyme
120 nM
inhibition
(Pein et al.,
2018)

Lipoxygenases 
TABLE 4 | Continued

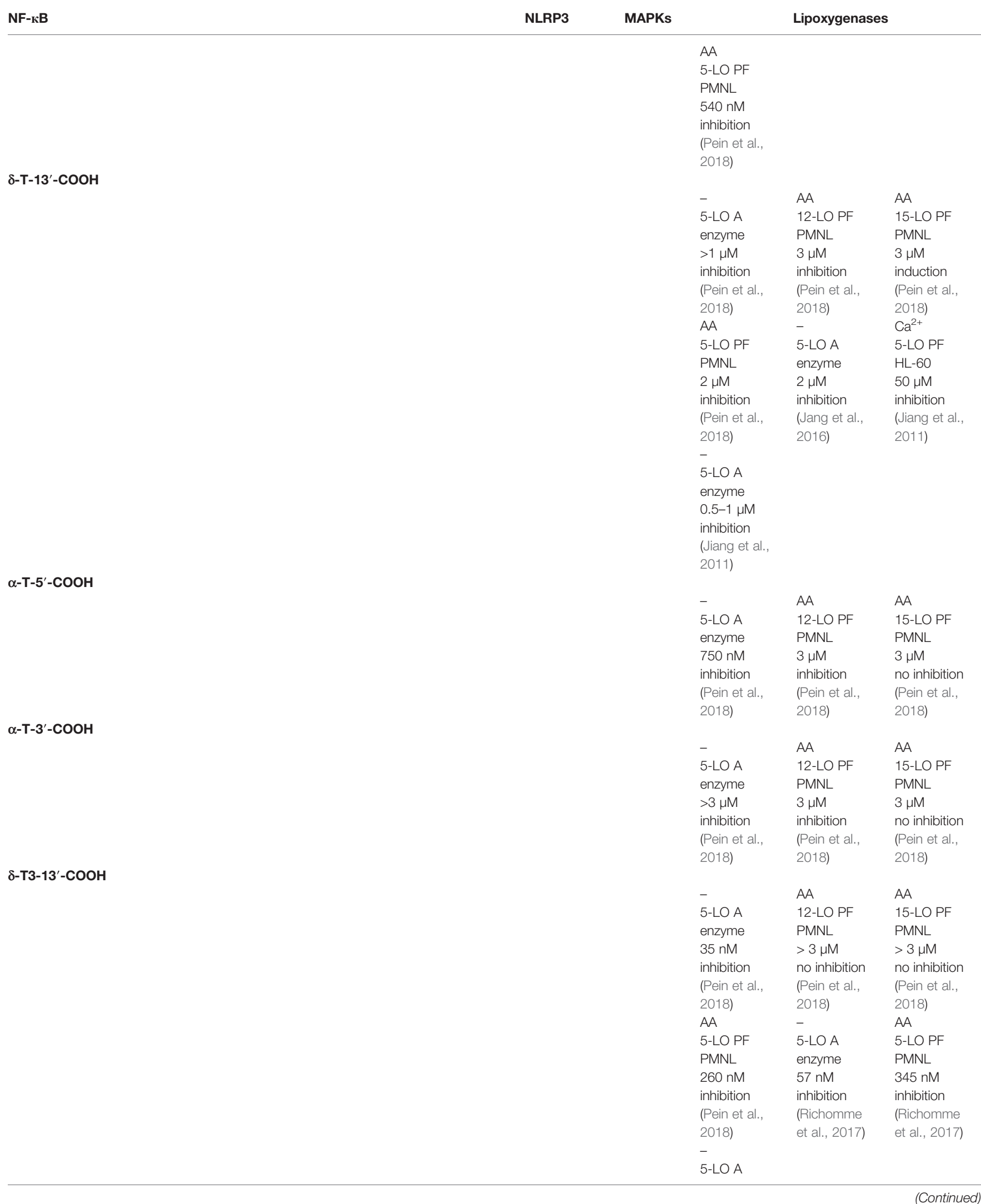


TABLE 4 | Continued

\begin{tabular}{ll} 
NF-кB & \\
\hline & \\
& \\
& \\
& \\
SCA D & LPS \\
LPS & IкB- $\alpha$ Phos \\
p65 Phos & RAW264.7 \\
RAW264.7 & $60 \mu M$ \\
$60 \mu M$ & inhibition \\
inhibition & $($ Heo et al., \\
(Heo et al., 2014) & $2014)$
\end{tabular}

SCA E

SCA G

IL-1 $\beta$

p65/p50 Phos

MG-63

$40 \mu \mathrm{M}$

inhibition

(Yoon et al.,

2012b)
IL-1 $\beta$

ІкB- $\alpha$ Phos

MG-63

$20 \mu \mathrm{M}$

inhibition

(Yoon et al., 2012b)
NLRP3

MAPKs

Lipoxygenases

enzyme

$1 \mu \mathrm{M}$

inhibition

(Jang et al.,

2016)
LPS

JNK Phos

RAW264.7

$30 \mu \mathrm{M}$

inhibition

(Heo et al.,

2014)

LPS

ERK Phos

RAW264.7

$30 \mu \mathrm{M}$

inhibition

(Heo et al.,

2014)

LPS

ERK Phos

RAW264.7

$58 \mu \mathrm{M}$

inhibition

(Lee et al.,

2013)

LPS

p38 Phos

RAW264.7

$58 \mu \mathrm{M}$

inhibition

(Lee et al.,

2013)

LPS

JNK Phos

RAW264.7

$58 \mu \mathrm{M}$

inhibition

(Lee et al.,

2013)

IL-1 $\beta$

ERK Phos

MG-63

$40 \mu \mathrm{M}$

inhibition

(Yoon et al.

2012b)

IL-1 $\beta$

p38 Phos

MG-63

$20 \mu \mathrm{M}$

inhibition

(Yoon et al.

2012b)

IL-1 $\beta$

JNK Phos

MG-63 


\begin{tabular}{|c|c|c|c|}
\hline NF-кB & NLRP3 & MAPKs & Lipoxygenases \\
\hline & & $\begin{array}{l}40 \mu \mathrm{M} \\
\text { inhibition } \\
\text { (Yoon et al., } \\
\text { 2012b) }\end{array}$ & \\
\hline
\end{tabular}

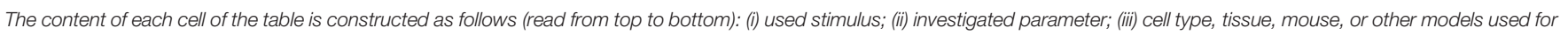

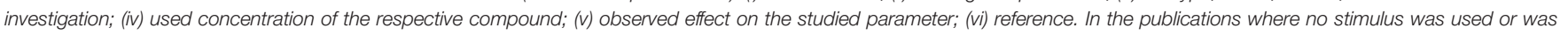
required for the studies, the respective row is marked with "-". Actv, activation; A, activity; AT, adipose tissue; BALB/c mice, albino laboratory-bred strain of the house mouse; AA,

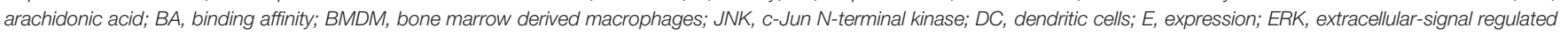

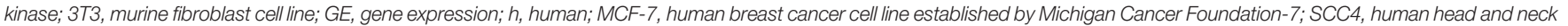

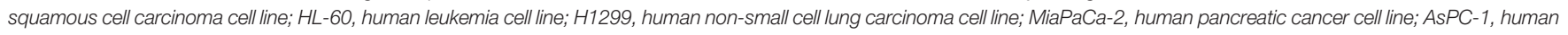
pancreas adenocarcinoma cell line; U226, human peripheral blood myeloma, plasmacytoma cell line; MG-63, human osteosarcoma cell line; INF- $\gamma$, interferon $\gamma$, IL, interleukin; db/db mice, leptin receptor activity deficient mice; LPS, lipopolysaccharide; LO, lipoxygenase; RAW264.7, macrophages derived from abelson murine leukemia virus-induced tumor; MAPK, mitogenactivated protein kinase; $m$, murine; KBM-5, murine myelogenous leukemia cell line; Ng, nigericine; NLRP3, NLR family pyrin domain containing 3; NF- $\kappa B$, nuclear factor kappa-light-chainenhancer of activated B cells; p65, nuclear factor NF-кB p65 subunit; I BB, nuclear factor of kappa light polypeptide gene enhancer in B-cells inhibitor; pal, palmitate; PM, peritoneal macrophages; PMA, phorbol-12-myristat-13-acetat; Phos, phosphorylation; PMNL, polymorphonuclear neutrophils; PF, product formation; PGE, prostaglandin $E_{2}$; PE, protein expression; Trl, translocation; TNF- $\alpha$, tumor necrosis factor $\alpha$; T, tumor tissue.

All results obtained from in vivo studies are marked in gray.

microenvironment, in particular by 15 -LO-expressing macrophages of the M2 subtype) have further been shown to play pivotal roles in tumor initiation and development as well as angiogenesis and metastasis (Serhan, 2014; Rådmark et al., 2015; Wculek and Malanchi, 2015; Gilligan et al., 2019). All forms of TOHs inhibit the activity of the isolated 5-LO enzyme in the following sequence of their inhibitory capacity: $\delta$-TOH $\left(\mathrm{IC}_{50}\right.$ $0.31 \mu \mathrm{M})<\beta-\mathrm{TOH}\left(\mathrm{IC}_{50} 0.75 \mu \mathrm{M}\right)<\alpha-\mathrm{TOH}\left(\mathrm{IC}_{50} 1-5 \mu \mathrm{M}\right)=\gamma$ TOH ( IC $_{50}$ 0.9-3 $\left.\mu \mathrm{M}\right)$ (Reddanna et al., 1985; Pein et al., 2018). In activated polymorphonuclear leukocytes (PMNL), inhibitory concentrations are 10- to100-fold higher with the following order: $\beta-\mathrm{TOH}<\delta$-TOH $<\gamma-\mathrm{TOH}<\alpha-\mathrm{TOH}$ (Pein et al., 2018). However, activity of 12 - and 15-LO, which catalyze the formation of 12- and 15-HETE, respectively, remained unaltered by $3 \mu \mathrm{M}$ TOH in LPS-activated PMNL, except for $\delta$-TOH which inhibited 15-LO with an $\mathrm{IC}_{50}$ of $3 \mu \mathrm{M}$ (Pein et al., 2018). $\alpha-, \beta-, \gamma-$, and $\delta$-T3 appeared as efficient inhibitors of isolated 5-LO, all with $\mathrm{IC}_{50}$ values below $0.5 \mu \mathrm{M}$, whereas the inhibition of 5 -LO product formation in activated PMNL required concentrations of $60 \mu \mathrm{M}$ ( $\delta$-T3) to $277 \mu \mathrm{M}(\alpha-\mathrm{T} 3)$ (Pein et al., 2018). 12-Lipoxygenase product formation in PMNL was significantly inhibited by all T3 forms, whereas 15-LO-derived products remained unchanged or were even significantly elevated using concentrations of $3 \mu \mathrm{M}$ (Pein et al., 2018).

MAPK pathways mediate a multitude of cellular processes, including growth, proliferation, differentiation, migration, apoptosis, and inflammation, in response to external stress signals. Therefore, MAPK pathways represent interesting targets for the development of anti-carcinogenic as well as anti-inflammatory therapeutics. Within the MAPK protein family, extracellular signal-regulated kinase (ERK) represents a prominent target for cancer research, because ERK deregulation is linked to approximately one-third of all human cancers (Dhillon et al., 2007). In addition, ERK affects cellular inflammation via modulation of cytokine expression (Kim, 2014). However, the stress-activated kinases, c-Jun N-terminal kinase (JNK) and p38, have emerged as interesting therapeutic targets, due to their involvement in the regulation of inflammation, DNA damage response, and apoptosis
(Kaminska, 2005). Inhibitory effects of $\gamma$-T3 on the MAPK pathway, more precisely the phosphorylation of ERK, p38 and JNK have been observed in epididymal adipose tissues from $\gamma$ T3-fed $d b / d b$ mice ( $0.1 \%$ of the diet), in LPS-activated BMDMs using $0.5 \mu \mathrm{M} \gamma$-T3 (Kim et al., 2016), and in TNF- $\alpha$-activated RAW264.7 cells (Wang et al., 2015). The relevance of NLRP3 inflammasome activation and subsequent formation of proinflammatory cytokines, namely IL-1 $\beta$ and IL- 8 , in inflammation and related diseases has been shown. $\gamma$-T3 decreased NLRP3 inflammasome activation by inhibiting the mRNA and protein expression of the NLRP3 inflammasome in BMDM activated with LPS/palmitate, rather than with LPS/ nigericin, in peritoneal macrophages and adipose tissue isolated from $\gamma$-T3-fed $d b / d b$ mice (Kim et al., 2016). In addition, in BMDMs treated with chloroquine, an inhibitor of lysosomal degradation, the accumulation of microtubuleassociated protein $1 \mathrm{~A} / 1 \mathrm{~B}$-light chain 3 (LC3)-II, and the degradation of p62 were decreased implying that $\gamma$-T3 coregulates autophagosome formation and inflammasome activation (Kim et al., 2016).

\section{Metabolites of Tocopherols and Tocotrienols}

Tocopherols and T3s inhibit the activity of isolated recombinant human 5-LO enzyme 10- to 100-fold more efficiently than in activated PMNL. The respective long-chain $\mathrm{TOH}$ - and T3derived metabolites inhibited isolated 5-LO to a similar extent (Jiang et al., 2011; Jang et al., 2016; Pein et al., 2018). Notably, in activated PMNL, $\alpha-\mathrm{T}-13^{\prime}-\mathrm{COOH}$ was the most potent inhibitor of 5-LO activity with an $\mathrm{IC}_{50}$ value of $80 \mathrm{nM}$ followed by $\alpha$-T$13^{\prime}-\mathrm{OH}(190 \mathrm{nM}), \delta-\mathrm{T}-13^{\prime}-\mathrm{OH}(540 \mathrm{nM})$, and $\delta-\mathrm{T}-13^{\prime}-\mathrm{COOH}$ $(2 \mu \mathrm{M})$ (Pein et al., 2018). Treatment of activated PMNL with 3 $\mu \mathrm{M}$ LCM effectively blocked 12- and 15-LO product formation, whereas only the $12-\mathrm{LO}$ pathway was blocked by $\alpha-5^{\prime}-\mathrm{T}-\mathrm{COOH}$, $\alpha-3^{\prime}-\mathrm{T}-\mathrm{COOH}$, and $\gamma-3^{\prime}-\mathrm{T}-\mathrm{COOH}$ (Pein et al., 2018). Conversion of arachidonic acid to leukotrienes via 5-LO was blocked by $\delta$-T3-13'-COOH (human recombinant enzyme: $\mathrm{IC}_{50}$ 35-57 nM) (Richomme et al., 2017; Pein et al., 2018) and $1 \mu \mathrm{M}$ (Jang et al., 2016); neutrophils (IC 260-345 nM) (Richomme et al., 2017; Pein et al., 2018), whereas product formation 
TABLE 5 | Overview on the interference of chromenols with molecular targets and key enzymes connecting inflammation and carcinogenesis.

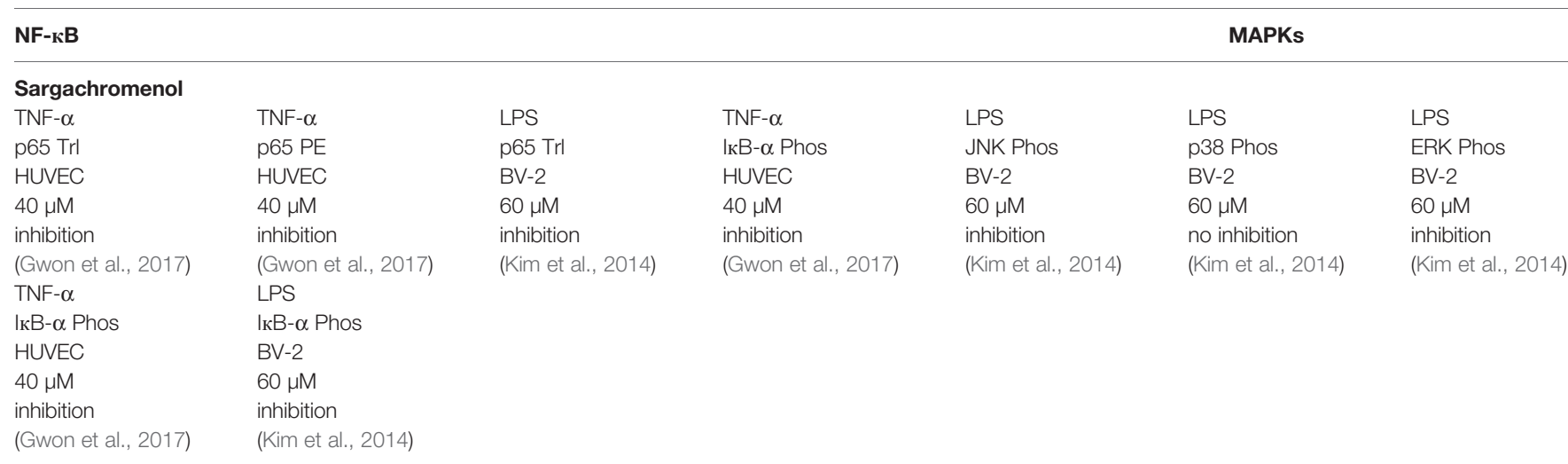

The content of each cell of the table is constructed as follows (read from top to bottom): (i) used stimulus; (ii) investigated parameter; (iii) cell type tissue, mouse, or other models used for the studies; (iv) used concentration of the respective compound; (v) observed effect on the studied parameter; (vi) reference. The following abbreviations are used. BV-2, brain microglial cells transformed by recombinant retrovirus (v-raf/V-mic); JNK, c-Jun N-terminal kinase; ERK, extracellular-signal regulated kinase; HUVEC, human umbilical vein endothelial cells; LPS, lipopolysaccharide; NF-kB, nuclear factor kappa-light-chain-enhancer of activated B cells; p65, nuclear factor NF-kB p65 subunit; I $\mathrm{kB}$, nuclear factor of kappa light polypeptide gene enhancer in B-cells inhibitor; Phos, phosphorylation; PE, protein expression; Trl, translocation; TNF- $\alpha$, tumor necrosis factor $\alpha$.

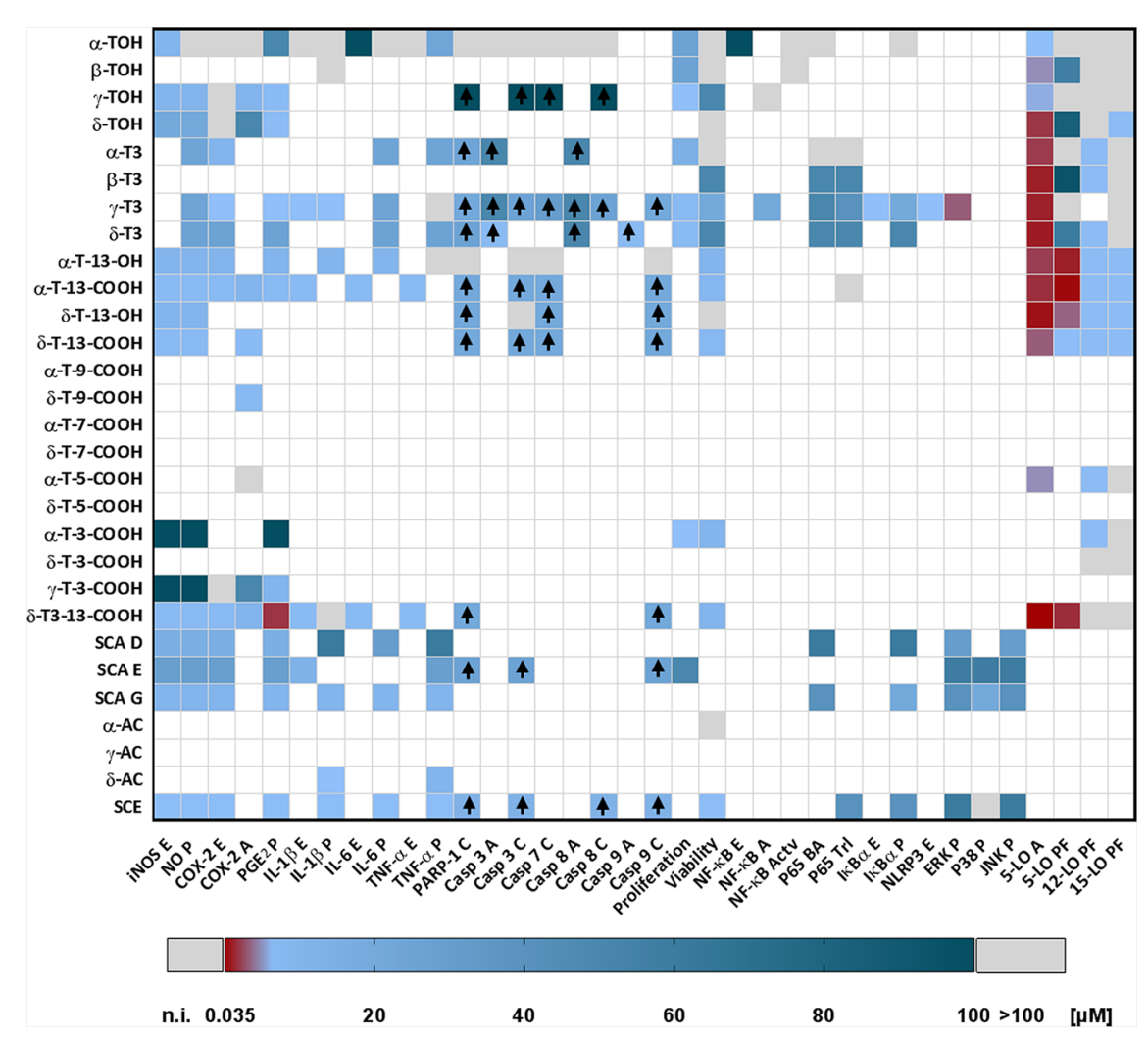

FIGURE 8 | Heatmap illustrating the effectiveness of chromanol and chromenol structures on selected targets. If not indicated otherwise, the plotted effects represent inhibitory effects of the respective compound on distinct parameters; induced parameters are marked with an arrow ( $\uparrow$ ). The color coding of the presented heat map ranges from high-affinity targets and parameters (effect with $<1 \mu \mathrm{M}$ ) presented in red to low-affinity targets and parameters (effects with $>1 \mu \mathrm{M}$ to $\leq 100 \mu \mathrm{M}$ ) presented in dark blue. If a compound did not affect a specific factor/parameter or showed low effectiveness (>100 $\mu \mathrm{M})$, the factor/parameter is marked in light gray. Factors and parameters lacking data are marked in white. The heat map is considered as simplified guide for orientation and does not provide a detailed summary of the topic. All concentrations are given micromole $(\mu \mathrm{M})$. Abbreviations used are: Actv, activation; A, activity; BA, binding affinity; C, cleavage; E, expression; PF, product formation; P, production; T, translocation. 
mediated by 12- and 15-LO remained unchanged (Jang et al., 2016). The discrepancy in $\mathrm{IC}_{50}$ values in the inhibition of cellfree 5-LO likely depends on the different assay conditions. While Pein et al. analyzed specific 5-LO products by reverse-phase high-performance liquid chromatography with ultraviolet detection, Jang et al. used an indirect colorimetric assay, which determines the formation of hydroperoxides. For SCMs, namely $5^{\prime}-\mathrm{T}-\mathrm{COOH}$ and $3^{\prime}-\mathrm{T}-\mathrm{COOH}$, no inhibitory effect was observed at the tested concentrations up to $3 \mu \mathrm{M}$, except for $\alpha-5^{\prime}-\mathrm{T}$ $\mathrm{COOH}\left(\mathrm{IC}_{50} 750 \mathrm{nM}\right)$ (Pein et al., 2018).

\section{Sargachromanols}

Blocking of NF- $\kappa \mathrm{B}$ activation with SCAs by inhibiting the

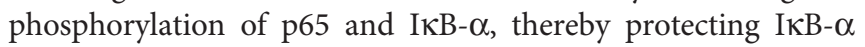
from degradation, has been shown in LPS-activated RAW264.7 macrophages (Heo et al., 2014) and in IL-1 $\beta$-activated MG-63 osteosarcoma fibroblasts (Yoon et al., 2012b) for SCA D $(60 \mu \mathrm{M})$ and $\mathrm{G}(20 \mu \mathrm{M})$, respectively. In addition, interference of SCAs D, $\mathrm{E}$, and $\mathrm{G}$ with the MAPK pathways, namely phosphorylation of JNK, ERK, and p38, has been observed in LPS-stimulated RAW264.7 macrophages and IL-1 $\beta$-activated MG-63 osteosarcoma fibroblasts (Yoon et al., 2012b; Lee et al., 2013; Heo et al., 2014).

\section{Chromenols}

Like SCAs, $\delta$-SCE has been shown to interfere with the NF- $\kappa B$ and the MAPK pathways. In TNF- $\alpha$-stimulated endothelial cells (Gwon et al., 2017) and LPS-stimulated microglia cells (Kim et al., 2018), p65 translocation and the phosphorylation of IкB- $\alpha$ were inhibited by $40 \mu \mathrm{M}$ and $60 \mu \mathrm{M} \delta$-SCE, respectively. In the same cell models inflammation-induced phosphorylation of JNK and ERK was diminished by $\delta$-SCE, whereas p38 remained unchanged (Kim et al., 2018) (Table 5).

\section{LOW AND HIGH-AFFINITY MOLECULAR TARGETS}

The heat map in Figure 8 provides a simplified overview about high- and low-dose bioactivities of the different chromanols and chromenols for a rapid assessment. The selection of compounds and parameters is based on a comprehensive review of the current literature about chromanols and chromenols and focusses on the important biological functions described for these compounds in the context of inflammation and cancer. For reasons of simplification, we did not take into account compound-specific uptake kinetics or cell type- or animal model-specific differences. For more detailed information, the reader is referred to Tables $\mathbf{1 - 5}$ which summarize our current knowledge on the chromanols and chromenols described in the respective sections. For comparison, presented concentrations are $\mathrm{IC}_{50}$ values or the lowest reported concentrations affecting the respective parameters.

In the studies considered here, T3s often showed higher effectiveness on the induction or suppression of biological activities linked to inflammation and cancer than TOHs.
Furthermore, oxidative modification of the terminal side-chain often substantially increases the anti-inflammatory capacity of respective compounds compared to parental compounds, such as TOHs and T3s. Amplexichromanols, sargachromanols and sargachromenols are also characterized by oxidative modifications of the side-chain, which might rationalize potent interactions with inflammatory targets, which needs further investigation. Notably, regulation of different target genes, proteins, and nuclear receptors can hardly be generalized. For instance, within the group of investigated targets, 5-LO is mostly inhibited by a few compounds, with $\delta$-T3-13'-COOH showing strongest inhibitory effects $\left(\mathrm{IC}_{50} 35 \mathrm{nM}\right)$ and $\alpha-\mathrm{TOH}$ showing the least $\left(\mathrm{IC}_{50} 1 \mu \mathrm{M}\right)$. In contrast, the COX-2-regulated formation of signaling molecules is most efficiently inhibited by $\gamma$-T3. In summary, especially 5 -LO seems to represent a high affinity (affected at concentrations $<1 \mu \mathrm{M}$ ) and therefore specific target for the LCMs of vitamin E. Most of the other observed effects, like mediation of caspase activity, anti-proliferative effects, inhibition of NO formation, are probably the result of a stimulation involving low-affinity targets (affected at concentrations $\geq 1 \mu \mathrm{M}$ ). However, as implied by the heat map in Figure 8, further studies are required for a comprehensive evaluation of the potential of chromanol and chromenol structures to serve as lead structures for the development of future anti-inflammatory therapeutic approaches.

\section{CONCLUSION}

For our review, we selected chromanols and chromenols for which data on anti-inflammatory and anti-carcinogenic effects were available in public databases of the scientific literature. The structures of our interests were tocopherols, tocotrienols, and their respective metabolites (which are produced in the liver under physiological and pathophysiological conditions) as well as structurally related compounds including sargachromanols, sargachromenols, and amplexichromanols. Criteria for the evaluation of compounds as possible lead structures for future therapeutic targets were their effects on key inflammatory and apoptotic pathways, proliferation, and interaction with (nuclear) receptor and enzymes that connect inflammation with carcinogenesis. Within this group of selected structures, tocopherols, more precisely $\alpha-\mathrm{TOH}$, are by far the most extensively studied compounds. However, the effects of TOHs are mostly only marginal compared to other compounds described in this review.

It should be noted that the methylation pattern of the chromanol ring system significantly affects inflammation and carcinogenesis. For instance, non- $\alpha-\mathrm{TOH}$ and non- $\alpha-\mathrm{T} 3$ forms affect eicosanoid- and cytokine-mediated inflammation as well as the cleavage of caspases that mediate apoptosis. Further, T3s are more potent in inhibiting caspase cleavage compared to the respective $\mathrm{TOH}$ forms. Tocopherol- and T3-derived metabolites and carboxychromanols more than hydroxychromanols inhibit $\mathrm{LO}$, and in particular 5-LO, effectively and reduce the viability of multiple cancer cell lines. Furthermore, sargachromanols interact 
with MAPK and NF-אB pathways, assuming their crosstalk with both, carcinogenesis and inflammation, while sargachromenols mediate anti-carcinogenic effects. Although our knowledge about biological activities of amplexichromanols is sparse, first results indicate their potential for pharmacological applications.

The development of clinically relevant nitric oxide-, eicosanoid-, or cytokine-inhibiting agents or agents that interact with signaling pathways of inflammation is challenging with respect to selectivity and toxicity. Next, although blocking inflammation is meant to be protective, its permanent or long-term inhibition may cause damage to the body (Brasky et al., 2017). Although detrimental effects of naturally occurring chromanols and chromenols cannot be excluded yet, they are less likely for this group of lead compounds in light of the good tolerability of TOHs and T3s at low to moderate doses. Further studies are required to evaluate whether the observed effects of chromanols and chromenols on inflammation and carcinogenesis are indeed beneficial in humans. Until today, no human clinical trials have been published that provide valid information on the biological activity, bioavailability, kinetics, systemic distribution, or local accumulation of these compounds. However, this groups of molecules appears to be promising as lead structures for future anti-inflammatory and/or anti-cancerogenic therapeutic approaches.

\section{LIMITATIONS}

Our review is based on a recent systematic review of Birringer et al. (2018), which presented the first comprehensive overview on the diversity of chromanol and chromenol structures and their biological functions. The aim of our review was to more selectively describe the effects on signaling pathways involved in inflammation, apoptosis, cell proliferation, and carcinogenesis and the underlying modes of action for selected chromanols and chromenols. We are aware of the lack of data for a variety of chromenol structures in our overview. We therefore focused on chromanols and chromenols only where adequate data was available that reported anti-inflammatory and anti-carcinogenic

\section{REFERENCES}

Aggarwal, B. B. (2009). Inflammation, a silent killer in cancer is not so silent! Curr. Opin. Pharmacol. 9, 347-350. doi: 10.1016/j.coph.2009.06.018

Ahn, K. S., Sethi, G., Krishnan, K., and Aggarwal, B. B. (2007). Gamma-tocotrienol inhibits nuclear factor-kappaB signaling pathway through inhibition of receptorinteracting protein and TAK1 leading to suppression of antiapoptotic gene products and potentiation of apoptosis. J. Biol. Chem. 282, 809-820. doi: 10.1074/ jbc.M610028200

Alawin, O. A., Ahmed, R. A., Ibrahim, B. A., Briski, K. P., and Sylvester, P. W. (2016). Antiproliferative effects of $\gamma$-tocotrienol are associated with lipid raft disruption in HER2-positive human breast cancer cells. J. Nutr. Biochem. 27, 266-277. doi: 10.1016/j.jnutbio.2015.09.018

Ali, M. Y., Kim, D. H., Seong, S. H., Kim, H.-R., Jung, H. A., and Choi, J. S. (2017). $\alpha$-Glucosidase and Protein Tyrosine Phosphatase 1B Inhibitory Activity of Plastoquinones from Marine Brown Alga Sargassum serratifolium. Marine Drugs 15(12). pii: E368. doi: 10.3390/md15120368 properties. For a more detailed description of the structural and chemical properties of all 230 chromanol and chromenol structures, the reader is referred to (Birringer et al., 2018).

\section{AUTHOR CONTRIBUTIONS}

MW and SK wrote the manuscript. MW, SK, MS, MB, and SL designed and structured the manuscript, MS, MB, SL, AK, and OW supervised the project and carefully read, evaluated, and discussed the content of the manuscript.

\section{FUNDING}

SL and OW were supported by the Free State of Thuringia and the European Social Fund (2016 FGR 0045), and The Deutsche Forschungsgemeinschaft (CRC 1278 "Polymer-based nanoparticle libraries for targeted anti-inflammatory strategies (PolyTarget). Work of SL and AK was supported by the Deutsche Forschungsgemeinschaft (DFG, RTG 1715), and AK was funded by the DFG (KO 4589/7-1). In addition, work of OW and SL is also funded within the Collaborative Research Centre (SFB) 1278 (PolyTarget) by the DFG. Other sources of funding include the Forschungskreis der Ernährungsindustrie (FEI) as part of an AiF (Arbeitsgemeinschaft industrieller Forschungsvereinigungen "Otto von Guericke") project of the Industrielle Gemeinschaftsforschung (IGF), and the German Federal Ministry of Education and Research (nutriCARD, grant agreement number 01EA1411A).

\section{ACKNOWLEDGMENTS}

We thank Sijia Liao for her assistance with the schematic drawings. We acknowledge support by the German Research Foundation and the Open Access Publication Fund of the Thueringer Universitaetsund Landesbibliothek Jena Projekt-Nr. 433052568.

Alsabil, K., Suor-Cherer, S., Koeberle, A., Viault, G., Lavaud, A., Temml, ,. V., et al. (2016). Semisynthetic and Natural Garcinoic Acid Isoforms as New mPGES-1 Inhibitors. Planta Med. 82, 1110-1116. doi: 10.1055/s-0042108739

Azzi, A., Boscoboinik, D., Chatelain, E., Ozer, N. K., and Stäuble, B. (1993). dalpha-tocopherol control of cell proliferation. Mol. Aspects Med. 14, 265-271. doi: 10.1016/0098-2997(93)90014-5

Azzi, A. (2019). Tocopherols, tocotrienols and tocomonoenols: Many similar molecules but only one vitamin E. Redox Biol. 26, 101259. doi: 10.1016/ j.redox.2019.101259

Bartolini, D., Franco, F. D., Torquato, P., Marinelli, R., Cerra, B., Ronchetti, R., et al. (2019). Garcinoic acid is a natural and selective agonist of Pregnane X Receptor. ChemRxiv. doi: 10.1021/acs.jmedchem.0c00012

Beharka, A. A., Wu, D., Serafini, M., and Meydani, S. N. (2002). Mechanism of vitamin $\mathrm{E}$ inhibition of cyclooxygenase activity in macrophages from old mice: role of peroxynitrite. Free Radical Biol. Med. 32, 503-511. doi: 10.1016/s08915849(01)00817-6 
Birringer, M., Pfluger, P., Kluth, D., Landes, N., and Brigelius-Flohé, R. (2002). Identities and differences in the metabolism of tocotrienols and tocopherols in HepG2 cells. J. Nutr. 132, 3113-3118. doi: 10.1093/jn/131.10.3113

Birringer, M., EyTina, J. H., Salvatore, B. A., and Neuzil, J. (2003). Vitamin E analogues as inducers of apoptosis. Structure-function relation. Br. J. Cancer 88, 1948-1955. doi: 10.1038/sj.bjc.6600981

Birringer, M., Lington, D., Vertuani, S., Manfredini, S., Scharlau, D., Glei, M., et al. (2010). Proapoptotic effects of long-chain vitamin E metabolites in HepG2 cells are mediated by oxidative stress. Free Radical Biol. Med. 49, 1315-1322. doi: 10.1016/j.freeradbiomed.2010.07.024

Birringer, M., Siems, K., Maxones, A., Frank, J., and Lorkowski, S. (2018). Natural 6-hydroxy-chromanols and -chromenols. Structural diversity, biosynthetic pathways and health implications. RSC Adv. 8, 4803-4841. doi: 10.1039/ C7RA11819H

Brasky, T. M., Felix, A. S., Cohn, D. E., McMeekin, D. S., Mutch, D. G., Creasman, W. T., et al. (2017). Nonsteroidal Anti-inflammatory Drugs and Endometrial Carcinoma Mortality and Recurrence. J. Natl. Cancer Ins. 109, 1-10. doi: $10.1093 /$ jnci/djw251

Brigelius-Flohé, R. ed. (2009). Vitamin E: the shrew waiting to be tamed. Free. Radic. Biol. Med. 46 (5), 543-554. doi: 10.1016/j.freeradbiomed.2008.12.007

Campbell, S. E., Stone, W. L., Lee, S., Whaley, S., Yang, H., Qui, M., et al. (2006). Comparative effects of RRR-alpha- and RRR-gamma-tocopherol on proliferation and apoptosis in human colon cancer cell lines. BMC Cancer 6, 13. doi: 10.1186/1471-2407-6-13

Choi, B. W., Ryu, G., Park, S. H., Kim, E. S., Shin, J., Roh, S. S., et al. (2007). Anticholinesterase activity of plastoquinones from Sargassum sagamianum. Lead compounds for Alzheimer's disease therapy. Phytother. Res. 21, 423-426. doi: $10.1002 /$ ptr.2090

Ciffolilli, S., Wallert, M., Bartolini, D., Krauth, V., Werz, O., Piroddi, M., et al. (2015). Human serum determination and in vitro anti-inflammatory activity of the vitamin E metabolite $\alpha$-(13'-hydroxy)-6-hydroxychroman. Free Radical Biol. Med. 89, 952-962. doi: 10.1016/j.freeradbiomed.2015.08.019

Dhillon, A. S., Hagan, S., Rath, O., and Kolch, W. (2007). MAP kinase signalling pathways in cancer. Oncogene 26, 3279-3290. doi: 10.1038/sj.onc.1210421

Dieber-Rotheneder, M., Puhl, H., Waeg, G., Striegl, G., and Esterbauer, H. (1991). Effect of oral supplementation with D-alpha-tocopherol on the vitamin E content of human low density lipoproteins and resistance to oxidation. J. Lipid Res. 32, 1325-1332.

Evans, H. M., and Bishop, K. S.(1922). On The Existence of a hitherto unrecognized dietary factor essential for reproduction. Sci. (N\} York N.Y.) 56, 650-651. doi: 10.1126/science.56.1458.650

Freiser, H., and Jiang, Q. (2009). Gamma-tocotrienol and gamma-tocopherol are primarily metabolized to conjugated 2-(beta-carboxyethyl)-6-hydroxy-2,7,8trimethylchroman and sulfated long-chain carboxychromanols in rats. J. Nutr. 139, 884-889. doi: 10.3945/jn.108.103309

Fujisawa, A., Dunlap, W. C., and Yamamoto, Y. (2010). Vitamin E protection in the biochemical adaptation of marine organisms to cold-water environments. Comp. Biochem. Physiol. Part B Biochem. Mol. Biol. 157, 145-158. doi: 10.1016/ j.cbpb.2010.04.011

Galli, F., Lee, R., Dunster, C., and Kelly, F. J. (2002). Gas chromatography mass spectrometry analysis of carboxyethyl-hydroxychroman metabolites of $\alpha$ - and $\gamma$-tocopherol in human plasma. Free Radical Biol. Med. 32, 333-340. doi: 10.1016/S0891-5849(01)00800-0

Galli, F., Stabile, A. M., Betti, M., Conte, C., Pistilli, A., Rende, M., et al. (2004). The effect of alpha- and gamma-tocopherol and their carboxyethyl hydroxychroman metabolites on prostate cancer cell proliferation. Arch. Biochem. Biophys. 423, 97-102. doi: 10.1016/j.abb.2003.11.014

Gilligan, M. M., Gartung, A., Sulciner, M. L., Norris, P. C., Sukhatme, V. P., Bielenberg, D. R., et al. (2019). Aspirin-triggered proresolving mediators stimulate resolution incancer. Proc. Natl. Acad. Sci. U. S. A. 116, 6292-6297. doi: $10.1073 /$ pnas. 1804000116

Giusepponi, D., Torquato, P., Bartolini, D., Piroddi, M., Birringer, M., Lorkowski, S., et al. (2017). Determination of tocopherols and their metabolites by liquidchromatography coupled with tandem mass spectrometry in human plasma and serum. Talanta 170, 552-561. doi: 10.1016/j.talanta.2017.04.030

Gkouveris, I., and Nikitakis, N. G. (2017). Role of JNK signaling in oral cancer: A mini review. Tumour Biol. 39 (6), 1010428317711659. doi: 10.1177/1010428317711659

Glauert, H. P. (2007). "Vitamin E and NF- $\kappa B$ Activation: A Review: Vitamins and Hormones. 76, 135-153. doi: 10.1016/S0083-6729(07)76006-5
Grammas, P., Hamdheydari, L., Benaksas, E. J., Mou, S., Pye, Q. N., Wechter, W. J., et al. (2004). Anti-inflammatory effects of tocopherol metabolites. Biochem. Biophys. Res. Commun. 319, 1047-1052. doi: 10.1016/j.bbrc.2004.05.082

Guthrie, N., Gapor, A., Chambers, A. F., and Carroll, K. K. (1997). Inhibition of proliferation of estrogen receptor-negative MDA-MB-435 and -positive MCF7 human breast cancer cells by palm oil tocotrienols and tamoxifen, alone and in combination. J. Nutr. 127, 544S-548S. doi: 10.1093/jn/127.3.544S

Gwon, W.-G., Joung, E.-J., Kwon, M.-S., Lim, S.-J., Utsuki, T., and Kim, H.-R. (2017). Sargachromenol protects against vascular inflammation by preventing TNF- $\alpha-$ induced monocyte adhesion to primary endothelial cells via inhibition of NF- $\mathrm{KB}$ activation. Int. Immunopharmacol. 42, 81-89. doi: 10.1016/j.intimp.2016.11.014

Gysin, R., Azzi, A., and Visarius, T. (2002). Gamma-tocopherol inhibits human cancer cell cycle progression and cell proliferation by down-regulation of cyclins. FASEB J.: Off. Publ. Fed. Am. Soc. Exp. Biol. 16, 1952-1954. doi: $10.1096 /$ fj.02-0362fje

He, L., Mo, H., Hadisusilo, S., Qureshi, A. A., and Elson, C. E. (1997). Isoprenoids suppress the growth of murine B16 melanomas in vitro and in vivo. J. Nutr. 127, 668-674. doi: 10.1093/jn/127.5.668

Heo, S.-J., Kim, K.-N., Yoon, W.-J., Oh, C., Choi, Y.-U., Affan, A., et al. (2011). Chromene induces apoptosis via caspase- 3 activation in human leukemia HL60 cells. Food Chem. Toxicol. 49, 1998-2004. doi: 10.1016/j.fct.2011.05.011

Heo, S.-J., Jang, J., Ye, B.-R., Kim, M.-S., Yoon, W.-J., Oh, C., et al. (2014). Chromene suppresses the activation of inflammatory mediators in lipopolysaccharide-stimulated RAW 264.7 cells. Food Chem. Toxicol. 67, 169-175. doi: 10.1016/j.fct.2014.02.023

Hosomi, A., Arita, M., Sato, Y., Kiyose, C., Ueda, T., Igarashi, O., et al. (1997). Affinity for alpha-tocopherol transfer protein as a determinant of the biological activities of vitamin E analogs. FEBS Lett. 409, 105-108. doi: 10.1016/s00145793(97)00499-7

Hur, S., Lee, H., Kim, Y., Lee, B.-H., Shin, J., and Kim, T.-Y. (2008). Sargaquinoic acid and sargachromenol, extracts of Sargassum sagamianum, induce apoptosis in $\mathrm{HaCaT}$ cells and mice skin. Its potentiation of UVB-induced apoptosis. Eur. J. Pharmacol. 582, 1-11. doi: 10.1016/j.ejphar.2007.12.025

Husain, K., Francois, R. A., Yamauchi, T., Perez, M., Sebti, S. M., and Malafa, M. P. (2011). Vitamin $\mathrm{E} \delta$-tocotrienol augments the antitumor activity of gemcitabine and suppresses constitutive NF- $\mathrm{\kappa B}$ activation in pancreatic cancer. Mol. Cancer Ther. 10, 2363-2372. doi: 10.1158/1535-7163.MCT-11-0424

Im Lee, J., and Seo, Y.(2011). Chromanols from Sargassum siliquastrum and their antioxidant activity in HT 1080 cells. Chem. Pharm. Bull. 59, 757-761. doi: $10.1248 /$ cpb.59.757

Infante, J. P. (1999). A function for the vitamin E metabolite $\alpha$-tocopherol quinone as an essential enzyme cofactor for the mitochondrial fatty acid desaturases. FEBS Lett. 446, 1-5. doi: 10.1016/S0014-5793(99)00170-2

Jang, K. H., Lee, B. H., Choi, B. W., Lee, H.-S., and Shin, J.(2005). Chromenes from the brown alga Sargassum siliquastrum. J. Natural Prod. 68, 716-723. doi: $10.1021 / \mathrm{np} 058003 \mathrm{i}$

Jang, Y., Park, N.-Y., Rostgaard-Hansen, A. L., Huang, J., and Jiang, Q. (2016). Vitamin E metabolite $13^{\prime}$-carboxychromanols inhibit pro-inflammatory enzymes, induce apoptosis and autophagy in human cancer cells by modulating sphingolipids and suppress colon tumor development in mice. Free Radical Biol. Med. 95, 190-199. doi: 10.1016/j.freeradbiomed.2016.03.018

Jiang, Q., Elson-Schwab, I., Courtemanche, C., and Ames, B. N.(2000). Gammatocopherol and its major metabolite, in contrast to alpha-tocopherol, inhibit cyclooxygenase activity in macrophages and epithelial cells. Proc. Natl. Acad. Sci. U. S. A. 97, 11494-11499. doi: 10.1073/pnas.200357097

Jiang, Q., Freiser, H., Wood, K. V., and Yin, X. (2007). Identification and quantitation of novel vitamin $\mathrm{E}$ metabolites, sulfated long-chain carboxychromanols, in human A549 cells and in rats. J. Lipid Res. 48, 12211230. doi: 10.1194/jlr.D700001-JLR200

Jiang, Q., Yin, X., Lill, M. A., Danielson, M. L., Freiser, H., and Huang, J. (2008). Long-chain carboxychromanols, metabolites of vitamin E, are potent inhibitors of cyclooxygenases. Proc. Natl. Acad. Sci. U. S. A. 105, 20464-20469. doi: $10.1073 /$ pnas. 0810962106

Jiang, Z., Yin, X., and Jiang, Q. (2011). Natural forms of vitamin E and 13'carboxychromanol, a long-chain vitamin E metabolite, inhibit leukotriene generation from stimulated neutrophils by blocking calcium influx and suppressing 5-lipoxygenase activity, respectively. J. Immunol. (Baltimore Md. : 1950) 186, 1173-1179. doi: 10.4049/jimmunol.1002342 
Jiang, Q., Rao, X., Kim, C. Y., Freiser, H., Zhang, Q., Jiang, ,. Z., et al. (2012). Gamma-tocotrienol induces apoptosis and autophagy in prostate cancer cells by increasing intracellular dihydrosphingosine and dihydroceramide. Int. J. Cancer 130, 685-693. doi: 10.1002/ijc.26054

Jiang, Q., Jiang, Z., Hall, Y. J., Jang, Y., Snyder, P. W., Bain, C., et al. (2013). Gamma-tocopherol attenuates moderate but not severe colitis and suppresses moderate colitis-promoted colon tumorigenesis in mice. Free Radical Biol. Med. 65, 1069-1077. doi: 10.1016/j.freeradbiomed.2013.08.187

Jiang, Q. (2014). Natural forms of vitamin E: metabolism, antioxidant, and antiinflammatory activities and their role in disease prevention and therapy. Free Radical Biol. Med. 72, 76-90. doi: 10.1016/j.freeradbiomed.2014.03.035

Jiménez-Martínez, M., Stamatakis, K., and Fresno, M. (2019). The Dual-Specificity Phosphatase 10 (DUSP10): Its Role in Cancer, Inflammation, and Immunity. Int. J. Mol. Sci. 20 (7). pii: 1626. doi: 10.3390/ijms20071626

Johnson, C. H., Slanař, O., Krausz, K. W., Kang, D. W., Patterson, A. D., Kim, J.H., et al. (2012). Novel metabolites and roles for $\alpha$-tocopherol in humans and mice discovered by mass spectrometry-based metabolomics. Am. J. Clin. Nutr. 96, 818-830. doi: 10.3945/ajcn.112.042929

Jurjus, A., Eid, A., Al Kattar, S., Zeenny, M. N., Gerges-Geagea, A., Haydar, H., et al. (2016). Inflammatory bowel disease, colorectal cancer and type 2 diabetes mellitus: The links. BBA Clin. 5, 16-24. doi: 10.1016/j.bbacli.2015.11.002

Kaminska, B. (2005). MAPK signalling pathways as molecular targets for antiinflammatory therapy-from molecular mechanisms to therapeutic benefits. Biochim. Biophys. Acta 1754, 253-262. doi: 10.1016/j.bbapap.2005.08.017

Kim, J.-A., Ahn, B.-N., Kong, C.-S., and Kim, S.-K. (2012). Protective effect of chromene isolated from Sargassum horneri against UV-A-induced damage in skin dermal fibroblasts. Exp. Dermatol. 21, 630-631. doi: 10.1111/j.16000625.2012.01535.x

Kim, S., Lee, M.-S., Lee, B., Gwon, W.-G., Joung, E.-J., Yoon, N.-Y., et al. (2014). Anti-inflammatory effects of sargachromenol-rich ethanolic extract of Myagropsis myagroides on lipopolysaccharide-stimulated BV-2 cells. BMC Complementary Altern. Med. 14, 231. doi: 10.1186/1472-6882-14-231

Kim, Y., Wang, W., Okla, M., Kang, I., Moreau, R., and Chung, S. (2016). Suppression of NLRP3 inflammasome by $\gamma$-tocotrienol ameliorates type 2 diabetes. J. Lipid Res. 57, 66-76. doi: 10.1194/jlr.M062828

Kim, Y., Gromovsky, A. D., Brown, J. M., and Chung, S. (2018). Gammatocotrienol attenuates the aberrant lipid mediator production in NLRP3 inflammasome-stimulated macrophages. J. Nutr. Biochem. 58, 169-177. doi: 10.1016/j.jnutbio.2018.05.007

Kim, H. K.(2014). Role of ERK/MAPK signalling pathway in anti-inflammatory effects of Ecklonia cava in activated human mast cell line-1 cells. Asian Pac. J. Trop. Med. 7, 703-708. doi: 10.1016/S1995-7645(14)60120-6

Klein, E. A., Thompson, I. M., Tangen, C. M., Crowley, J. J., Lucia, M. S., Goodman, P. J., et al. (2011). Vitamin E and the risk of prostate cancer: the Selenium and Vitamin E Cancer Prevention Trial (SELECT). JAMA 306, 15491556. doi: 10.1001/jama.2011.1437

Kluge, S., Schubert, M., Schmölz, L., Birringer, M., Wallert, M., and Lorkowski, S. (2016). "Garcinoic Acid," in Studies in natural products chemistry, vol. Volume 51. Ed. A.-u. Rahman (Amsterdam, Netherlands: Elsevier), 435-481.

Kruk, J., Pisarski, A., and Szymańska, R. (2011). Novel vitamin E forms in leaves of Kalanchoe daigremontiana and Phaseolus coccineus. J. Plant Physiol. 168, 2021-2027. doi: 10.1016/j.jplph.2011.06.015

Kunnumakkara, A. B., Sung, B., Ravindran, J., Diagaradjane, P., Deorukhkar, A., Dey, S., et al. (2010). \{Gamma\}-tocotrienol inhibits pancreatic tumors and sensitizes them to gemcitabine treatment by modulating the inflammatory microenvironment. Cancer Res. 70, 8695-8705. doi: 10.1158/0008-5472.CAN-10-2318

Kunnumakkara, A. B., Sailo, B. L., Banik, K., Harsha, C., Prasad, S., Gupta, S. C., et al. (2018). Chronic diseases, inflammation, and spices: how are they linked? J. Trans. Med. 16, 14. doi: 10.1186/s12967-018-1381-2

Kusumi, T., Shibata, Y., Ishitsuka, M., Kinoshita, T., and Kakisawa, H. (1979). Structures of new Plastoquinones from the brown alga sargassum serratifolium. Chem. Lett. 8, 277-278. doi: 10.1246/cl.1979.277

Lasry, A., and Ben-Neriah, Y. (2015). Senescence-associated inflammatory responses: aging and cancer perspectives. Trends Immunol. 36, 217-228. doi: 10.1016/j.it.2015.02.009

Lavaud, A., Richomme, P., Litaudon, M., Andriantsitohaina, R., and Guilet, D.(2013). Antiangiogenic tocotrienol derivatives from Garcinia amplexicaulis. J. Natural Prod. 76, 2246-2252. doi: 10.1021/np400598y
Lavaud, A., Richomme, P., Gatto, J., Aumond, M.-C., Poullain, C., Litaudon, M., et al. (2015). A tocotrienol series with an oxidative terminal prenyl unit from Garcinia amplexicaulis. Phytochemistry 109, 103-110. doi: 10.1016/ j.phytochem.2014.10.024

Lee, J.-H., Ko, J.-Y., Samarakoon, K., Oh, J.-Y., Heo, S.-J., Kim, C.-Y., et al. (2013). Preparative isolation of sargachromanol E from Sargassum siliquastrum by centrifugal partition chromatography and its anti-inflammatory activity. Food Chem. Toxicol. 62, 54-60. doi: 10.1016/j.fct.2013.08.010

Liebler, D. C., Baker, P. F., and Kaysen, K. L. (1990). Oxidation of vitamin E: evidence for competing autoxidation and peroxyl radical trapping reactions of the tocopheroxyl radical. J. Am. Chem. Soc. 112, 6995-7000. doi: 10.1021/ ja00175a037

Lim, S., Choi, A.-H., Kwon, M., Joung, E.-J., Shin, T., Lee, S.-G., et al. (2019). Evaluation of antioxidant activities of various solvent extract from Sargassum serratifolium and its major antioxidant components. Food Chem. 278, 178184. doi: 10.1016/j.foodchem.2018.11.058

Lippman, S. M., Klein, E. A., Goodman, P. J., Lucia, M. S., Thompson, I. M., Ford, L. G., et al. (2009). Effect of selenium and vitamin E on risk of prostate cancer and other cancers: the Selenium and Vitamin E Cancer Prevention Trial (SELECT). JAMA 301, 39-51. doi: 10.1001/jama.2008.864

Loganathan, R., Selvaduray, K. R., Nesaretnam, K., and Radhakrishnan, A. K. (2013). Tocotrienols promote apoptosis in human breast cancer cells by inducing poly(ADP-ribose) polymerase cleavage and inhibiting nuclear factor kappa-B activity. Cell Proliferation 46, 203-213. doi: 10.1111/cpr.12014

Maloney, D. J., and Hecht, S. M. (2005). A stereocontrolled synthesis of deltatrans-tocotrienoloic acid. Organic Lett. 7, 4297-4300. doi: 10.1021/ol051849t

Mazzini, F., Betti, M., Netscher, T., Galli, F., and Salvadori, P. (2009). Configuration of the vitamin $\mathrm{E}$ analogue garcinoic acid extracted from Garcinia Kola seeds. Chirality 21, 519-524. doi: 10.1002/chir.20630

Merchant, N., Bhaskar, L. V. K. S., Momin, S., Sujatha, P., Reddy, A. B. M., and Nagaraju, G. P. (2018). 5-Lipoxygenase: Its involvement in gastrointestinal malignancies. Crit. Rev. Oncology/Hematology 127, 50-55. doi: 10.1016/ j.critrevonc.2018.05.012

Meydani, S. N., Barklund, M. P., Liu, S., Meydani, M., Miller, R. A., Cannon, J. G., et al. (1990). Vitamin E supplementation enhances cell-mediated immunity in healthy elderly subjects. Am. J. Clin. Nutr. 52, 557-563. doi: 10.1093/ajcn/52.3.557

Moossavi, M., Parsamanesh, N., Bahrami, A., Atkin, S. L., and Sahebkar, A. (2018). Role of the NLRP3 inflammasome in cancer. Mol. Cancer 17, 158. doi: 10.1186/ s12943-018-0900-3

Nesaretnam, K., Guthrie, N., Chambers, A. F., and Carroll, K. K. (1995). Effect of tocotrienols on the growth of a human breast cancer cell line in culture. Lipids 30, 1139-1143. doi: 10.1007/bf02536615

Nesaretnam, K., Stephen, R., Dils, R., and Darbre, P. (1998). Tocotrienols inhibit the growth of human breast cancer cells irrespective of estrogen receptor status. Lipids 33, 461-469. doi: 10.1007/s11745-998-0229-3

Pak, W.-M., Kim, K.-B.-W. R., Kim, M.-J., Cho, J.-Y., and Ahn, D.-H. (2015). Inhibitory effect of hexane fraction from Myagropsis myagroides on pancreatic $\alpha$-amylase in vitro. J. Microbiol. Biotechnol. 25, 328-333. doi: 10.4014/jmb.1409.09012

Parker, R. S., Sontag, T. J., and Swanson, J. E. (2000). Cytochrome P4503Adependent metabolism of tocopherols and inhibition by sesamin. Biochem. Biophys. Res. Commun. 277, 531-534. doi: 10.1006/bbrc.2000.3706

Pein, H., Ville, A., Pace, S., Temml, V., Garscha, U., Raasch, ,. M., et al. (2018). Endogenous metabolites of vitamin $\mathrm{E}$ limit inflammation by targeting 5lipoxygenase. Nat. Commun. 9, 3834. doi: 10.1038/s41467-018-06158-5

Péter, S., Friedel, A., Roos, F. F., Wyss, A., Eggersdorfer, M., Hoffmann, ,. K., et al. (2015). A Systematic Review of Global Alpha-Tocopherol Status as Assessed by Nutritional Intake Levels and Blood Serum Concentrations. Int. J. Vitamin Nutr. Res. 85, 261-281. doi: 10.1024/0300-9831/a000281

Podszun, M. C., Jakobi, M., Birringer, M., Weiss, J., and Frank, J. (2017). The long chain $\alpha$-tocopherol metabolite $\alpha$-13'-COOH and $\gamma$-tocotrienol induce P-glycoprotein expression and activity by activation of the pregnane $\mathrm{X}$ receptor in the intestinal cell line LS 180. Mol. Nutr. Food Res. 61 (3). doi: 10.1002/mnfr.201600605

Rådmark, O., Werz, O., Steinhilber, D., and Samuelsson, B. (2015). 5Lipoxygenase, a key enzyme for leukotriene biosynthesis in health and disease. Biochim. Biophys. Acta (BBA) - Mol. Cell Biol. Lipids 1851, 331-339. doi: 10.1016/j.bbalip.2014.08.012

Reddanna, P., Krishna Rao, M., and Channa Reddy, C. (1985). Inhibition of 5-lipoxygenase by vitamin E. FEBS Lett. 193, 39-43. doi: 10.1016/0014-5793(85)80075-2 
Richomme, P., Helesbeux, J.-J., Guilet, D., Seraphin, D., Stuppner, H., Waltenberger, B., et al. (2017) 2, 2017. WO2017032881A1, filed March.

Rimbach, G., Moehring, J., Huebbe, P., and Lodge, J. K. (2010). Gene-regulatory activity of alpha-tocopherol. Mol. (Basel Switzerland) 15, 1746-1761. doi: 10.3390/molecules15031746

Roos, J., Grösch, S., Werz, O., Schröder, P., Ziegler, S., Fulda, S., et al. (2016). Regulation of tumorigenic Wnt signaling by cyclooxygenase-2, 5-lipoxygenase and their pharmacological inhibitors: A basis for novel drugs targeting cancer cells? Pharmacol. Ther. 157, 43-64. doi: 10.1016/j.pharmthera.2015.11.001

Sakai, M., Okabe, M., Yamasaki, M., Tachibana, H., and Yamada, K. (2004). Induction of apoptosis by tocotrienol in rat hepatoma dRLh-84 cells. Anticancer Res. 24, 1683-1688.

Schmölz, L., Birringer, M., Lorkowski, S., and Wallert, M. (2016). Complexity of vitamin E metabolism. World J. Biol. Chem. 7, 14-43. doi: 10.4331/wjbc.v7.i1.14

Schmölz, L., Wallert, M., Rozzino, N., Cignarella, A., Galli, F., Glei, ,. M., et al. (2017). Structure-function relationship studies in vitro reveal distinct and specific effects of long-chain metabolites of Vitamin E. Mol. Nutr. Food Res. 61 (12). doi: $10.1002 / \mathrm{mnfr} .201700562$

Serhan, C. N. (2014). Pro-resolving lipid mediators are leads for resolution physiology. Nature 510, 92-101. doi: 10.1038/nature13479

Silva, D. H. S., Zhang, Y., Santos, L. A., Bolzani, V. S., and Nair, M. G. (2007). Lipoperoxidation and cyclooxygenases 1 and 2 inhibitory compounds from Iryanthera juruensis. J. Agric. Food Chem. 55, 2569-2574. doi: 10.1021/jf063451x

Sontag, T. J., and Parker, R. S. (2002). Cytochrome P450 omega-hydroxylase pathway of tocopherol catabolism. Novel mechanism of regulation of vitamin E status. J. Biol. Chem. 277, 25290-25296. doi: 10.1074/jbc.M201466200

Swanson, K. V., Deng, M., and Ting, J. P.-Y. (2019). The NLRP3 inflammasome: molecular activation and regulation to therapeutics. Nat. Rev. Immunol. 19, 477-489. doi: 10.1038/s41577-019-0165-0

Tan, P. H., Sagoo, P., Chan, C., Yates, J. B., Campbell, J., Beutelspacher, S. C., et al. (2005). Inhibition of NF-kappa B and oxidative pathways in human dendritic cells by antioxidative vitamins generates regulatory $\mathrm{T}$ cells. J. Immunol. (Baltimore Md. : 1950) 174, 7633-7644. doi: 10.4049/jimmunol.174.12.7633

Tsang, C. K., Ina, A., Goto, T., and Kamei, Y. (2005). Sargachromenol, a novel nerve growth factor-potentiating substance isolated from Sargassum macrocarpum, promotes neurite outgrowth and survival via distinct signaling pathways in PC12D cells. Neuroscience 132, 633-643. doi: 10.1016/j.neuroscience.2005.01.028

Virtamo, J., Taylor, P. R., Kontto, J., Männistö, S., Utriainen, M., Weinstein, S. J., et al. (2014). Effects of $\alpha$-tocopherol and $\beta$-carotene supplementation on cancer incidence and mortality: 18-year postintervention follow-up of the Alpha-tocopherol, Beta-carotene Cancer Prevention Study. Int. J. Cancer 135, 178-185. doi: 10.1002/ijc.28641

Wallert, M., Mosig, S., Rennert, K., Funke, H., Ristow, M., Pellegrino, R. M., et al. (2014a). Long-chain metabolites of $\alpha$-tocopherol occur in human serum and inhibit macrophage foam cell formation in vitro. Free Radical Biol. Med. 68, 43-51. doi: 10.1016/j.freeradbiomed.2013.11.009

Wallert, M., Schmölz, L., Galli, F., Birringer, M., and Lorkowski, S. (Eds.) (2014b). Regulatory metabolites of vitamin E and their putative relevance for atherogenesis, Redox Biol. 2, 495-503. doi: 10.1016/j.redox.2014.02.002

Wallert, M., Schmölz, L., Koeberle, A., Krauth, V., Glei, M., Galli, ,. F., et al. (2015). $\alpha$-Tocopherol long-chain metabolite $\alpha-13^{\prime}-\mathrm{COOH}$ affects the inflammatory response of lipopolysaccharide-activated murine RAW264.7 macrophages. Mol. Nutr. Food Res. 59, 1524-1534. doi: 10.1002/mnfr.201400737
Wallert, M., Bauer, J., Kluge, S., Schmölz, L., Chen, Y.-C., Ziegler, M., et al. (2019). The vitamin $\mathrm{E}$ derivative garcinoic acid from Garcinia kola nut seeds attenuates the inflammatory response. Redox Biol. 24, 101166. doi: 10.1016/ j.redox.2019.101166

Wang, Y., Park, N.-Y., Jang, Y., Ma, A., and Jiang, Q. (2015). Vitamin E $\gamma$ tocotrienol inhibits cytokine-stimulated NF- $\mathrm{\kappa B}$ activation by induction of antiinflammatory A20 via stress adaptive response due to modulation of Sphingolipids. J. Immunol. (Baltimore Md. : 1950) 195, 126-133. doi: $10.4049 /$ jimmunol.1403149

Wculek, S. K., and Malanchi, I. (2015). Neutrophils support lung colonization of metastasis-initiating breast cancer cells. Nature 528, 413-417. doi: 10.1038/ nature 16140

Yam, M.-L., Abdul Hafid, S. R., Cheng, H.-M., and Nesaretnam, K. (2009). Tocotrienols suppress proinflammatory markers and cyclooxygenase-2 expression in RAW264.7 macrophages. Lipids 44, 787-797. doi: 10.1007/ s11745-009-3326-2

Yang, E.-J., Ham, Y. M., Yang, K.-W., Lee, N. H., and Hyun, C.-G. (2013). Sargachromenol from Sargassum micracanthum inhibits the lipopolysaccharide-induced production of inflammatory mediators in RAW 264.7 macrophages. Sci. World J. 2013, 712303. doi: 10.1155/2013/712303

Yap, W. N., Chang, P. N., Han, H. Y., Lee, D. T. W., Ling, M. T., Wong, Y. C., et al. (2008). Gamma-tocotrienol suppresses prostate cancer cell proliferation and invasion through multiple-signalling pathways. Br. J. Cancer 99, 1832-1841. doi: $10.1038 /$ sj.bjc. 6604763

Yoon, W.-J., Heo, S.-J., Han, S.-C., Lee, H.-J., Kang, G.-J., Kang, H.-K., et al. (2012a). Anti-inflammatory effect of sargachromanol G isolated from Sargassum siliquastrum in RAW 264.7 cells. Arch. Pharmacal Res. 35, 14211430. doi: 10.1007/s12272-012-0812-5

Yoon, W.-J., Heo, S.-J., Han, S.-C., Lee, H.-J., Kang, G.-J., Yang, E.-J., et al. (2012b). Sargachromanol G regulates the expression of osteoclastogenic factors in human osteoblast-like MG-63 cells. Food Chem. Toxicol. 50, 3273-3279. doi: $10.1016 /$ j.fct.2012.06.022

Yoon, W.-J., Kim, K.-N., Heo, S.-J., Han, S.-C., Kim, J., Ko, Y.-J., et al. (2013). Sargachromanol G inhibits osteoclastogenesis by suppressing the activation NF- $\mathrm{KB}$ and MAPKs in RANKL-induced RAW 264.7 cells. Biochem. Biophys. Res. Commun. 434, 892-897. doi: 10.1016/j.bbrc.2013.04.046

Zhao, Y., Lee, M.-J., Cheung, C., Ju, J.-H., Chen, Y.-K., Liu, B., et al. (2010). Analysis of multiple metabolites of tocopherols and tocotrienols in mice and humans. J. Agric. Food Chem. 58, 4844-4852. doi: 10.1021/jf904464u

Zingg, J.-M. (2019). Vitamin E: Regulatory Role on Signal Transduction. IUBMB Life 71, 456-478. doi: 10.1002/iub.1986

Conflict of Interest: The authors declare that the research was conducted in the absence of any commercial or financial relationships that could be construed as a potential conflict of interest.

Copyright (๑) 2020 Wallert, Kluge, Schubert, Koeberle, Werz, Birringer and Lorkowski. This is an open-access article distributed under the terms of the Creative Commons Attribution License (CC BY). The use, distribution or reproduction in other forums is permitted, provided the original author(s) and the copyright owner(s) are credited and that the original publication in this journal is cited, in accordance with accepted academic practice. No use, distribution or reproduction is permitted which does not comply with these terms. 